\title{
Computational Fluid Dynamics Modeling of the John Day Dam Tailrace
}

\author{
CL Rakowski \\ WA Perkins \\ MC Richmond \\ JA Serkowski
}

Hydrology Group

Pacifi Northwest National Laboratory

Richland, WA 99352

Prepared for:

US Army Corps of Engineers, Portland District

Portland, OR

July 2010

Pacific Northwest

NATIONAL LABORATORY

Proudly Operated by Battelle Since 1965 


\title{
DISCLAIMER
}

United States Government. Neither the United States Government nor any agency thereof, nor Battelle Memorial Institute, nor any of their employees, makes any warranty, express or implied, or assumes any legal liability or responsibility for the accuracy, completeness, or usefulness of any information, apparatus, product, or process disclosed, or represents that its use would not infringe privately owned rights. Reference herein to any specific commercial product, process, or service by trade name, trademark, manufacturer, or otherwise does not necessarily constitute or imply its endorsement, recommendation, or favoring by the United States Government or any agency thereof, or Battelle Memorial Institute. The views and opinions of authors expressed herein do not necessarily state or reflect those of the United States Government or any agency thereof.

\author{
PACIFIC NORTHWEST NATIONAL LABORATORY \\ operated by \\ BATTELLE \\ for the \\ UNITED STATES DEPARTMENT OF ENERGY \\ under Contract DE-AC05-76RLO1830
}

\author{
Printed in the United States of America \\ Available to DOE and DOE contractors from the \\ Office of Scientific and Technical Information, \\ P.O. Box 62, Oak Ridge, TN 37831-0062; \\ ph: (865) 576-8401 \\ fax: $\quad(865)$ 576-5728 \\ email: reports@adonis.osti.gov

\footnotetext{
Available to the public from the National Technical Information Service, U.S. Department of Commerce, 5285 Port Royal Rd., Springfield, VA 22161 ph: $\quad(800)$ 553-6847 fax: (703) 605-6900

email: orders@ntis.fedworld.gov

online ordering: http://www.ntis.gov/ordering.htm
} \\ This document was printed on recycled paper. \\ $(9 / 2003)$
}


PNNL-19349

\title{
Computational Fluid Dynamics Modeling of the John Day Dam Tailrace
}

\author{
CL Rakowski \\ WA Perkins \\ MC Richmond \\ JA Serkowski \\ Hydrology Group \\ Pacific Northwest National Laboratory \\ Richland, WA 99352
}

Prepared for:

U.S.Army Corps of Engineers, Portland District

Portland, OR 



\section{Summary}

The U.S. Army Corps of Engineers-Portland District required that a two-dimensional (2D) depth-averaged and a three-dimensional (3D) free-surface numerical model be developed and validated for the John Day tailrace. These models were used to assess the potential impact of a select group of structural and operational alternatives to tailrace flows aimed at improving fish survival at John Day Dam. The 2D model was used for the initial assessment of the alternatives in conjunction with a reduced-scale physical model of the John Day Project. A finer resolution 3D model was used to more accurately model the details of flow in the stilling basin and nearproject tailrace hydraulics.

Three-dimensional model results were used as input to the Pacific Northwest National Laboratory particle tracking software, and particle paths and times to pass a downstream cross section were used to assess the relative differences in travel times resulting from project operations and structural scenarios for multiple total river flows. Streamlines and neutrally buoyant particles were seeded in all turbine and spill bays with flows.

For a Total River of $250 \mathrm{kcfs}$ running with the Fish Passage Plan spill pattern and a spillwall, the mean residence times for all particles were little changed; however the tails of the distribution were truncated for both spillway and powerhouse release points, and, for the powerhouse releases, reduced the residence time for $75 \%$ of the particles to pass a downstream cross section from 45.5 minutes to 41.3 minutes. For a total river of $125 \mathrm{kcfs}$ configured with the operations from the Fish Passage Plan for the temporary spillway weirs and for a proposed spillwall, the neutrally buoyant particle tracking data showed that the river with a spillwall in place had the overall mean residence time increase; however, the residence time for $75 \%$ of the powerhousereleased particles to pass a downstream cross section was reduced from 102.4 to 89 minutes. 



\section{Acknowledgments}

Financial support for this study was provided by the U.S. Army Corps of Engineers under MIPR W66QKZ82596904. The authors would like to thank Sean Askelson and Laurie Ebner, U.S. Army Corps of Engineers, Portland District, for the discussions, support, and insight that improved this study. The authors would like to thank Adam Maxwell (PNNL) for his careful technical review and Wayne Cosby for his editorial review. Their roles in the preparation of this document were appreciated and improved the final product. 



\section{Abbreviations and Acronyms}

$\begin{array}{ll}\text { ABBREV } & \text { DEFINITION } \\ \text { 2D } & \text { two dimensional } \\ \text { 3D } & \text { three dimensional } \\ \text { ADCP } & \text { acoustic Doppler current profiler } \\ \text { CAD } & \text { Computer-aided design } \\ \text { CENWP } & \text { U.S. Army Corps of Engineers, Portland District } \\ \text { CFD } & \text { computational fluid dynamics } \\ \text { DGAS } & \text { Dissolved Gas Abatement Study } \\ \text { ERDC } & \text { Engineer Research and Development Center, Vicksburg, MS } \\ \text { FPP } & \text { Fish Passage Plan } \\ \text { GIS } & \text { Geographic Information System } \\ \text { JDA } & \text { John Day Dam } \\ \text { kcfs } & \text { Thousand cubic feet per second } \\ \text { MASS2 } & \text { Modular Aquatic Simulation System in Two Dimensions } \\ \text { NAD83 } & \text { North American Datum of 1983 } \\ \text { NGVD29 } & \text { National Geodetic Vertical Datum of 1929 with the 1947 adjustment } \\ \text { MARS } & \text { monotone advection and reconstruction scheme } \\ \text { PNNL } & \text { Pacific Northwest National Laboratory } \\ \text { STL } & \text { stereolithography } \\ \text { TR } & \text { Total River flow } \\ \text { TSW } & \text { Temporary Spillway Weir } \\ \text { USACE } & \text { U.S. Army Corps of Engineers } \\ \text { USGS } & \text { U.S. Geological Survey } \\ \text { UD } & \text { Upwind difference } \\ \text { VOF } & \text { volume of fluid } \\ & \end{array}$





\section{Contents}

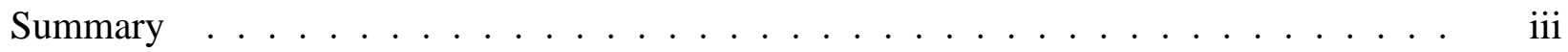

Acknowledgments .......................... . . . . . .

Abbreviations and Acronyms . . . . . . . . . . . . . . vii

1.0 Introduction $\ldots \ldots \ldots \ldots \ldots \ldots$

2.0 Methods . . . . . . . . . . . . . . . . . . . . . . . . 2.1

2.1 Tailrace Geometry $\ldots \ldots \ldots \ldots \ldots \ldots$

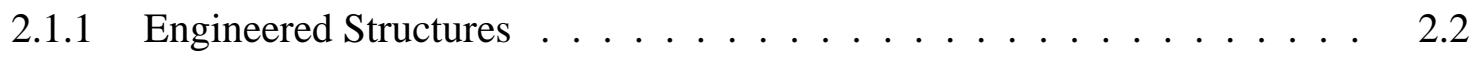

2.1 .2 Land Elevation Surface $\ldots \ldots \ldots$. . . . . . . . . . . . . . 2.8

2.2 Two-Dimensional Model: MASS2 . . . . . . . . . . . . . . . . 2.14

2.2.1 John Day Tailrace MASS2 Model: Computational Mesh . . . . . . . . 2.14

2.2.2 John Day Tailrace MASS2 Model: Configuration, Calibration, and Val-

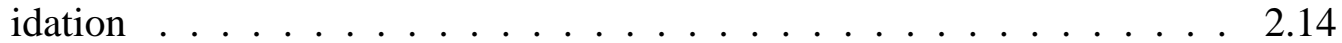

2.2 .3 Tailrace Alternatives Tested in MASS2 . . . . . . . . . . . . . 2.15

2.3 Tailrace 3D CFD Model $\ldots \ldots \ldots \ldots \ldots \ldots$

2.3 .1 3D Computational Mesh . . . . . . . . . . . . . . 2.18

2.3 .2 3D Model Configuration . . . . . . . . . . . . . . . . 2.18

2.3 .3 3D Model Validation . . . . . . . . . . . . . . . . . . . 2.19

2.3 .4 Tailrace Alternatives - 3D Model . . . . . . . . . . . . . 2.20

2.4 Particle Tracking . . . . . . . . . . . . . . . . . . . 2.23

3.0 Results and Discussion . . . . . . . . . . . . . . . . . . . . . . . . 3.1

3.1 MASS2 2D Depth-Averaged Model $\ldots \ldots \ldots . \ldots \ldots$

3.1 .1 MASS2 Calibration and Validation $\ldots \ldots \ldots . \ldots \ldots$ 
3.1 .2 MASS2 Scenarios, TR $250 \mathrm{kcfs} \ldots \ldots \ldots \ldots$

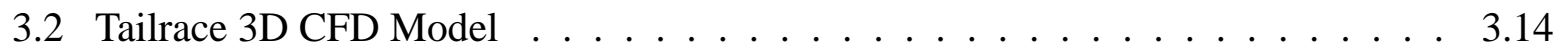

3.2.1 Need for a 3D Model for Near-Project Alternatives . . . . . . . . . . . . 3.14

3.2 .2 STAR-CD 3D VOF Model Validation . . . . . . . . . . . . . . . 3.14

3.2 .3 Additional Validation Information . . . . . . . . . . . . . . . . 3.25

3.2 .4 3D Flow Scenarios . . . . . . . . . . . . . . . . . 3.25

4.0 Conclusions $\ldots \ldots \ldots \ldots$

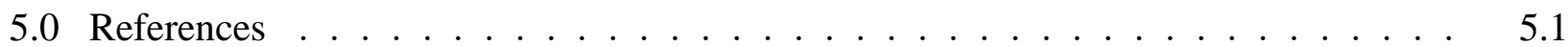

Appendix A -Statistical Measures of Simulation Error . . . . . . . . . . . . . . . . . . A.1

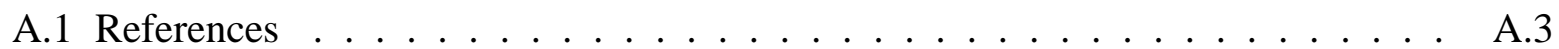

Appendix B - Additional Validation Graphics . . . . . . . . . . . . . . . . . . B.1

Appendix C - Additional Results Graphics . . . . . . . . . . . . . . . . . . . . . . . . C.1 


\section{Figures}

$2.1 \quad$ Geometry Model Domain $\ldots \ldots \ldots \ldots$

$2.2 \quad$ John Day Dam Engineered Structures $\ldots \ldots \ldots$. . . . . . . . . . . . . . . 2.2

$2.3 \quad$ John Day Dam Engineered Structures, Plan View $\ldots \ldots \ldots$

$2.4 \quad$ North Fishway Entrance and Spillway, Plan View _ . . . . . . . . . . . . . . . . . 2.4

2.5 John Day Dam Spillway, Elevation View $\ldots \ldots \ldots \ldots$

$2.6 \quad$ South Fishway Entrance and Powerhouse, Plan View _ . . . . . . . . . . . . . . 2.5

$2.7 \quad$ Non-spill Dam Between Spillway and Powerhouse Isometric View . . . . . . . . . 2.6

$2.8 \quad$ Powerhouse, Elevation View $\ldots \ldots \ldots \ldots \ldots$

$2.9 \quad$ Land Surface Data Sets . . . . . . . . . . . . . . . . . . . . . 2.10

2.10 Land Elevation Surface for Full Domain . . . . . . . . . . . . . . . . . . . . 2.11

2.11 Bathymetry in River Channel . . . . . . . . . . . . . . . . . . . . . . 2.12

2.12 Bathymetry in Tailrace . . . . . . . . . . . . . . . 2.13

$3.1 \quad$ Water-Surface Elevation Simulated by MASS2 for a Manning's n of 0.028 . . . . 3.1

\begin{tabular}{|lll}
\hline 3.2 & TR $210.1 \mathrm{kcfs}, 30 \%$ Spill ADCP and MASS2 Results for Fixed Stations and Tran- \\
\hline \hline sects $\ldots \ldots \ldots \ldots \ldots$
\end{tabular}

\begin{tabular}{|lll}
\hline 3.3 & TR $151.7 \mathrm{kcfs}, 10 \%$ Spill ADCP and MASS2 Results for Fixed Stations and Tran- \\
\hline \hline sects $\ldots \ldots \ldots \ldots \ldots$
\end{tabular}

$3.4 \quad$ TR $122.7 \mathrm{kcfs}, 21 \%$ Spill and MASS2 Results for Fixed Stations and Transects $\quad$. 3.7

$3.5 \quad$ MASS2 Results for the Baseline Case, $250 \mathrm{kcfs}, 30 \%$ Spill $\ldots \ldots \ldots$

3.6 MASS2 Results for the Island Removal Scenario, $250 \mathrm{kcfs}, 30 \%$ Spill $\ldots . . . . .3 .10$

$3.7 \quad$ MASS2 Results for the Shoreline Removal Scenario, $250 \mathrm{kcfs}, 30 \%$ Spill . . . . . . 3.11

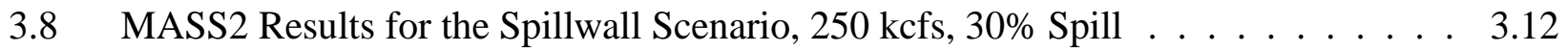

$3.9 \quad$ MASS2 Results for the Skeleton Bay Blockage Scenario, $250 \mathrm{kcfs}, 30 \%$ Spill . . . 3.13 
3.10 Downstream Boundary Discharge for the TR $151.7 \mathrm{kcfs}, 10 \%$ Spill Case . . . . . . 3.15

3.11 Comparison of the Long- and Short-Domain 3D Validation Simulation Results . . . 3.17

3.12 Comparison of Different Time Slices for the TR $151.7 \mathrm{kcfs}, 10 \%$ Spill Validation Simulation Results at an Elevation of $150 \mathrm{ft}(46 \mathrm{~m})$

3.13 Comparison of UD and MARS Validation Simulation Results for TR $151.7 \mathrm{kcfs}$,

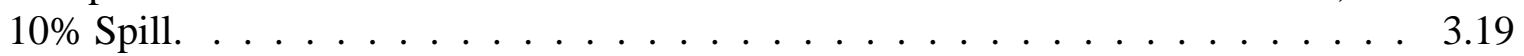

3.14 Comparison of UD and MARS Simulation Results for $125 \mathrm{kcfs}$ at $30 \%$ Spill . . . . 3.20

3.15 Comparison of UD Simulation Results for TR $151.7 \mathrm{kcfs}, 10 \%$ Spill and Field-Measured ADCP Velocities . . . . . . . . . . . . . . . . . 3.22

3.16 Simulated and Field-Measured Velocity Magnitude for the On-Station TR 151.7 kcfs, 10\% Spill Model with Shorter Extents and Upwind Differencing. . . . . . . . 3.23

3.17 Validation 1 to 1 Plots for the Transecting and On-Station ADCP Measurements for TR $151.7 \mathrm{kcfs}, 10 \%$ Spill, TR $122.7 \mathrm{kcfs}, 21 \%$ Spill, and TR $210.1 \mathrm{kcfs}, 30 \%$

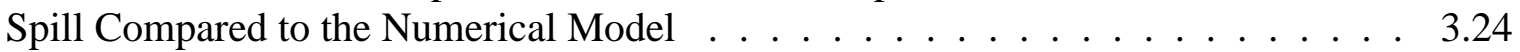

3.18 Particle Tracks Seeded at the Start Location of USGS Released Drogues in 2003 . . 3.26

3.19 Baseline Flows at Elevation $155 \mathrm{ft}(250 \mathrm{kcfs}, 30 \% \mathrm{spill}) \ldots \ldots$. . . . . . . . . . 3.27

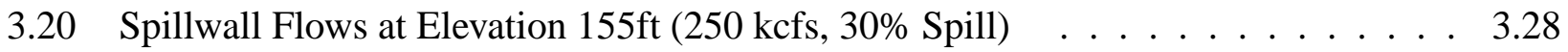

3.21 The Baseline FPP and Spillwall (250 kcfs, 30\% spill) Streamline Particle Tracks . . 3.30

3.22 The Baseline FPP and Spillwall (250 kcfs, 30\% spill) Neutrally Buoyant Particle

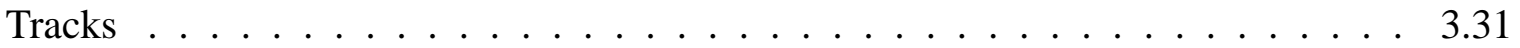

3.23 The Baseline FPP and Spillwall (250 kcfs, 30\% Spill) Neutrally Buoyant Spillway Seeded Particle Tracks . . . . . . . . . . . . . . . . . 3.32

3.24 The Baseline FPP and Spillwall (250 kcfs, 30\% spill) Neutrally Buoyant Powerhouse Seeded Particle Tracks . . . . . . . . . . . . . . . . . 3.33

3.25 Residence Times for TR $250 \mathrm{kcfs}$ for all Particles $\ldots \ldots$. . . . . . . . . 3.35

3.26 Residence times for TR $250 \mathrm{kcfs}$ for spillway particles. . . . . . . . . . . . . 3.36

3.27 Residence times for TR $250 \mathrm{kcfs}$ for Powerhouse Particles. . . . . . . . . . . . . . 3.37 
3.28 Particle Population Gate 2 Residence Times for the FPP and Spillwall (250 kcfs, $30 \%$ spill) Neutrally Buoyant Powerhouse Seeded Particle Tracks . . . . . . . . . . 3.38

3.29 The Baseline Overall Flow Pattern at Elevation $155 \mathrm{ft}$ for TR $125 \mathrm{kcfs}$. . . . . . . 3.40

3.30 The Spillwall with 30\% Spill Overall Flow Pattern at Elevation $155 \mathrm{ft}$ for TR 125

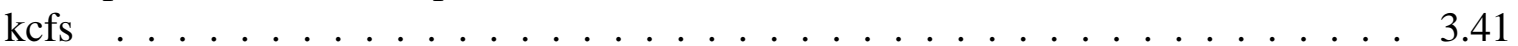

3.31 The Spillwall with 25\% Spill Overall Flow Pattern at Elevation $155 \mathrm{ft}$ for TR 125

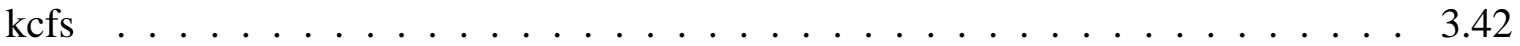

3.32 The Flow Pattern for $21 \%$ Spill at Elevation $155 \mathrm{ft}$ for TR $122.7 \mathrm{kcfs}$. . . . . . . . 3.43

3.33 The Baseline FPP and Spillwall (125 kcfs, 30\% spill) Streamline Particle Tracks . . 3.45

3.34 The Baseline FPP and Spillwall (125 kcfs, 30\% spill) Neutrally Buoyant Particle

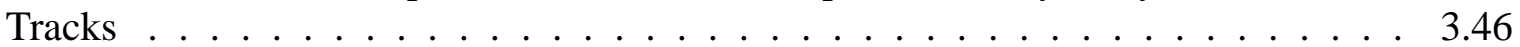

3.35 The Baseline FPP and Spillwall (125 kcfs, 30\% spill) Neutrally Buoyant PowerhouseSeeded Particle Tracks . . . . . . . . . . . . . . . . . . 3.47

3.36 The Baseline FPP and Spillwall (125 kcfs, 30\% spill) Neutrally Buoyant SpillwaySeeded Particle Tracks . . . . . . . . . . . . . . . . . 3.48

3.37 Residence Times for TR $125 \mathrm{kcfs} . \ldots \ldots \ldots$. . . . . . . . . . . 3.50

3.38 Residence Times for TR $125 \mathrm{kcfs}$, Powerhouse Particles . . . . . . . . . . . . . . 3.51

3.39 Residence Times for TR $125 \mathrm{kcfs}$, Spillway Particles. . . . . . . . . . . . . . . . . 3.52

3.40 Residence Times for the Baseline FPP TR $125 \mathrm{kcfs}$ : Particles of Neutral), $972 \mathrm{~kg} / \mathrm{m}^{3}$, and $947 \mathrm{~kg} / \mathrm{m}^{3}$ Densities . . . . . . . . . . . . . . . . 3.53

3.41 Residence Times for the Baseline FPP TR $125 \mathrm{kcfs}$, Powerhouse-Released Parti-

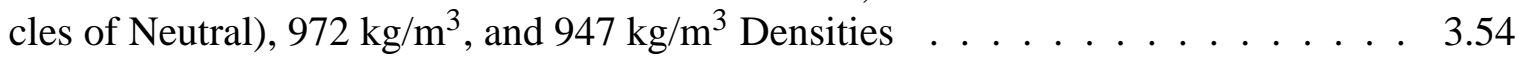

3.42 Residence Times for the Baseline FPP TR $125 \mathrm{kcfs}$, Spillway-Released Particles

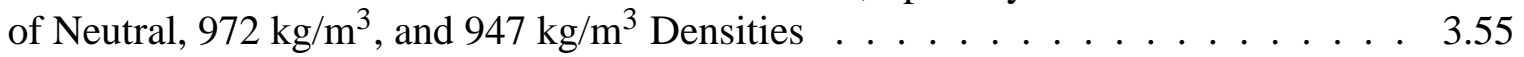

3.43 The Baseline FPP (125 kcfs, 30\% spill) Tracking Results for Powerhouse-Released Particles of Density $972 \mathrm{~kg} / \mathrm{m}^{3}$, and $947 \mathrm{~kg} / \mathrm{m}^{3} \ldots \ldots \ldots . \ldots . \ldots . . \ldots 66$

3.44 Particle Population Gate 2 Passage Times (in seconds) for the Baseline and Spill-

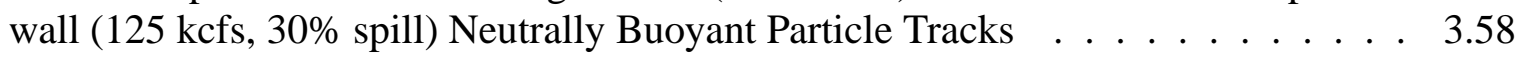

B.1 Comparison of UD Simulation and ENSR Field Measurements of Velocity. . . . . . B.2 
B.2 Comparison of UD Simulation and TR $122.7 \mathrm{kcfs}, 21 \%$ Spill Field Measurements

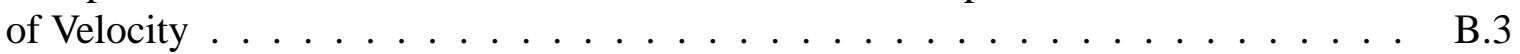

B.3 Validation 1 to 1 Plots for the TR $210.1 \mathrm{kcfs}, 30 \%$ Spill Transecting and On-Station

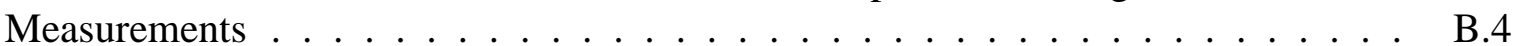

B.4 Validation 1 to 1 Plots for the TR $122.7 \mathrm{kcfs}, 21 \%$ Spill Transecting and On-Station

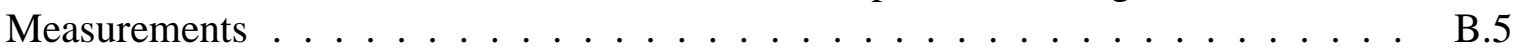

C.1 The Baseline (30\% spill) and Spillwall (25\% spill) TR $125 \mathrm{kcfs}$ Streamline Particle Tracks . . . . . . . . . . . . . . . . .

C.2 The Baseline (30\% spill) and Spillwall (25\% spill) TR 125 kcf Neutrally Buoyant Particle Tracks . . . . . . . . . . . . . . . . . C.3

C.3 The Baseline (30\% spill) and Spillwall (25\% spill) TR 125 kcfs Neutrally Buoyant Powerhouse-Seeded Particle Tracks

C.4 The Baseline (30\% spill) and spillwall (25\% spill) TR $125 \mathrm{kcfs}$ Neutrally Buoyant Spillway-Seeded Particle Tracks 


\section{Tables}

$2.1 \quad$ Source Documents for Engineered Structures . . . . . . . . . . . . . . . . . 2.2

$2.2 \quad$ Sources for Elevation Data. . . . . . . . . . . . . . . . . . . . . . . 2.9

2.3 Validation Runs: $\quad$ Average Flow Conditions (in kcfs) for the 3 Days on Which ADCP Velocity Measurements Were Collected $\ldots \ldots \ldots . \ldots . . \ldots 2.16$

$2.4 \quad$ John Day Tailrace MASS2 Scenarios $\ldots \ldots \ldots \ldots$. . . . . . . . . . 2.17

$2.5 \quad$ Baseline $250 \mathrm{cfs}$ and Spillwall Operations, Both with $30 \%$ Spill . . . . . . . . . . . 2.21

$2.6 \quad$ Operations for TR $125 \mathrm{kcfs} 3 \mathrm{D}$ scenarios: $\quad$ TSW Baseline (with 30\% spill) and Spill-

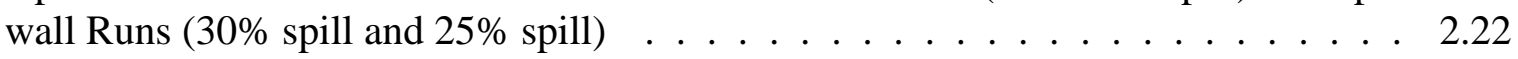

$3.1 \quad$ Summary Statistics for the Difference Between Observed Stage and that Simulated by MASS2 for the period May 11 to May 21, 2008 . . . . . . . . . . . . . 3.1

3.2 Observed and Modeled Water-Surface Elevations Near the Powerhouse for the Three

ADCP Validation Cases . . . . . . . . . . . . . . . . . . . . . 3.2

3.3 Observed and MASS2 Modeled Flows for the Three ADCP Validation Cases. . . . 3.3

$3.4 \quad$ Observed and 3D CFD Modeled Flow Splits for the ADCP Validation Cases. . . . . 3.21

3.5 TR 250 kcfs Gate 2 Residence Times (in seconds) for 25, 50, and 75\% of the Tracked Particle Populations for the FPP and for the Spillwall $\ldots \ldots . . . . . . .3 .34$

$3.6 \quad$ TR 125 kcfs Gate 2 Passage Times (in seconds) for 25, 50, and 75\% of the Tracked Particle Populations for the FPP with the TSWs and for the Spillwall . . . . . . . . 3.57 



\subsection{Introduction}

The Engineer Research and Development Center (ERDC) John Day 1:80 scale reduced-scale physical model has been used by U.S. Army Corps of Engineers (USACE) Portland District (CENWP) as the primary hydraulic model tool to support the biological program in the tailrace of John Day Dam. Improvements have been made to the John Day 1:80 general model that improve the model's ability to replicate the prototype flow features; however, additional hydraulic tools are desired to support CENWP's biological program at this project.

CENWP required that a two-dimensional (2D) depth-averaged and a three-dimensional (3D) free-surface numerical model be developed and validated for the John Day tailrace. These models were, and will be, used to assess the potential impact of a select group of structural and operational alternatives to tailrace flows aimed at improving fish survival at John Day Dam. The 2D model was used for the initial assessment of the alternatives in conjunction with the physical model. A finer resolution 3D model was used to more accurately model the details of flow in the stilling basin and near-project tailrace hydraulics.

In previous work (Project 52758), Pacific Northwest National Laboratory (PNNL) performed computational fluid dynamics (CFD) studies for the tailrace zone to evaluate the performance of The Dalles Dam spillwall extension alternatives for a broad range of wall alignments and operational conditions. Based on that prior work, PNNL applied a similar CFD modeling methodology to simulate and evaluate the flow conditions in the John Day Dam tailrace.

This objective of this study was to create and validate numerical modeling tools for the John Day tailrace and to evaluate their most appropriate uses for assessing proposed structural and operational alternatives. In addition, a possible set of assessment metrics was presented. 



\subsection{Methods}

The process of creating and running a numerical model required many steps. Engineering drawings and bathymetric and topographic data were gathered and processed, those data were used as the underlying geometry for the creation of a computational mesh, and then appropriate boundary conditions were applied to that mesh for model validation and operational and structural scenarios. The simulation results from the validated model were then used to numerically simulate John Day tailrace hydraulics and quantify the hydraulic differences between the alternatives.

\subsection{Tailrace Geometry}

PNNL created a digital geometry model of the John Day Dam structure and surrounding bathymetry and topography. The geometry defined the boundaries of the CFD mesh and provided a backdrop for result visualizations. The geometry domain (Figure 2.1) extends along the Columbia River between river kilometers 341 and 349.5; the dam is at river kilometer 348.5.

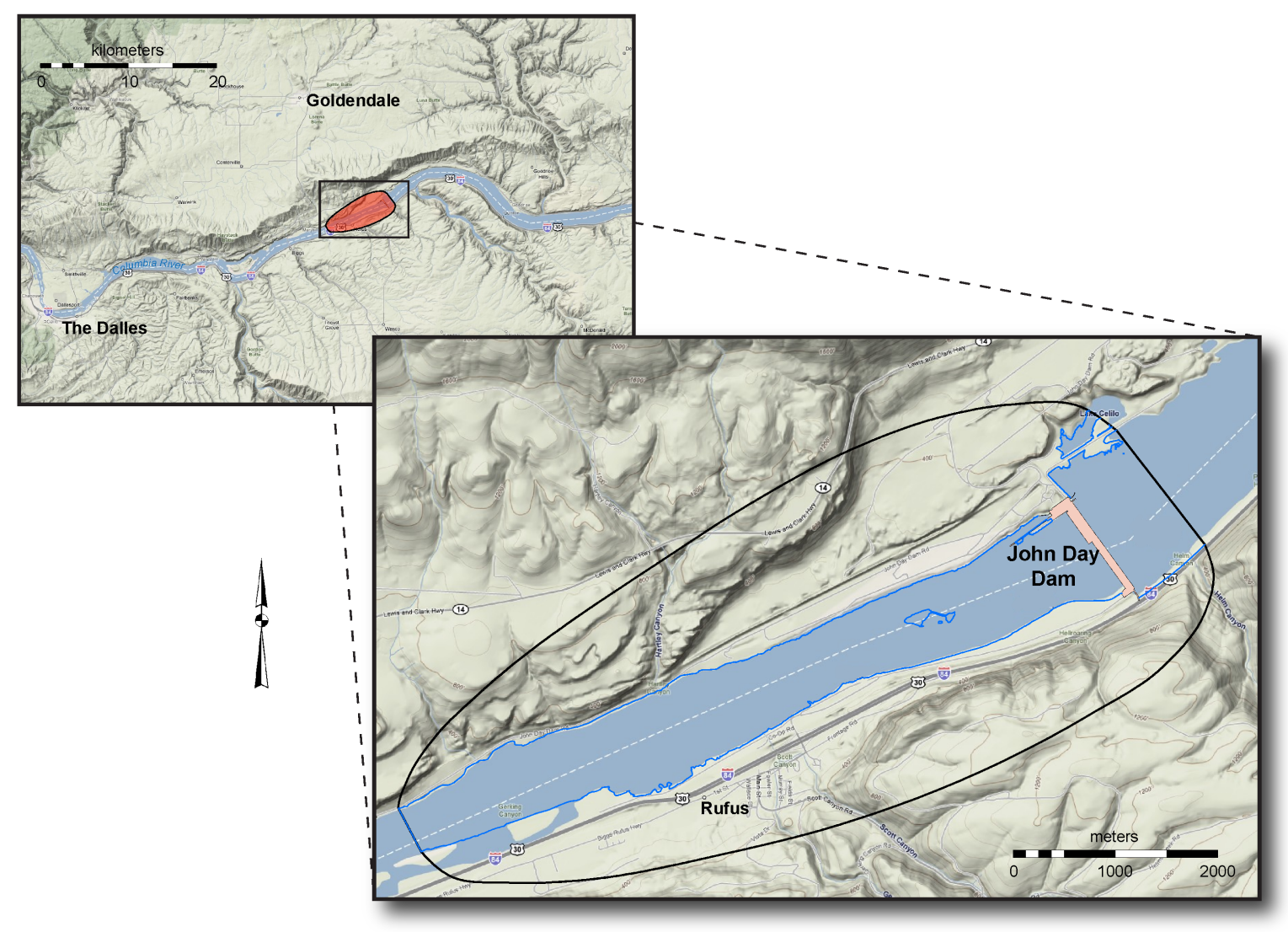

Figure 2.1. Geometry Model Domain 


\subsubsection{Engineered Structures}

Engineered structures include the spillway, powerhouse, non-spill dams, fishway intakes, and navigation lock at the John Day Dam (Figure 2.2). We used engineering drawings provided by CENWP to model these structures in TurboCAD, a 3D computer aided design (CAD) package. Table 2.1 lists the source drawings for each structure.

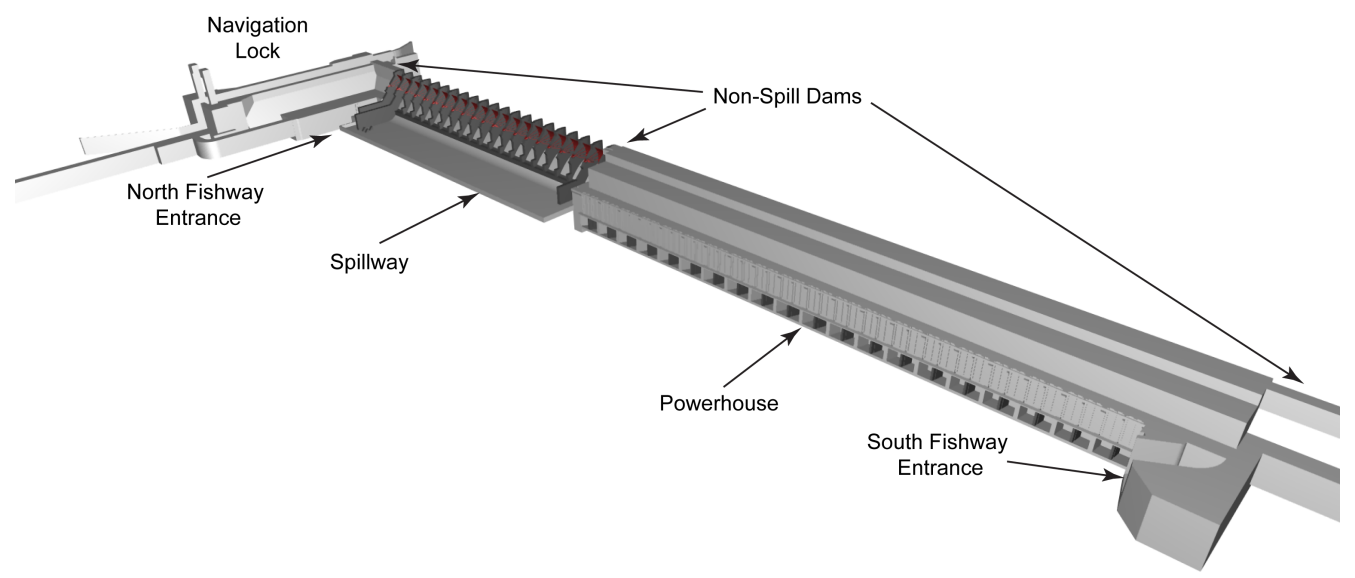

Figure 2.2. John Day Dam Engineered Structures

Table 2.1. Source Documents for Engineered Structures

\begin{tabular}{ll}
\hline Structure & Document \\
\hline Fishway Entrances & JDF-0-1/4, JDF-1-5-2/12, JDF-1-5-3/7, JDP-1-0-0/7 \\
\hline Navigation Lock & JDN-1-4-1/1, JDN-1-4-3/1 \\
\hline Non-Spill Dam & JDD-1-4-2/57, JDD-1-4-2/58, JDD-1-4-2/60, JDD-1-4- \\
& 2/80, JDD-1-4-2/100 \\
\hline Powerhouse & JDP-1-4-0/1, JDP-1-4-0/3, JDP-1-4-4/19, JDP-1-4-4/24, \\
& JDP-1-4-4/25, JDP-1-4-4/29, JDP-1-4-4/35, JDP-1-4-4/68, \\
& JDP-1-4-4/75, JDP-1-4-4/81, JDP-6-0-0/24 \\
\hline Spillway & JDD-1-4-4/1, JDD-2-2/2, JDD-2-2/1, JDP-5.21-5-4/2 \\
\hline
\end{tabular}

The original model coordinate system was in feet with the Y-axis coincident to the construction baseline for the powerhouse and spillway as indicated in the engineering drawings. The $\mathrm{X}$-axis points upstream with origin on the baseline, and the Z-axis points up and used the NGVD29 vertical datum. We subsequently projected the horizontal coordinates to NAD83 State Plane Oregon North Zone coordinates based on survey locations shown on the engineering drawings. Finally, we exported the files to stereolithographic format (STL) for use by the mesh building software, Gridgen (Pointwise, Inc.|2003). Figures 2.3 through 2.8 show details of the engineered structures model. 


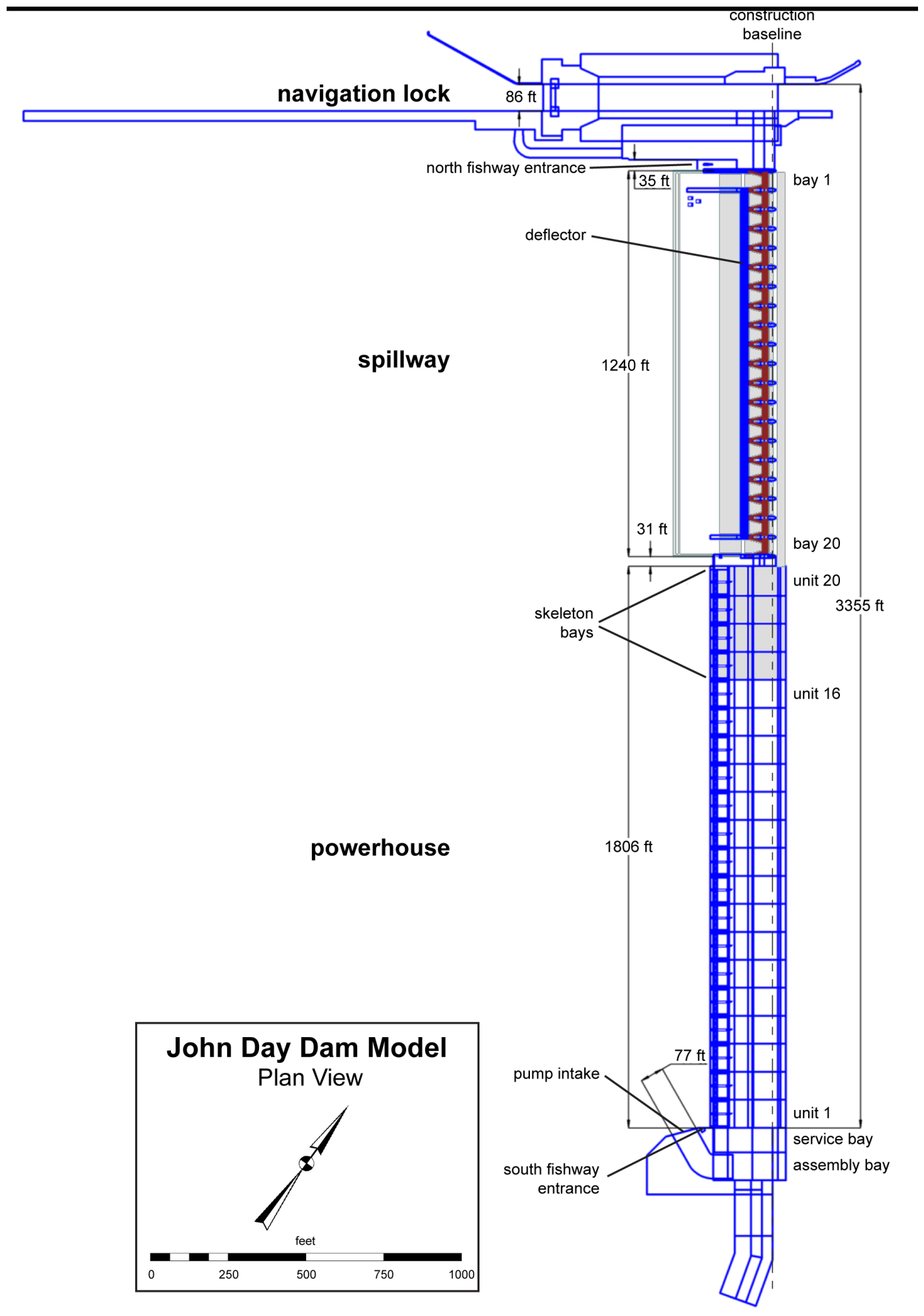

Figure 2.3. John Day Dam Engineered Structures, Plan View 


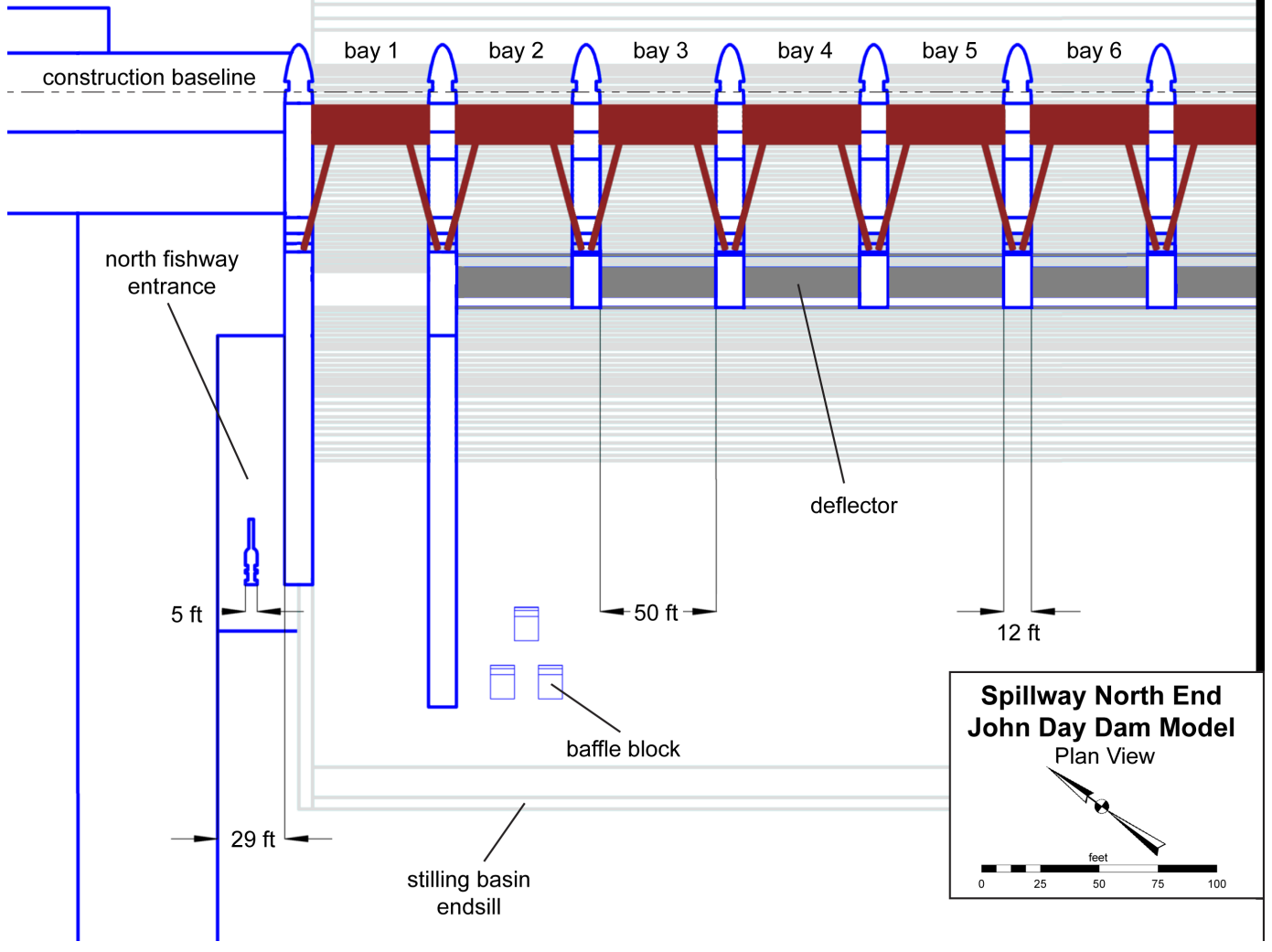

Figure 2.4. North Fishway Entrance and Spillway, Plan View 


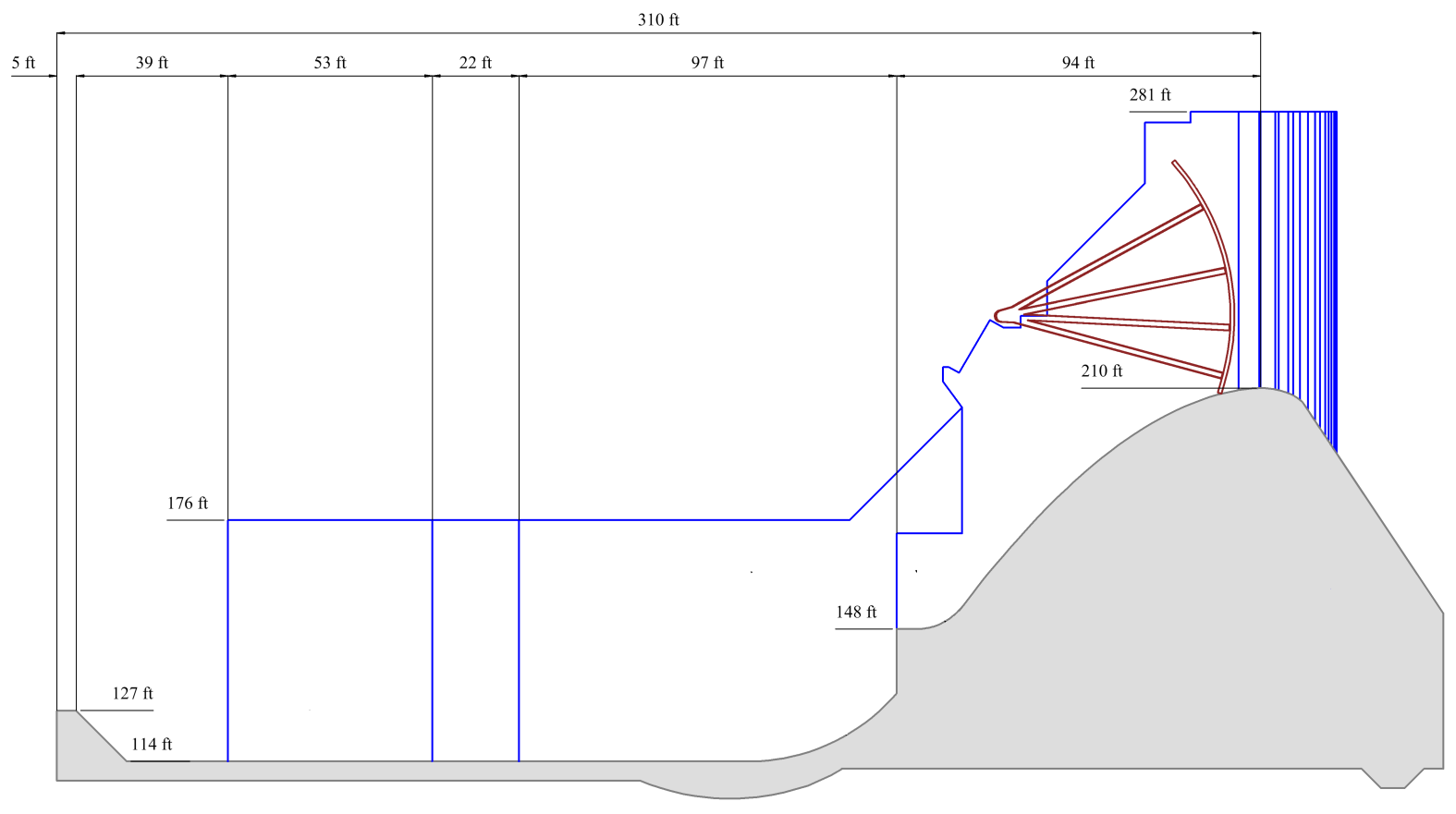

Figure 2.5. John Day Dam Spillway, Elevation View

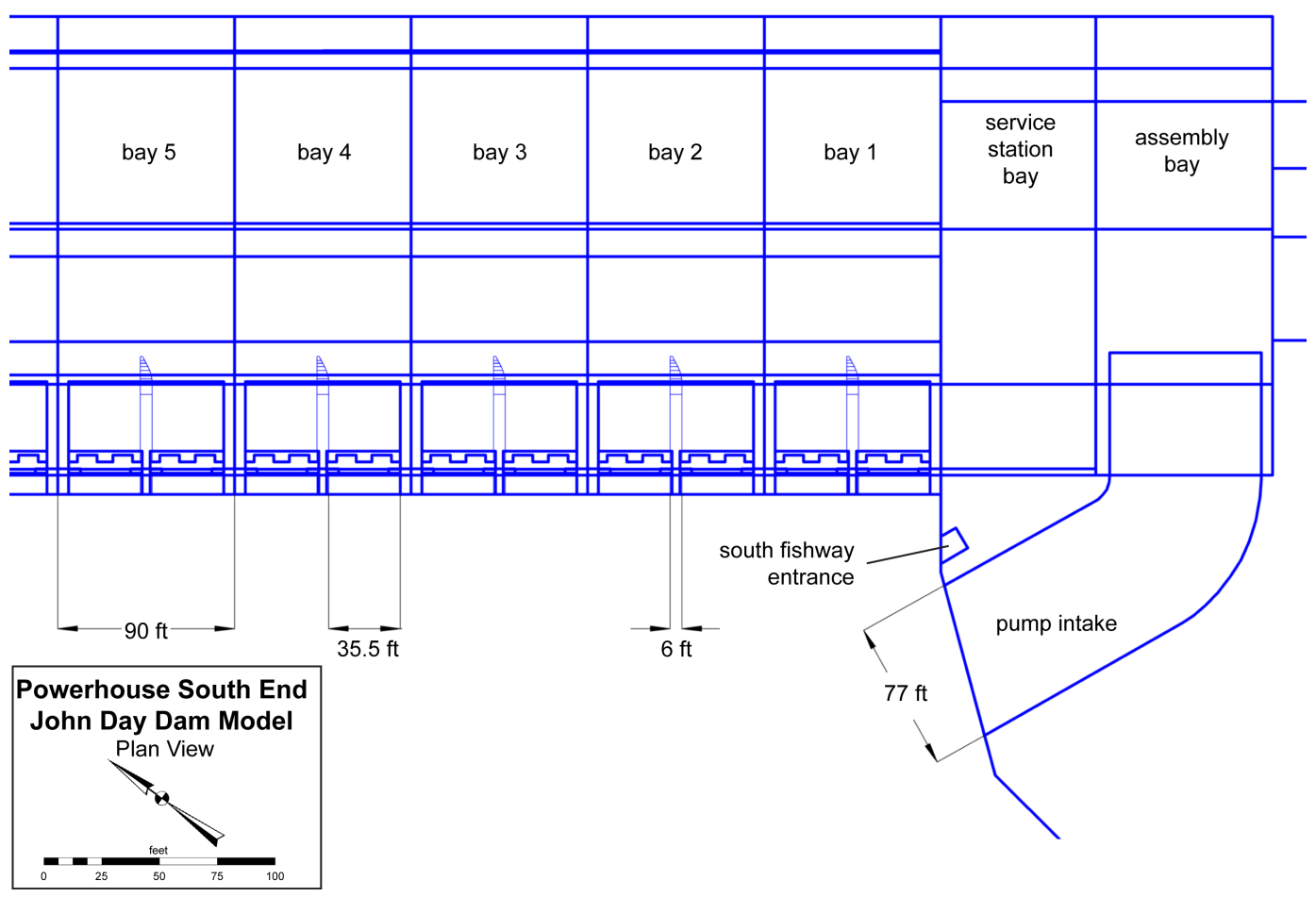

Figure 2.6. South Fishway Entrance and Powerhouse, Plan View 


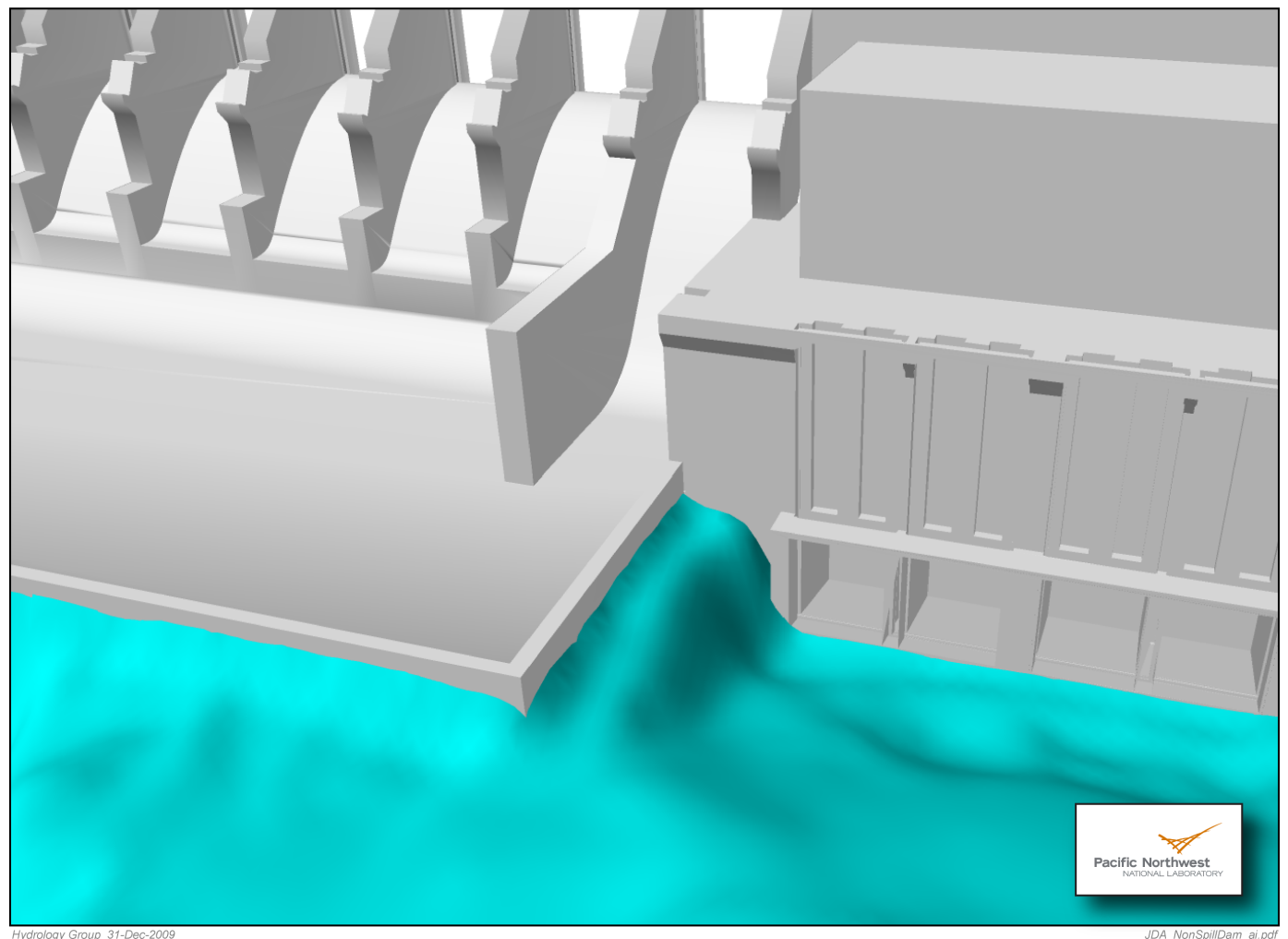

Figure 2.7. Non-spill Dam Between Spillway and Powerhouse Isometric View 


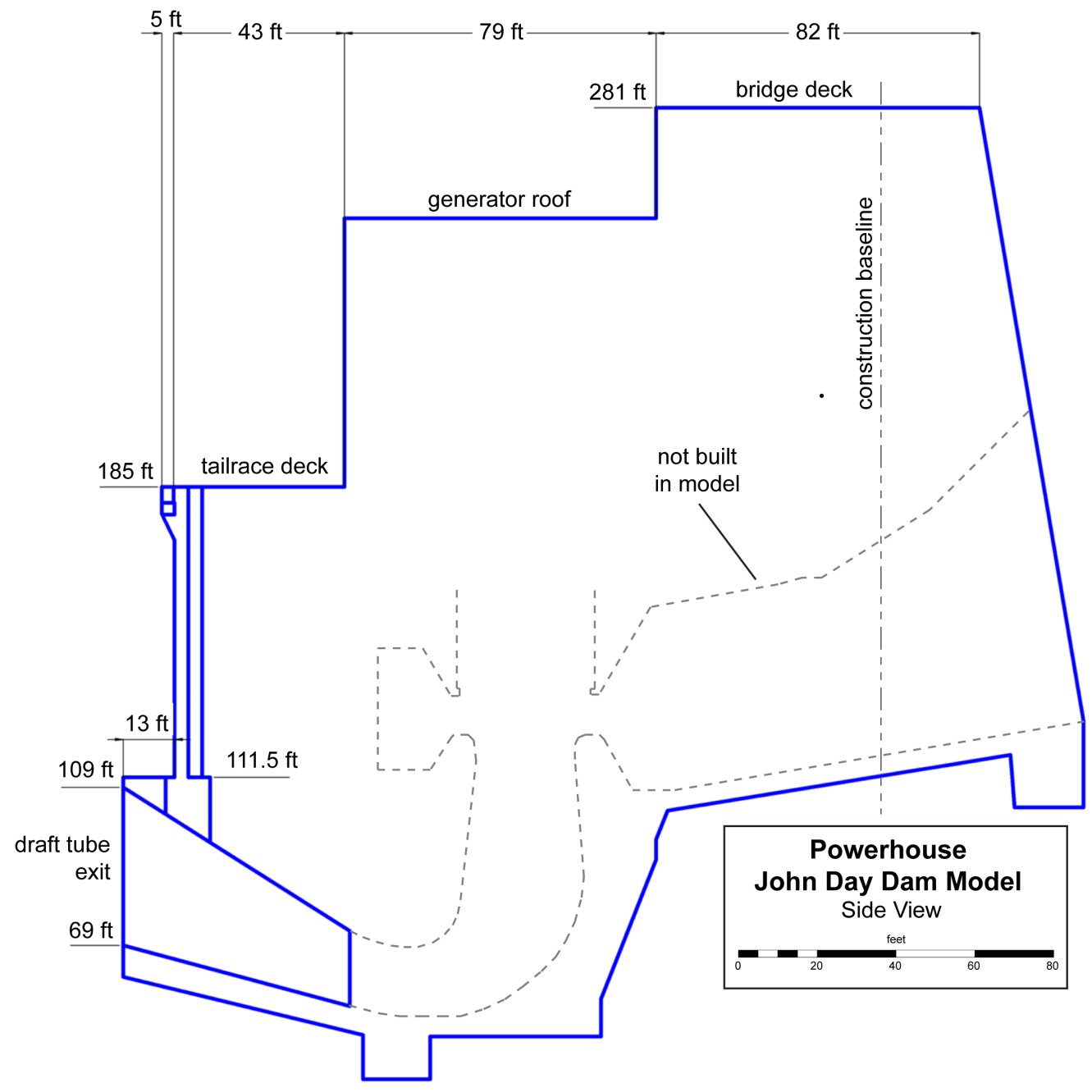

Figure 2.8. Powerhouse, Elevation View 


\subsubsection{Land Elevation Surface}

River bathymetry and surrounding topography form a single continuous land elevation surface. We used Arc/INFO, a geographic information system (GIS), and Tecplot, a data analysis and plotting software, to build this surface by interpolation of point and line elevations obtained from a variety of sources. Table 2.2 lists the sources of elevation data used for this project, and Figure 2.9 shows their spatial distribution.

We loaded the survey point information (the data sets prefixed with "a_" in Table 2.2) and aerial photography into the GIS to digitize, edit, and project the data. The horizontal coordinates were projected to NAD83 State Plane Oregon North Zone (U.S. feet), and elevations were referenced to the NGVD29 vertical datum. In regions where data sets overlapped, we selected the most recent or reliable data to prevail.

To assist with surface generation, we created three elevation contour data sets (those prefixed with "a_" in Table 2). Control lines (a_Control) establish the interface between the land surface and the engineered structures and prevent gaps from forming at these boundaries. River shorelines (a_Shore), digitized from high-resolution ortho-photographs of the site, define contours of known elevation (namely the forebay and tailrace elevations at the time of the image) and aid in separating terrestrial topography from bathymetric data. In areas of sparse data, we supplemented the available elevation points with manually generated contours (a_contour). We based the supplemental bathymetry contours on river channel characteristics observed in areas where data were abundant. Supplemental topography contours were based on features, such as slope breaks due to cliffs, identified in high-resolution aerial photographs.

Next, we exported the point and contour data into Tecplot to generate the land elevation surface by interpolation. In Tecplot, we created multiple rectangular meshes of variable resolution to limit the number of nodes to several million over the model domain, making the surface more computationally manageable. Finally, the grid was exported to a custom Microsoft Access 2003 application, called 3D Data, for conversion to STL format, making it suitable for use as a boundary by the Gridgen (Pointwise, Inc. 2003) meshing software. Figures 2.10 to 2.12 show the final tailrace bathymetric surface and the engineered structures. 
Table 2.2. Sources for Elevation Data.

\begin{tabular}{|c|c|c|}
\hline Dataset & Source & Description \\
\hline a_Control & Engineered structures model & $\begin{array}{l}\text { Control lines used to force surface to } \\
\text { join with engineered structures. }\end{array}$ \\
\hline a_Shore & $\begin{array}{l}\text { CENWP file 1767HJD.dwg and } \\
\text { associated high-res aerial photog- } \\
\text { raphy files 1767HJD*.tif. Also, } \\
\text { USGS orthophotos nw_rufus_1996.tif } \\
\text { and ne_biggs_junction_1996.tif }\end{array}$ & Columbia River shoreline. \\
\hline a_Contours & $\begin{array}{l}\text { p_Area1, p_TDASurvey, CENWP } \\
\text { file 1767HJD.dwg and associated } \\
\text { high-res aerial photography files } \\
\text { 1767HJD*.tif. }\end{array}$ & $\begin{array}{l}\text { Manual interpolation of } p \_ \text {Areal } \\
\text { and p_TDASurvey data; topo- } \\
\text { graphic contours based on data in } \\
\text { file } 1767 \text { HJD.dwg. }\end{array}$ \\
\hline p_Area1 & George Kalli (USACE, Portland) & $\begin{array}{l}\text { Series of transects downstream of } \\
\text { spoils islands about } 100 \mathrm{~m} \text { apart with } \\
\text { data soundings every } 3 \mathrm{~m} \text {. }\end{array}$ \\
\hline p_Area4 & George Kalli (USACE, Portland) & $\begin{array}{l}\text { Subset of full data set covering a } \\
150 \text { x } 50 \mathrm{~m} \text { section downstream } \\
\text { of navigation lock that covers sec- } \\
\text { tion omitted by } 2006 \text { survey. } 10 \mathrm{~m} \\
\text { transects with soundings every } 2 \mathrm{~m} \text {. }\end{array}$ \\
\hline p_sb06 & David Evans and Associates, 2006 & $\begin{array}{l}\text { Singlebeam acoustic survey of shoals } \\
\text { and around islands in the John Day } \\
\text { tailrace. Transects about } 15 \mathrm{~m} \text { apart } \\
\text { with soundings every } 3 \mathrm{~m} \text {. }\end{array}$ \\
\hline p_mb06 & David Evans and Associates, 2006 & $\begin{array}{l}\text { Multibeam acoustic survey of JDA } \\
\text { tailrace bathymetry to } 2.4 \mathrm{~km} \text { down- } \\
\text { stream of dam. } 1 \text {-m grid spacing. }\end{array}$ \\
\hline p_TDASurvey & George Kalli (USACE, Portland) & $\begin{array}{l}\text { Series of transects downstream of } \\
\text { spoils islands about } 150 \mathrm{~m} \text { apart with } \\
\text { data soundings every } 20 \mathrm{~m} \text {. }\end{array}$ \\
\hline p_Forebay & $\begin{array}{l}\text { Miscellaneous surveys and naviga- } \\
\text { tion charts assembled for dissolved } \\
\text { gas project }\end{array}$ & $\begin{array}{l}\text { Bathymetry surface with } 30-\mathrm{m} \text { grid } \\
\text { resolution. }\end{array}$ \\
\hline p_DEM & USGS DEM & $\begin{array}{l}\text { 10-m digital elevation model of } \\
\text { topography near Columbia River. }\end{array}$ \\
\hline
\end{tabular}




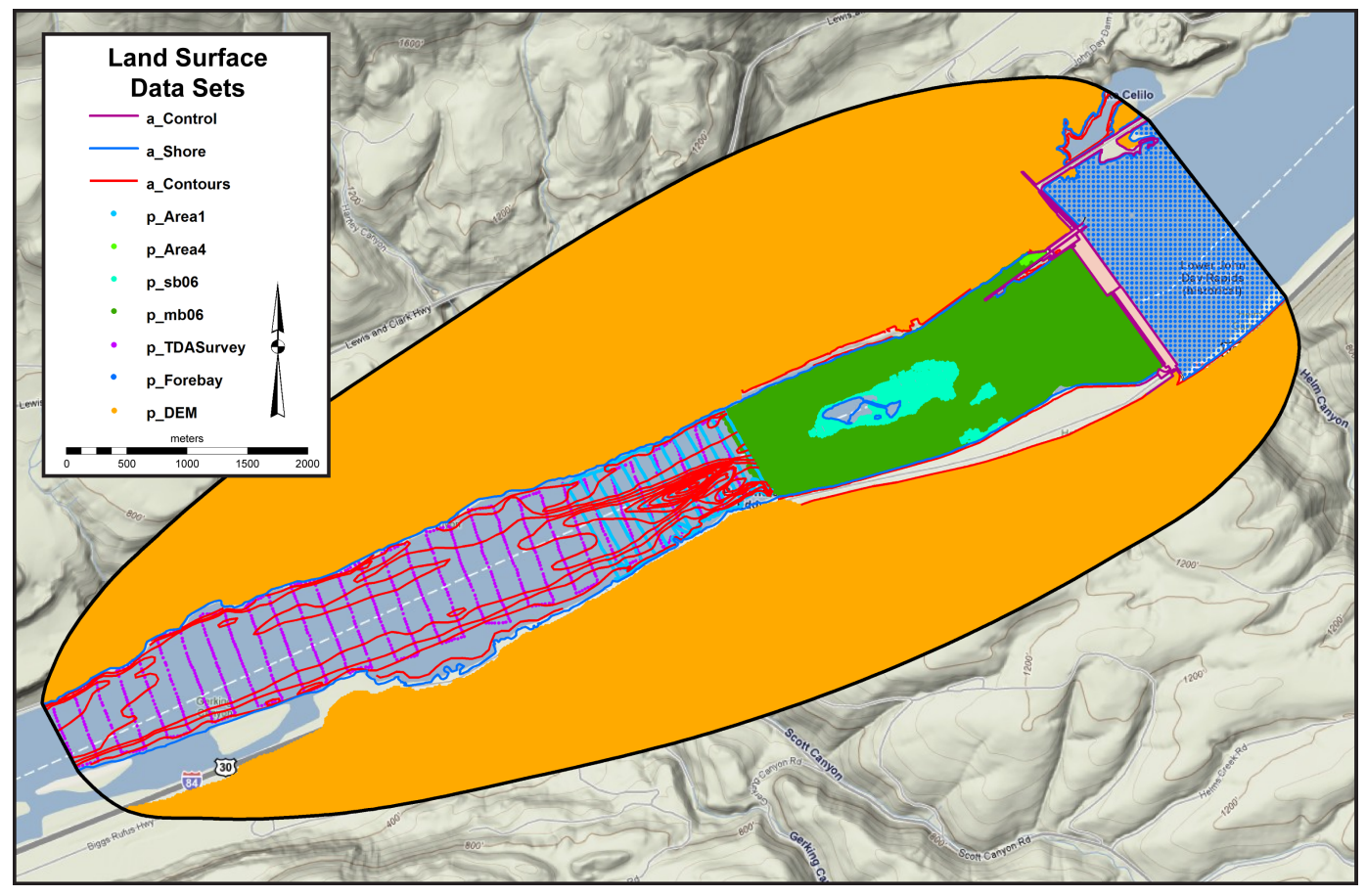

Figure 2.9. Land Surface Data Sets 


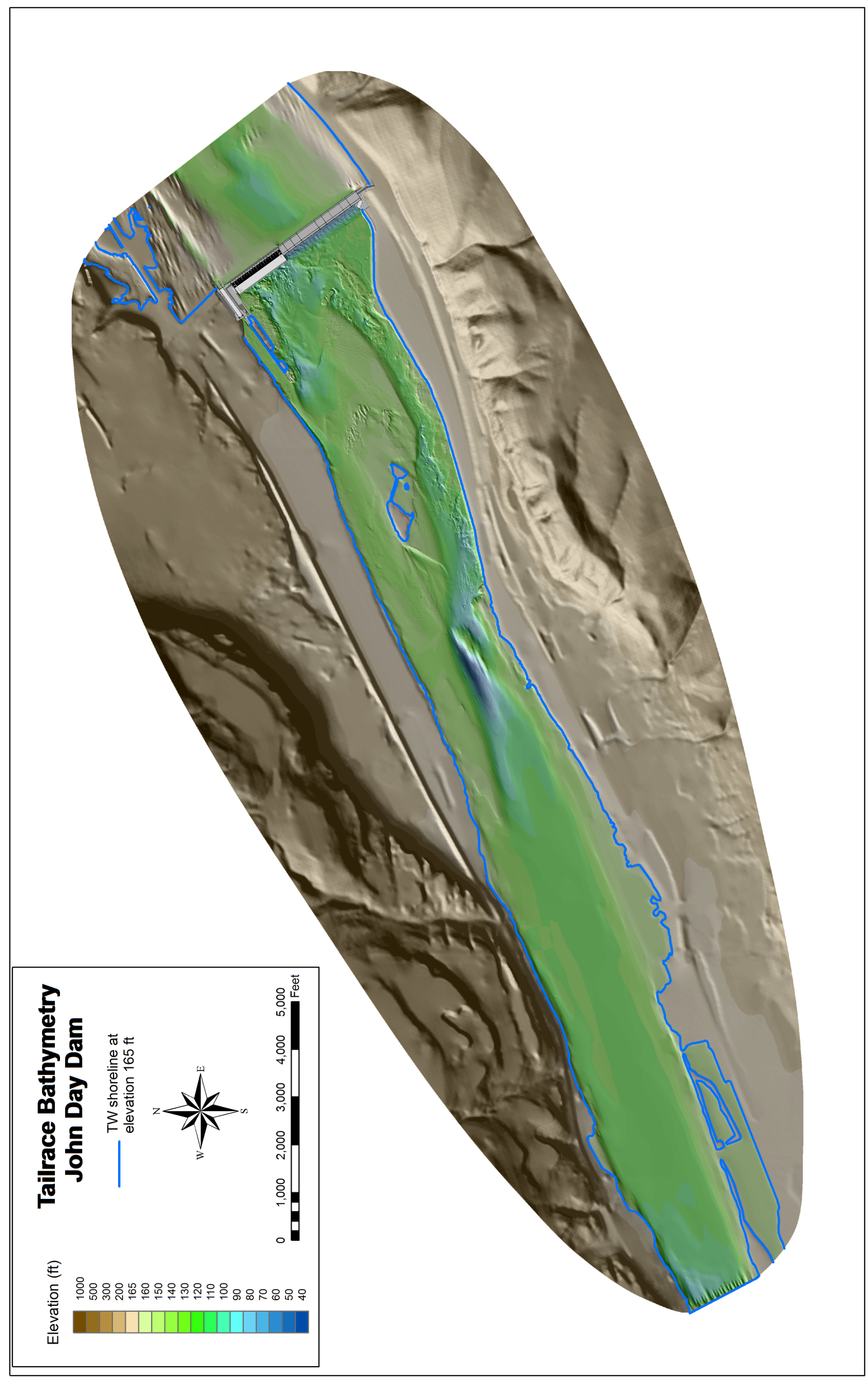

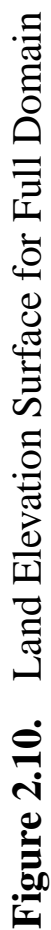




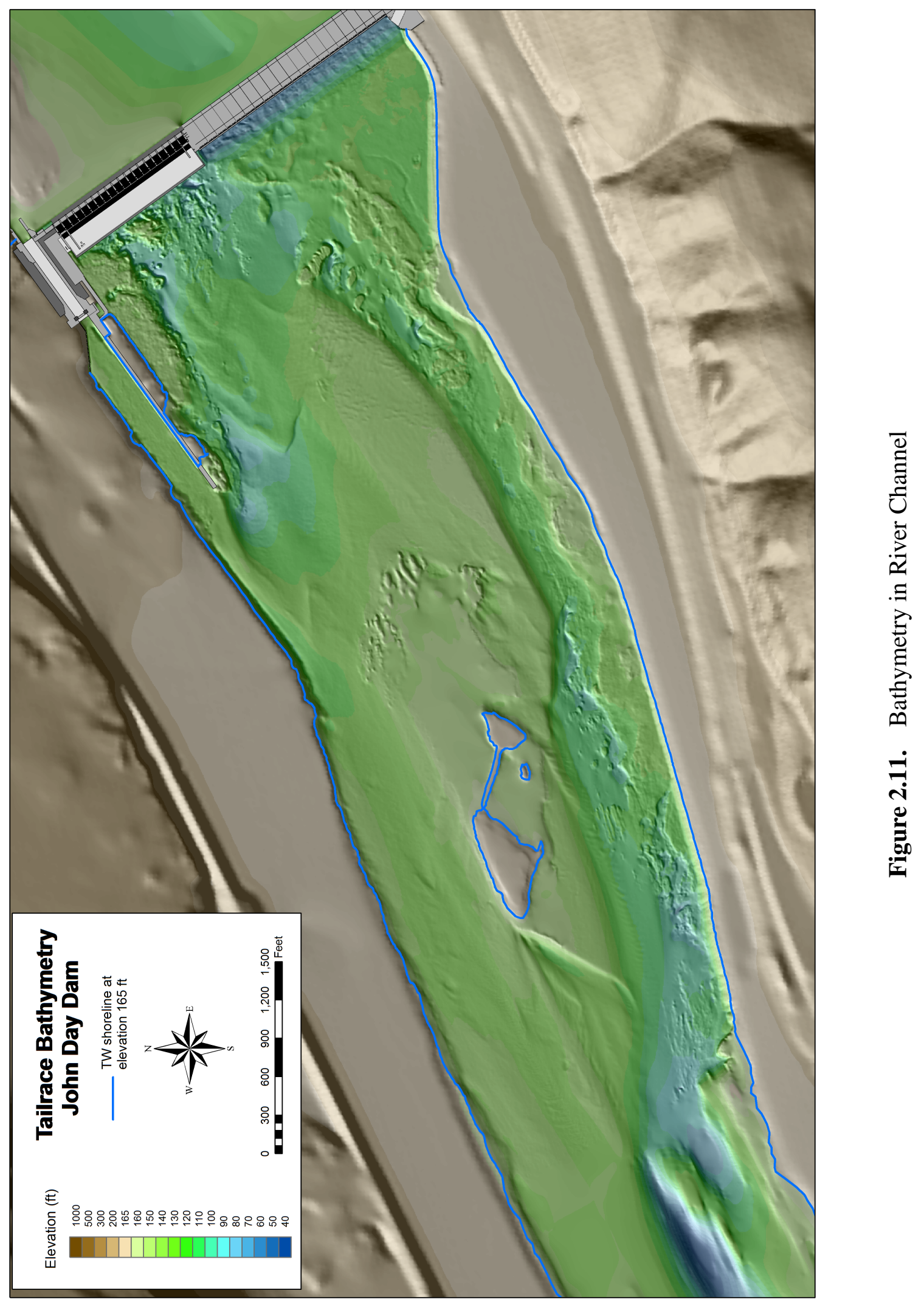




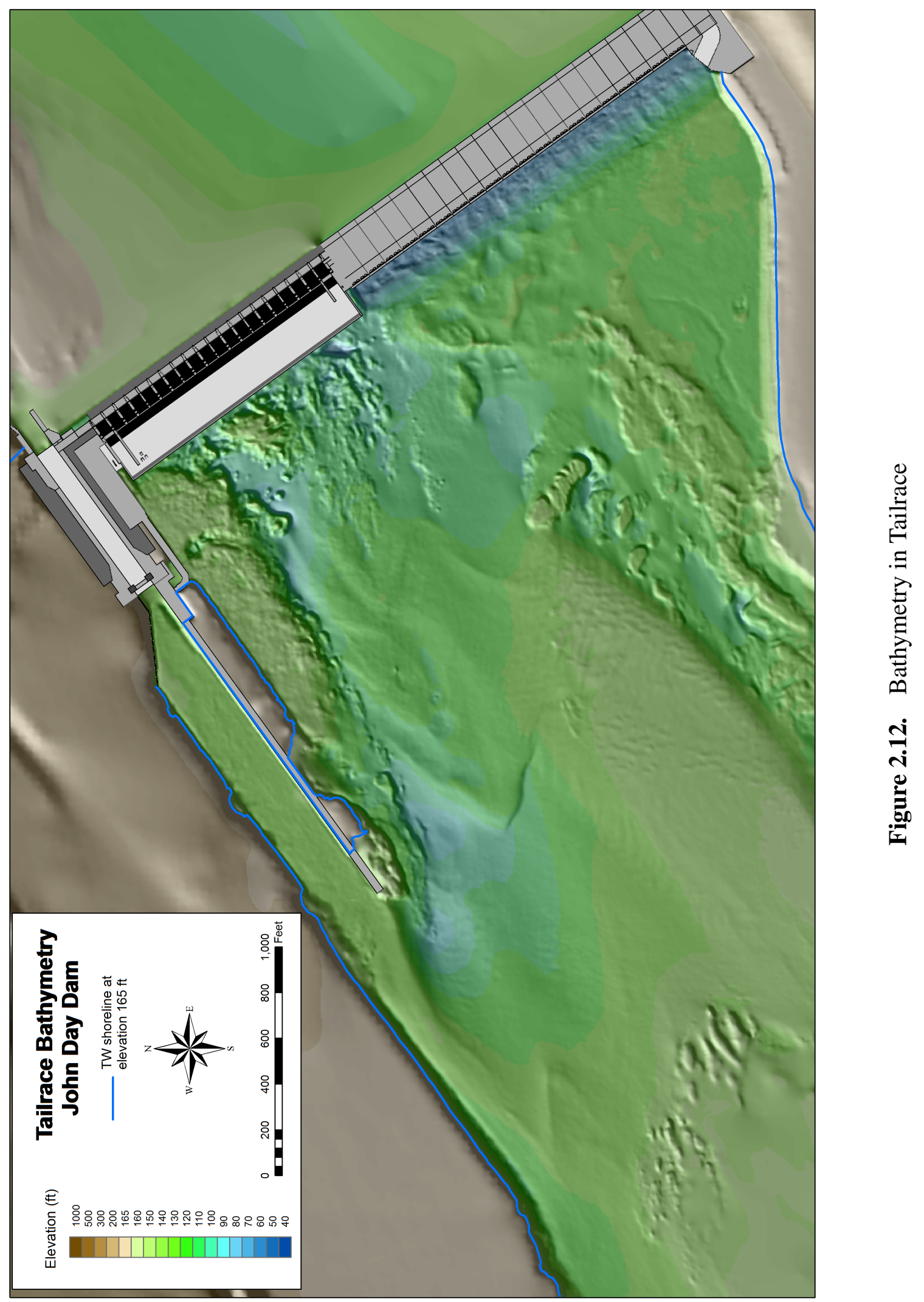




\subsection{Two-Dimensional Model: MASS2}

Although a 2D depth-averaged model, Modular Aquatic Simulation System (MASS2), had recently been run in the John Day Tailrace (Rakowski et al.2008a), the MASS2 model did not use the most recently collected bathmetry nor was the lateral extent (which includes higher tailwater elevations) as much as desired for this study. In addition, the $2 \mathrm{D}$ and $3 \mathrm{D}$ models were to be compared, so both models were created on a shifted coordinate system (by -8100000 easting and -700000 northing) to reduce the number of significant digits required for the geometry. Although not required for the MASS2 model, the shift is required for the 3D model and was done for ease of pre- and post-processing.

\subsubsection{John Day Tailrace MASS2 Model: Computational Mesh}

A new computational mesh that met the requirements of this study was created. The most recent bathmetry (see Section 2.1) was used and shorelines extracted for an elevation of $182 \mathrm{ft}$. This contour was used to define the lateral extent of MASS2 computational mesh and the highest tailwater elevation required near the John Day Project. Elevations for each computational point were extracted from an ARC/Grid of the tailrace land surface bathmetry (see Section 2.1.2). For this study, however, it was necessary to have the MASS2 mesh extend to a downstream location with a known boundary condition. Consequently, the computational mesh was extended from the John Day Project downstream to the forebay of The Dalles Dam. There were no new bathymetric surveys for this reach, so the bathymetric surface developed for the Dissolved Gas Abatement Study (DGAS, Richmond et al.2000) study was projected, translated, and then used to provide the point elevations for the downstream computational mesh.

\subsubsection{John Day Tailrace MASS2 Model: Configuration, Calibration, and Validation}

The MASS2 model (Perkins and Richmond 2004), a depth-averaged 2D model, has been validated and used extensively in the Columbia and Snake Rivers. In the MASS2 model, a Manning's $\mathrm{n}$ roughness coefficient was used to calibrate the model. After determining the appropriate Manning's n, the model was validated to field-measured velocity data. The MASS2 model for the John Day Tailrace was configured by specifying bay-by-bay operations for the spillway and unit operations for the turbine flows. The downstream boundary was the forebay of The Dalles. The model was run with a second order differencing scheme.

To calibrate the model, it was necessary to determine an appropriate Manning's n. To do this, the period (May 10, 2008, to May 21, 2008) was used with the calibrated Manning's value from the DGAS study. The first day was used to warm up the model, and then the rest of the period was run for comparison to field data. The water surface elevation for an established gage and the simulated water surface elevation were compared at 5-min intervals. Based on these comparisons, the Manning's n was adjusted to provide the best fit of modeled water surface elevation. Summary statistics were generated for each Manning's n tested to quantify model performance. Summary statistics included $\mathrm{R}^{2}$, SE, RMS, MSE, MAE, and bias as defined in Appendix A.

After an appropriate Manning's n was determined, the MASS2 model was run for three different days on which acoustic Doppler current profiler (ADCP) measurements were made (Mannheim 
and Sweeney 2003 and Cook et al.2006; see Table 2.3). Total river flows (TRs) were TR 122.7 kcfs, TR $151.7 \mathrm{kcfs}$, and TR $210.1 \mathrm{kcfs}$. The operations were, for the most part, held steady throughout the day while measurements were being made. The ADCP measurements were depth-averaged and compared to the simulated velocities at the measurement locations.

\subsubsection{Tailrace Alternatives Tested in MASS2}

CENWP identified four possible alternatives to improve the hydraulics of the John Day tailrace:

- removing the "dredge spoils island" to an elevation of 140.0ft,

- reshaping the south shoreline, excavating to an elevation of $130.0 \mathrm{ft}$,

- blocking the area below the skeleton bays to reduce lateral entrainment and predator habitat area, and

- adding a long spillwall between bays 12 and 13 .

These alternatives were run in MASS2 for screening purposes to help guide choices of the alternatives tested at the ERDC physical model.

The bathymetry for the shoreline reshaping and the island removal alternatives were incorporated into bathymetric surfaces. For the island removal case, the elevations in the computational mesh were modified, but the mesh coordinates were unchanged. For the shoreline reshaping alternative, the 2D mesh was modified on the south shore to incorporate the increased lateral extent needed. For the skeleton bay blockage, the mesh node elevation was modified to be greater than the water surface elevation. For the spillwall, a 2D wall was added to the model configuration in the correct location for the proposed wall.

These four alternatives and the exiting conditions (baseline-Fish Passage Plan without TSWs in place) were run in MASS2 for a single flow, TR $250 \mathrm{kcfs}$ with $30 \%$ spill. Although the spill volume was the same for all runs, it was distributed differently for the alternatives (Table 2.4). The baseline, island removal and shoreline removal had identical inflows based on the existing Fish Passage Plan (FPP). The spillwall and skeleton bay blockage used conditions modeled in the physical model and probable project operations.

\subsection{Tailrace 3D CFD Model}

The 2D model was used for initial assessment of alternatives; however, a 3D model with a free surface was desired to more accurately simulate the tailrace hydraulics, especially near the powerhouse and spillway. We knew from the comparison of the MASS2 model to the field-measured velocities of Mannheim and Sweeney (2003) and Cook et al. (2006) that the 2D model did not accurately represent the lateral entrainment from the powerhouse to the stilling basin and spillway jet.

PNNL has previously applied free-surface models using the volume of fluid (VOF) method to 
Table 2.3. Validation Runs: Average Flow Conditions (in kcfs) for the 3 Days on Which ADCP Velocity Measurements Were Collected

\begin{tabular}{|c|c|c|c|}
\hline Unit & $\begin{array}{c}\text { TR 210kcfs, } \\
\text { 30\% Spill }\end{array}$ & $\begin{array}{c}\text { TR 151.7kcfs, } \\
10 \% \text { Spill }\end{array}$ & $\begin{array}{c}\text { TR } 123 \text { kcfs, } \\
21 \% \text { Spill }\end{array}$ \\
\hline Spill 1 & 0.0 & 0 & 0 \\
\hline Spill 2 & 6.4 & 4.9 & 4.6 \\
\hline Spill 3 & 4.8 & 4.9 & 4.6 \\
\hline Spill 4 & 4.8 & 3.1 & 4.6 \\
\hline Spill 5 & 4.8 & 2.2 & 3.2 \\
\hline Spill 6 & 4.8 & 0 & 3.3 \\
\hline Spill 7 & 4.8 & 0 & 3.4 \\
\hline Spill 8 & 4.8 & 0 & 1.7 \\
\hline Spill 9 & 3.2 & 0 & 0 \\
\hline Spill 10 & 3.2 & 0 & 0 \\
\hline Spill 11 & 3.2 & 0 & 0 \\
\hline Spill 12 & 3.2 & 0 & 0 \\
\hline Spill 13 & 3.2 & 0 & 0 \\
\hline Spill 14 & 3.2 & 0 & 0 \\
\hline Spill 15 & 3.2 & 0 & 0 \\
\hline Spill 16 & 3.2 & 0 & 0 \\
\hline Spill 17 & 1.6 & 0 & 0 \\
\hline Spill 18 & 0.0 & 0 & 0 \\
\hline Spill 19 & 0.0 & 0 & 0 \\
\hline Spill 20 & 0.0 & 0 & 0 \\
\hline Total Spill & 62.4 & 15.1 & 25.4 \\
\hline PH-1 & 14.77 & 0 & 0 \\
\hline PH-2 & 0 & 0 & 0 \\
\hline PH-3 & 0 & 15.2 & 14 \\
\hline PH-4 & 14.77 & 14.9 & 0 \\
\hline PH-5 & 14.77 & 0 & 13.9 \\
\hline PH-6 & 14.77 & 15.2 & 0 \\
\hline PH-7 & 14.77 & 15.2 & 14 \\
\hline PH-8 & 0 & 15.2 & 0 \\
\hline PH-9 & 0 & 15.2 & 13.6 \\
\hline PH-10 & 14.77 & 0 & 0 \\
\hline PH-11 & 14.77 & 15.5 & 13.6 \\
\hline PH-12 & 14.77 & 0 & 0 \\
\hline PH-13 & 0 & 0 & 0 \\
\hline PH-14 & 14.77 & 15 & 14 \\
\hline PH-15 & 0 & 0 & 0 \\
\hline PH-16 & 14.77 & 15.2 & 14.2 \\
\hline Total PH & 147.7 & 136.6 & 97.3 \\
\hline Total River & 210.1 & 151.7 & 122.7 \\
\hline
\end{tabular}


Table 2.4. John Day Tailrace MASS2 Scenarios (flows in kcfs). The baseline, island removal and shoreline removal had identical flow conditions.

\begin{tabular}{|c|c|c|c|}
\hline Unit & $\begin{array}{c}\text { Baseline, Island Removal } \\
\text { and Shoreline Removal }\end{array}$ & Spillwall & Skeleton Bay Blockage \\
\hline Spill 1 & 0.0 & 0.0 & 3.2 \\
\hline Spill 2 & 6.4 & 0.0 & 3.2 \\
\hline Spill 3 & 8 & 0.0 & 3.2 \\
\hline Spill 4 & 6.4 & 0.0 & 3.2 \\
\hline Spill 5 & 6.4 & 0.0 & 3.2 \\
\hline Spill 6 & 6.4 & 0.0 & 3.2 \\
\hline Spill 7 & 4.8 & 0.0 & 3.2 \\
\hline Spill 8 & 4.8 & 0.0 & 3.2 \\
\hline Spill 9 & 4.8 & 0.0 & 3.2 \\
\hline Spill 10 & 4.8 & 0.0 & 4.8 \\
\hline Spill 11 & 3.2 & 0.0 & 3.2 \\
\hline Spill 12 & 3.2 & 0.0 & 4.8 \\
\hline Spill 13 & 3.2 & 9.6 & 3.2 \\
\hline Spill 14 & 3.2 & 9.6 & 4.8 \\
\hline Spill 15 & 3.2 & 9.6 & 3.2 \\
\hline Spill 16 & 3.2 & 9.6 & 4.8 \\
\hline Spill 17 & 3.2 & 9.6 & 4.8 \\
\hline Spill 18 & 0.0 & 9.6 & 4.8 \\
\hline Spill 19 & 0.0 & 9.6 & 4.8 \\
\hline Spill 20 & 0.0 & 8.0 & 3.2 \\
\hline Total Spill & 75.2 & 75.2 & 75.2 \\
\hline PH-1 & 15.0 & 15.0 & 15.0 \\
\hline PH-2 & 15.0 & 15.0 & 15.0 \\
\hline PH-3 & 15.0 & 15.0 & 15.0 \\
\hline PH-4 & 0.0 & 0.0 & 0.0 \\
\hline PH-5 & 15.0 & 15.0 & 15.0 \\
\hline PH-6 & 0.0 & 0.0 & 0.0 \\
\hline PH-7 & 12.4 & 12.4 & 12.4 \\
\hline PH-8 & 15.0 & 15.0 & 15.0 \\
\hline PH-9 & 0.0 & 0.0 & 0.0 \\
\hline PH-10 & 15.0 & 15.0 & 15.0 \\
\hline PH-11 & 12.4 & 12.4 & 12.4 \\
\hline PH-12 & 15.0 & 15.0 & 15.0 \\
\hline PH-13 & 0.0 & 0.0 & 0.0 \\
\hline PH-14 & 15.0 & 15.0 & 15.0 \\
\hline PH-15 & 15.0 & 15.0 & 15.0 \\
\hline PH-16 & 15.0 & 15.0 & 15.0 \\
\hline Total PH & 174.8 & 174.8 & 174.8 \\
\hline Total River & 250.0 & 250.0 & 250.0 \\
\hline
\end{tabular}


The Dalles tailrace in the lower Columbia River (Rakowski et al. 2008b and Richmond et al. 2009). Particle tracking was used to characterize and quantify particle paths and egress times. The methodologies applied there served to guide our approach to the John Day tailrace freesurface model.

\subsubsection{D Computational Mesh}

Using the 2D mesh and the tailrace bathmetry as a starting point, a 3D hexahedral mesh was created for the tailrace. This mesh was designed to be used with a VOF simulation in a commercial CFD solver, STAR-CD (CD-adapco, Computational Dynamics Limited 2006). The mesh included a clustering of cells in the vertical near the expected water surface. A stilling basin was constructed with a flat bottom, and the upstream extent was at the end of the ogee deflectors. The draft tubes, from the splitter wall to the tailrace, were included so that each bay of each unit, with an appropriate flow split, could be included as part of the boundary conditions. For the final model, there were about 3.9 million cells with 1 - $\mathrm{ft}$ vertical resolution near the water surface (10 layers), 5-ft vertical resolution below that, 5-ft vertical resolution for $30 \mathrm{ft}$ above the refined layer near the expected water surface. There was increased vertical resolution in the stilling basin, on the ogee face, and in and near the draft tube barrels.

\subsubsection{D Model Configuration}

In the 3D model, there were two classes of inflow boundaries with very different energy characteristics: the spillway and the draft tubes. The spillway flows were high velocity (about 60 to $70 \mathrm{ft} / \mathrm{s}$ ) and of relatively small flow depths. The draft tube flows start just downstream of the splitter wall and, based on measurements, observations, and reduced-scale physical-model studies, were typically a very complex flow environment with transient eddies and recirculation. Consequently, additional work was done to characterize these environments appropriately in the numerical model.

To understand the spillway inflow, a 2D model was created of a short forebay, the tainter gate, and the ogee. That model was used to assess typical flow velocities and depths at the foot of the ogee. To represent the prototype stilling basin conditions, it was critical to have velocities (and not just the flow volume) to simulate the momentum flux and hence reproduce the resulting lateral entrainment of the powerhouse flows into the spillway jet.

To more accurately represent the inflow conditions at the spillway, additional refinements were made to the computational mesh at the spillway inflow boundaries to increase the number of cells in the vertical. The estimated inflow velocity (from the $2 \mathrm{D}$ model), the spill bay width, and the flow volume were used to calculate an initial flow depth for each bay.

For the powerhouse, the boundary conditions were configured using flow splits (60/40) for the draft tube barrels. These splits were determined from physical model data (ENSR and VA Tech Hydro 2008) and communications with CENWP (pers. comm., Sean Askelson, 2008). The 60/40 (barrels A/C, respectively) split between draft tube barrels was typical, but splits as uneven as 70/30 were measured for some turbine discharges. Based on the measurements by ENSR and VA Tech Hydro (2008), several approaches to setting the draft tube inflow boundary condition 
were tested for a single flow, and the overall downstream influence was assessed. A numerical model was created for the single-unit geometry and downstream flume used in ENSR and VA Tech Hydro (2008). The downstream geometry was assessed to confirm that it represented the prototype tailrace. Several sensitivity tests were conducted using the measured flow splits and inflows at the inflow boundary. The boundary condition was adjusted so that inflows were 1) horizontal, 2) parallel to the draft tube floor, and 3) with swirl added at the inflow boundary. These tests showed that, approximately $200 \mathrm{ft}$ downstream near the rise in the tailrace bathymetry the impacts of the angle of the inflow, or adding swirl to the inflows, were small for the single discharge modeled.

For each draft tube bay, a specified inflow velocity was calculated from the flow volume, boundary area, and flow split. The velocity was purely horizontal and orthogonal to the boundary. The area of interest for this study is downstream of the bathymetry rise, so this approach is adequate. If future studies are concerned with the hydraulics near the powerhouse, this approach should be revisited. The interaction between operational and non-operational units probably plays a significant role in the dynamics near the powerhouse and should also be evaluated.

The downstream boundary for this 3D VOF model was configured to be a hydrostatic boundary with a specified water-surface elevation. The water-surface elevation at the downstream boundary was determined from the validated MASS2 model (which extended to The Dalles forebay) when run for the same flow conditions and The Dalles forebay elevation.

The discharge passing the downstream boundary was used to assess the model's progress in approaching a quasi-steady solution. Based on past experience with VOF models, we expect the outflow volume to oscillate about the target value for at least an hour of real time. The model was run as a transient VOF model with a time step between 0.07 and 0.12 seconds with steady inflows and a global residual tolerance of 0.001. In the final runs, upwind differencing was used (see discussion in Section 3.2.2), although results were checked against the second-order monotone advection and reconstruction scheme (MARS) solution.

\subsubsection{D Model Validation}

The same three flow scenarios with ADCP measurements that were used for the MASS2 validation were also used for the STAR-CD validation. These were for total river flows of $122.7 \mathrm{kcfs}$, $151.7 \mathrm{kcfs}$, and $210.1 \mathrm{kcfs}$ (see Table 2.3).

Initially, the model extented $6900 \mathrm{~m}$ downstream from the dam. While that model had the downstream boundary far from the areas of interest, the run times were excessive due to the propagation of waves off the downstream boundary through the domain, aka "sloshing," and the additional run time required for the waves to dissipate.

The model was truncated so that the downstream extent was at the flow constriction downstream of the dredge spoils island, about $3000 \mathrm{~m}$ downstream. Truncating the model and using upwind differencing (a first-order method) had three factors that reduced run times:

- fewer number of cells in the model, 
- reduced period for the sloshing wave and the time it took to dampen out, and

- the upwind differencing that made it possible to greatly increase the time step (from 0.07 to 0.12 or 0.15 seconds) with stable results and few inner iterations.

However, it was important to assess whether any of these changes made a functional difference in the flow field results in the areas of concern. Consequently, we compared long model to short for upwind differencing and then compared the short model results for the upwind and MARS differencing schemes. Finally, we successfully validated the final configuration to the field-measured data.

\subsubsection{Tailrace Alternatives - 3D Model}

Initially, MASS2 was used to screen alternatives. As validation of the 2D and 3D models proceeded, we confirmed that it was necessary to use a 3D model to more accurately represent flows near the project. Near and downstream of the dredge spoils island, MASS2 represented the general flow fields; however, upstream of the dredge spoils island, a depth-averaged velocity did not well represent the highly 3D flows.

In April 2009, a trip was made to ERDC by CENWP personnel to work with the reduced-scale physical model of the John Day Project to assess the impacts of selected alternatives. During work with the physical model, it was determined that the spillwall alternative was to be the primary alternative. As the spillwall is adjacent to the project, the additional CFD runs to assess the impact of the alternative needed to be run in the 3D model rather than the 2D model.

\section{Initial Alternatives at $250 \mathrm{kcfs}$}

The 3D model was configured to run for the Baseline $250 \mathrm{kcfs}$ river, but with a spill pattern representative of the current fish passage plan pattern. The spillwall case was run with a spill pattern appropriate for the wall being in place (see Table 2.5p).

\section{Additional Runs at 125 kcfs}

While at the ERDC reduced-scale physical model (April 7 - 10, 2009), CENWP focused on the lower total river flows. At lower flows, such as TR $125 \mathrm{kcfs}$, the tailrace egress times, especially from the powerhouse units, were longer. As the lower flows are common during the out-migration period, improved understanding of river flow hydraulics and flow paths for these flows was desired.

To increase that understanding and quantify the differences in the river hydraulics at low flows, three scenarios were run: $125 \mathrm{kcfs}$ with two temporary spillway weirs (TSWs) (TSW Baseline, 2008 Test Fish Passage Plan spill pattern), $125 \mathrm{kcfs}$ with 30\% spill and a spillwall, and $125 \mathrm{kcfs}$ with 25\% spill and a spillwall (Table 2.6). The TSWs were added at John Day Dam in 2008 and represent the existing conditions at that time. However, prior to 2008, the Fish Passage Plan spill pattern was bulked to the north (the Washington shore). 
Table 2.5. Baseline $250 \mathrm{cfs}$ and Spillwall Operations, Both with $30 \%$ Spill

\begin{tabular}{lcc}
\hline Unit & $\begin{array}{c}\text { Baseline 250 } \\
\text { (kcfs) }\end{array}$ & $\begin{array}{c}\text { Spillwall 250, 30\% } \\
\text { (kcfs) }\end{array}$ \\
\hline Spill 1 & 0.0 & 0.0 \\
Spill 2 & 6.4 & 0.0 \\
Spill 3 & 8 & 0.0 \\
Spill 4 & 6.4 & 0.0 \\
Spill 5 & 6.4 & 0.0 \\
Spill 6 & 6.4 & 0.0 \\
Spill 7 & 4.8 & 0.0 \\
Spill 8 & 4.8 & 0.0 \\
Spill 9 & 4.8 & 0.0 \\
Spill 10 & 4.8 & 0.0 \\
Spill 11 & 3.2 & 0.0 \\
Spill 12 & 3.2 & 0.0 \\
Spill 13 & 3.2 & 9.8 \\
Spill 14 & 3.2 & 9.6 \\
Spill 15 & 3.2 & 9.6 \\
Spill 16 & 3.2 & 9.6 \\
Spill 17 & 3.2 & 9.6 \\
Spill 18 & 0.0 & 9.6 \\
Spill 19 & 0.0 & 9.6 \\
Spill 20 & 0.0 & 8.0 \\
\hline Total Spill & 75.2 & 75.2 \\
\hline PH-1 & 15.0 & 15.0 \\
PH-2 & 15.0 & 15.0 \\
PH-3 & 15.0 & 15.0 \\
PH-4 & 0.0 & 0.0 \\
PH-5 & 15.0 & 15.0 \\
PH-6 & 0.0 & 0 \\
PH-7 & 12.4 & 12.4 \\
PH-8 & 15.0 & 15.0 \\
PH-9 & 0.0 & 0.0 \\
PH-10 & 15.0 & 15.0 \\
PH-11 & 12.4 & 12.4 \\
PH-12 & 15.0 & 15.0 \\
PH-13 & 0 & 0 \\
PH-14 & 15.0 & 15.0 \\
PH-15 & 15.0 & 15.0 \\
PH-16 & 15.0 & 15.0 \\
\hline Total PH & 174.8 & 174.8 \\
\hline \hline Total River & 250.0 & 250.0 \\
\hline & & \\
\hline & & \\
\hline
\end{tabular}


Table 2.6. Operations for TR 125 kcfs 3D scenarios: TSW Baseline (with $30 \%$ spill) and Spillwall Runs (30\% spill and $25 \%$ spill)

\begin{tabular}{|c|c|c|c|}
\hline Unit & $\begin{array}{l}\text { TSW Baseline } \\
\text { (kcfs) }\end{array}$ & $\begin{array}{c}\text { Spillwall 125, 30\% } \\
\text { (kcfs) }\end{array}$ & $\begin{array}{c}\text { Spillwall } 125 \mathrm{kcfs}, 25 \% \\
\text { (kcfs) }\end{array}$ \\
\hline Spill 1 & 2.4 & 0.0 & 0.0 \\
\hline Spill 2 & 2.4 & 0.0 & 0.0 \\
\hline Spill 3 & 0.0 & 0.0 & 0.0 \\
\hline Spill 4 & 0.0 & 0.0 & 0.0 \\
\hline Spill 5 & 0.0 & 0.0 & 0.0 \\
\hline Spill 6 & 0.0 & 0.0 & 0.0 \\
\hline Spill 7 & 0.0 & 0.0 & 0.0 \\
\hline Spill 8 & 0.0 & 0.0 & 0.0 \\
\hline Spill 9 & 1.6 & 0.0 & 0.0 \\
\hline Spill 10 & 1.6 & 0.0 & 0.0 \\
\hline Spill 11 & 1.6 & 0.0 & 0.0 \\
\hline Spill 12 & 1.6 & 0.0 & 0.0 \\
\hline Spill 13 & 1.6 & 3.2 & 4.8 \\
\hline Spill 14 & 1.6 & 3.2 & 4.0 \\
\hline Spill 15 & 9.7 & 9.7 & 5.14 \\
\hline Spill 16 & 9.7 & 3.2 & 3.2 \\
\hline Spill 17 & 4.0 & 3.2 & 3.2 \\
\hline Spill 18 & 1.6 & 9.7 & 5.14 \\
\hline Spill 19 & 0.0 & 3.2 & 3.2 \\
\hline Spill 20 & 0.0 & 2.4 & 2.4 \\
\hline Total Spill & 37.8 & 37.8 & 31.1 \\
\hline PH-1 & 15.0 & 15.0 & 15.0 \\
\hline PH-2 & 0.0 & 0.0 & 0.0 \\
\hline PH-3 & 15.0 & 15.0 & 15.0 \\
\hline PH-4 & 0.0 & 0.0 & 0.0 \\
\hline PH-5 & 15.0 & 15.0 & 15.3 \\
\hline PH-6 & 0.0 & 0.0 & 0.0 \\
\hline PH-7 & 0.0 & 0.0 & 0.0 \\
\hline PH-8 & 0.0 & 0.0 & 0.0 \\
\hline PH-9 & 0.0 & 0.0 & 0.0 \\
\hline PH-10 & 0.0 & 0.0 & 0.0 \\
\hline PH-11 & 0.0 & 0.0 & 0.0 \\
\hline PH-12 & 12.5 & 13.3 & 16.0 \\
\hline PH-13 & 0.0 & 0.0 & 0.0 \\
\hline PH-14 & 15.0 & 15.0 & 17.5 \\
\hline PH-15 & 0.0 & 0.0 & 0.0 \\
\hline PH-16 & 15.0 & 15.0 & 15.0 \\
\hline Total PH & 87.5 & 88.3 & 93.8 \\
\hline Total River & 125.3 & 125.5 & 124.9 \\
\hline
\end{tabular}


These TR $125 \mathrm{kcfs}$ simulation results were also compared to the TR $122.7 \mathrm{kcfs}$ model from the validation runs. Although the total river flow and spill percentage were slightly less (122.7 kcfs total river, $21 \%$ spill, see Table 2.3, it added insight to the changes in flow patterns in response to changes in operations.

\subsection{Particle Tracking}

Residence time in the tailrace is considered to be strongly tied to juvenile mortality. Particle tracking for streamlines, neutrally buoyant particles, and buoyant particles was done using the PNNL tracking code (Rakowski et al.2008b and Richmond et al. 2009).

For the 3D-tracking work, the STAR-CD simulation results and geometry files were used as inputs along with seed data files specifying a center point (in three dimensions) of the boundaries that had flow into the model. For the streamlines, a single point at the center of the boundary was used. For the neutrally buoyant particles, 50 particles were released at the center of each boundary; the particles were spherical with a diameter of $0.11 \mathrm{~m}$ and the density of water. A time step of $0.01 \mathrm{~s}$ was used. Turbulence quantities from the numerical model were used to estimate dispersion (see Rakowski et al. $2008 \mathrm{~b}$ for a detailed discussion). Buoyant particles were also tracked. Densities of 947 and $972 \mathrm{~kg} / \mathrm{m}^{3}$ were used for the buoyant particles, although there is not yet a validation data set to support one density choice over the other. These densities, plus the neutrally buoyant particles, were chosen to assess whether particle tracking results had a strong density dependency.

The tracking software created data files that included, for each time step, the particle location and the simulation results associated with each location. This ASCII data file was subsequently processed to produce graphics of the particle paths and residence time plots for two cross section ("gate") locations.

Tecplot was used to plot the particle paths through the computational domain, and the path lines were overlaid on an orthophoto and shaded river bathymetry to provide a greater context for the tracks. The two "gate" locations were included on the graphics. These gates are located near the end of the navigation lock wall and downstream of the dredge spoils island. These locations were chosen to quantify the retention times near the project and well past the project. At the physical model, it was observed that there were areas of delay downstream of the navigation lock-especially for dye released from the powerhouse bays. Creating residence time plots for these two gates provided a tool for quantifying the relative differences between operational and flow scenarios.

The residence time plots representing the particle residence times from the powerhouse and spillway for the two gate locations and the time it takes for $25 \%, 50 \%$, and $75 \%$ of the particle population to pass each of these gates were created for each scenario. These particle-path data may be further analyzed as fisheries biologists provide other hydraulic criteria that are deemed to be of biological interest. A potential hazard index could be developed that included parameters such as time spent in velocities below a threshold, time near the shore, or time in shallow areas. 



\subsection{Results and Discussion}

\subsection{MASS2 2D Depth-Averaged Model}

\subsubsection{MASS2 Calibration and Validation}

The MASS2 model was calibrated by warming up the model and then comparing the simulated and measured water-surface elevation. Initially, a Manning's n of 0.029 was used, as was validated in Richmond et al. (2000). However, the modeled water surface elevation was consistently high, as shown by the bias of $0.16 \mathrm{ft}$ in Table 3.1. The model was re-run with an $\mathrm{n}$ of 0.028 (Figure 3.1). This produced a better fit to the measured water surface elevation (see Table 3.1 for statistics). Consequently, a Manning's n of 0.028 was used for all subsequent MASS2 runs.

Table 3.1. Summary Statistics for the Difference Between Observed Stage and that Simulated by MASS2 for the period May 11 to May 21, 2008

\begin{tabular}{llllllll}
\hline \hline Location & Manning's n & $\mathrm{N}$ & $R^{2}$ & $\begin{array}{c}\text { Bias } \\
\text { feet }\end{array}$ & RMS & MAE & $\begin{array}{c}\text { MSE } \\
\text { feet }\end{array}$ \\
\hline Powerhouse Gage & 0.029 & 2640 & 0.99 & 0.16 & 0.24 & 0.20 & 0.06 \\
& 0.028 & 2640 & 0.99 & -0.04 & 0.20 & 0.15 & 0.04 \\
\hline
\end{tabular}

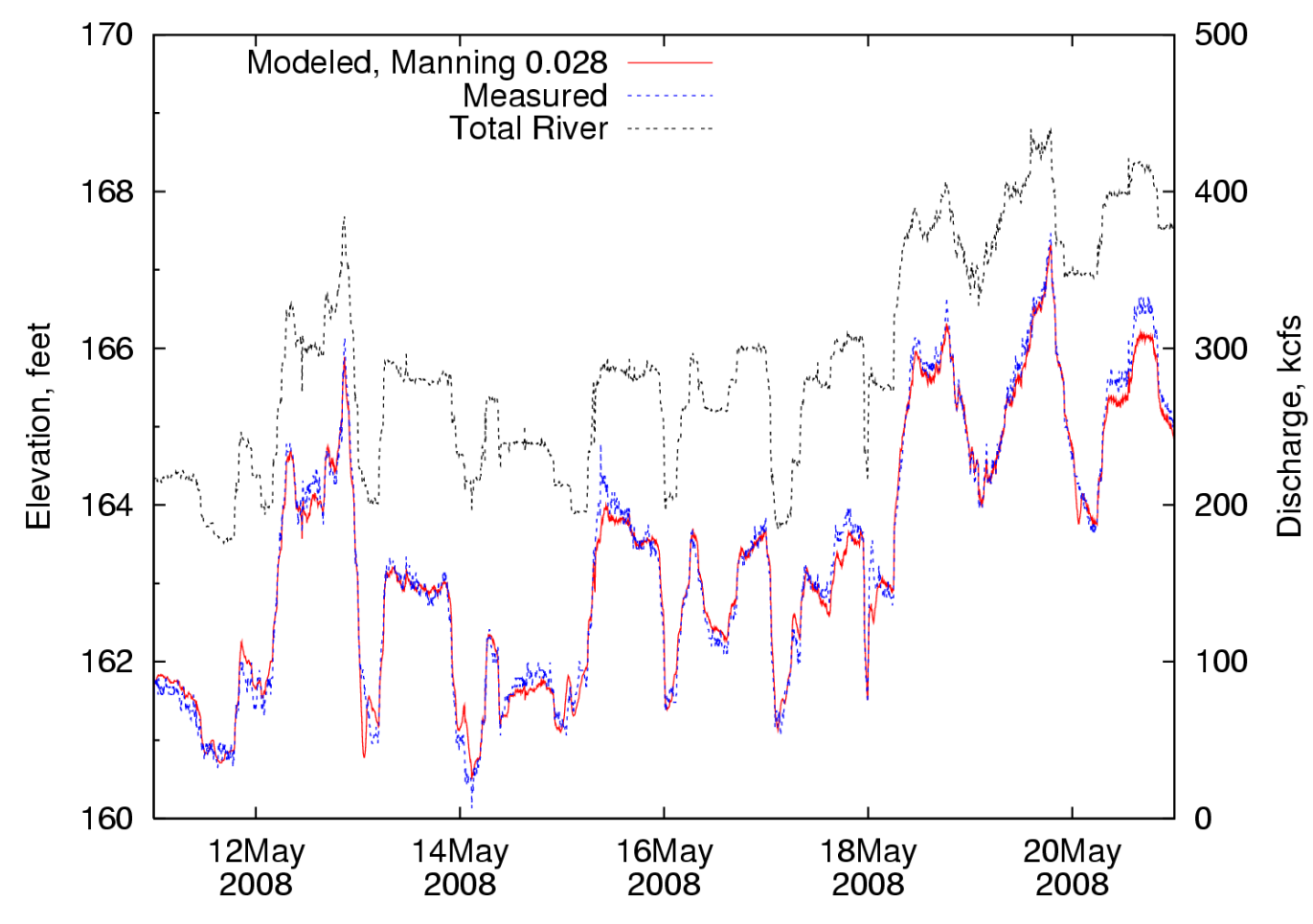

Figure 3.1. Water-Surface Elevation Simulated by MASS2 for a Manning's n of 0.028

The calibrated MASS2 model was run for a comparison to field-measured velocity data. These 
data sets consist of both on-station measurements and transecting measurements (Mannheim and Sweeney 2003 and Cook et al. 2006). The on-station measurements were depth-averaged for comparison. The transecting data were provided as a depth-averaged velocity vector.

Inherent in the depth-averaged model is that some aspects of the tailrace flows will not be as accurately represented as would be expected from a fully 3D model. One of the purposes of the validation of the MASS2 model was to increase our understanding of where the 2D model does, and does not, accurately represent flow conditions. This assessment guided how the models were used in the development of tailrace improvement alternatives.

The three flow cases simulated had 10 to $30 \%$ of the flow passed at the spillway (see Table 2.3). The largest total river flow (TR $210.1 \mathrm{kcfs}$ ) had $30 \%$ spill; the lowest total river flow (TR $122.7 \mathrm{kcfs}$ ) had $20 \%$. The comparisons will be discussed in terms of flows and flow splits and by zones-near the powerhouse, near the spillway, and near the dredge spoils island and the downstream.

\section{Validation: MASS2 Flows and Flow Splits}

The modeled and measured water-surface elevations near the powerhouse for the validation runs are given in Table 3.2. The modeled water-surface elevation was within the range of variation for each day. Table 3.3 compares the discharges calculated from the ADCP transecting data and the MASS2 model for the same cross sections (Figures 3.2 to 3.4 for cross section locations). The MASS2 data were integrated across the whole channel whereas the transecting data do not include near-shore locations and hence might be biased somewhat low. The MASS2 model had about the same flow split percentage for all cases rather than having the different spill percentage and operations skew the flow split as measured in the ADCP measurements (Table 3.3).

Table 3.2. Observed and Modeled Water-Surface Elevations Near the Powerhouse for the Three ADCP Validation Cases

\begin{tabular}{lccc}
\hline \hline Case & Modeled & Averaged Measured & Measured Range \\
\hline TR 210.1 kcfs, 30\% Spill & 161.5 & 161.5 & $160.3-162.5$ \\
TR 151.7 kcfs, 10\% Spill & 160.0 & 160.2 & $160.0-160.6$ \\
TR 122.7 kcfs, 21\% Spill & 159.9 & 159.6 & $159.2-160.1$ \\
\hline
\end{tabular}

As can be seen in Figures 3.2 to 3.4 , the transecting data are very noisy. The sampling conditions were sub-optimal on the day on which the TR $210.1 \mathrm{kcfs}$ measurements (Mannheim and Sweeney 2003) were made. There were 3- to 4-ft waves, and much air was entrained in the spillway flow. The on-station positions had to be held for long periods (10 minutes for all ADCP measurements) for the mean measured velocity to become stable. The TR 210.1 measurements had a large difference in the measured discharges between cross sections, which resulted, in part, from changing operational conditions during the sampling period. The measured range was 197 kcfs to $232 \mathrm{kcfs}$; the target flow used in the model was $210 \mathrm{kcfs}$. For these measurements, one should look at the overall pattern of the flow (Figures 3.2 to 3.4) and flow splits. Table 3.3 shows the discharge measured at each cross section, the percent difference of the MASS 2 model and the 
Table 3.3. Observed and MASS2 Modeled flows for the Three ADCP Validation Cases. See Figures 3.2 to 3.4 for cross section locations. The quantities in parentheses are the flow splits around the island.

\begin{tabular}{lccccc}
\hline \hline Case & XS-1 & XS-2 & XS-3N & XS-3S & Sum XS-3 \\
\hline TR 210.1 kcfs, 30\% Spill-Measured & 220 & 197 & $107(46 \%)$ & $125(54 \%)$ & 232 \\
TR 210.1 / MASS2 & 209 & 209 & $75(35 \%)$ & $135(65 \%)$ & 209 \\
Percent Difference & -4.9 & 6.2 & -30.1 & 7.7 & -9.8 \\
from field & & & & & \\
\hline TR 151.7 kcfs, 10\% Spill-Measured & 146 & 148 & $64(42 \%)$ & $87(58 \%)$ & 151 \\
TR 151.7 / MASS2 & 153 & 153 & $54(36 \%)$ & $98(64 \%)$ & 152 \\
Percent Difference & 4.6 & 3.3 & -14.9 & 12.6 & 0.7 \\
from field & & & & & \\
\hline Case & $\mathbf{X S - 1}$ & $\mathbf{X S - 2 N}$ & $\mathbf{X S - 2 S}$ & Sum XS-2 & XS-3 \\
\hline TR 122.7 kcfs, 21\% Spill-Measured & 125 & $64(52 \%)$ & $60(48 \%)$ & 124 & 125 \\
TR 122.7 kcfs / MASS2 & 120 & $43(36 \%)$ & $76(63 \%)$ & 119 & 119 \\
Percent Difference & -3.7 & -32.6 & 27.3 & -3.6 & -5.1 \\
from field & & & & & \\
\hline
\end{tabular}

field value, and the the flow split (north and south channel) percentage around the dredge spoils island. In all cases, the modeled flow split was about the same. The flow volume in the north channel by the dredge spoils island was underestimated in the 2D model for all cases. Although the differences were less for the low-spill case (TR $151.7 \mathrm{kcfs}$ ), the higher spill flow percentage case (TR $210.1 \mathrm{kcfs}$ ) had a larger difference as a result of lateral entrainment into the spill flow being under represented in MASS2.

\section{Overall Performance}

As is shown Figures 3.2 to 3.4, the MASS2 model does not simulate sufficient lateral entrainment between the powerhouse and the spillway in the John Day tailrace. The field data for all cases show an elongated zone of high velocity near the Washington shore and downstream of the spillway. Further downstream (just upstream of the dredge spoils island), however, the MASS2 model does a much better job of capturing the flow velocity and distribution, especially for the lower spill percentage cases. For all cases, the MASS2 model somewhat underestimates the flow volume on the Washington shore side of the island (the north channel), but the velocity distribution across channel is representative.

\section{Near the Powerhouse}

Near the Powerhouse, for all runs, simulated and measured flow velocities are similar; however, the flow direction near the higher numbered (more northern) turbines is more downstream directed than measured in the field. This difference is most pronounced at the TR $122.7 \mathrm{kcfs}$ flow with $21 \%$ spill. In the field data for this flow condition, the direction of the depth-averaged transecting measurements varies greatly from point to point, indicating the very turbulent and transient nature of the flows. These data are the closest measurements made to the powerhouse. 


\section{Near and Downstream of the Spillway}

The field measurements for all cases make it very clear that there is a pronounced jet near the Washington shore with lateral entrainment from the powerhouse flows. The lateral entrainment is most pronounced at the higher flows and spill volumes. At the lower flows, it appears that recirculation develops in front of the non-operational spillway bays and skeleton bays. MASS2 develops these areas of recirculation, although the simulated velocities are less than those measured. The larger velocities of the jet are not reproduced, but rather the flow is more evenly distributed across the channel.

\section{Upstream of the Island}

In all cases, just upstream of the dredge spoils island, MASS2 produced the lower velocities observed and the turning of flow toward the south channel. This was similar in pattern to the measured data, but not as angled toward the south. The turning of the flow at this location results from exceeding the capacity of the north channel.

\section{Flow Split Around the Island}

For all simulation results, the flow split around the island had about $35 \%$ of the flow in the north channel. The measured flow in the north channel was $46 \%, 42 \%$, and $51 \%$ for the TR 210.1 $\mathrm{kcfs}$, the TR $151.7 \mathrm{kcfs}$, and the TR $122.7 \mathrm{kcfs}$ cases, respectively. The velocities were higher in the north channel than the south channel, but the flow depths were less. In the deep south channel, the modeled and measured velocities appear to match better, but the deeper channel does not accentuate the differences as much as the shallow north channel. 


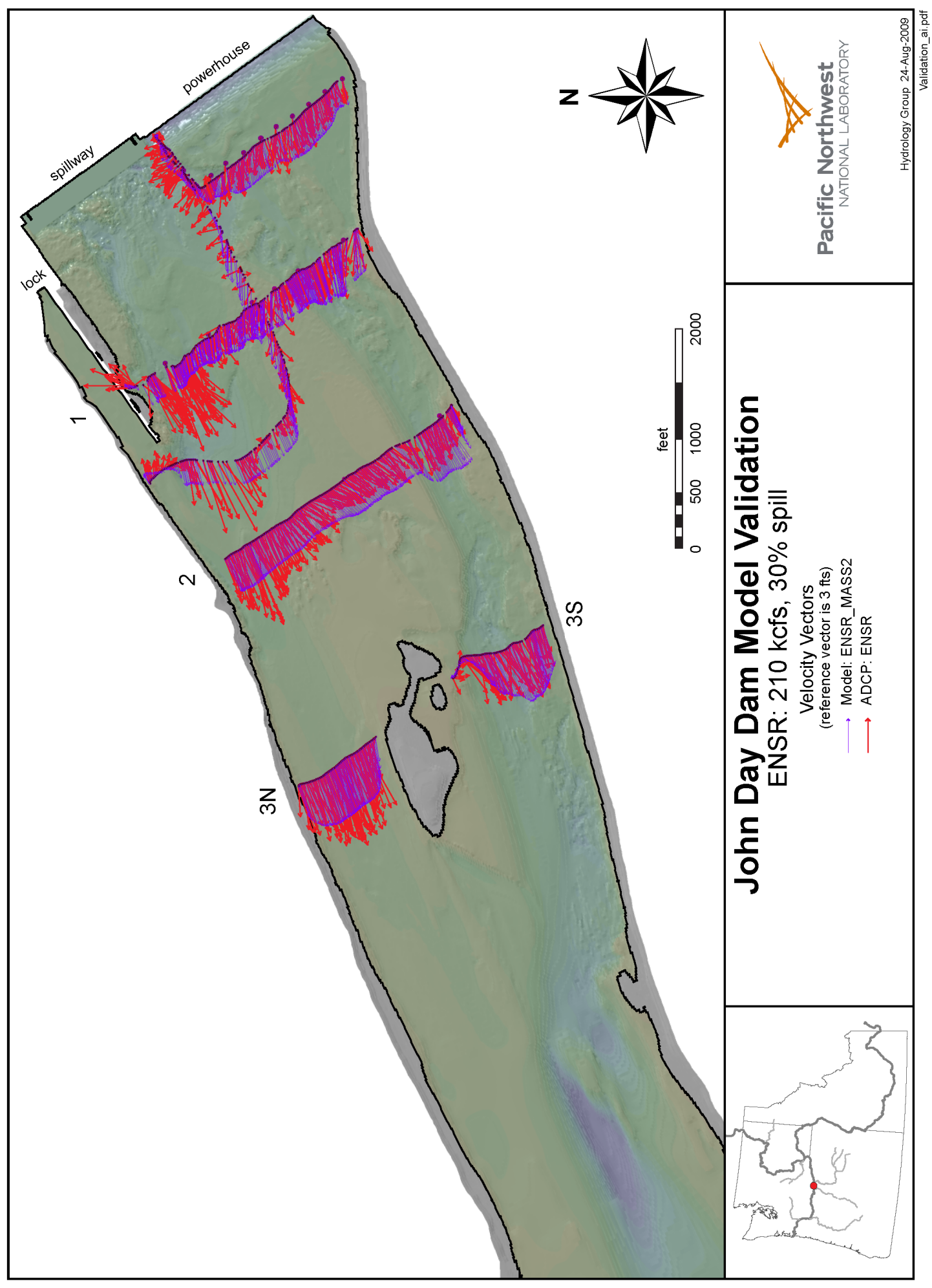

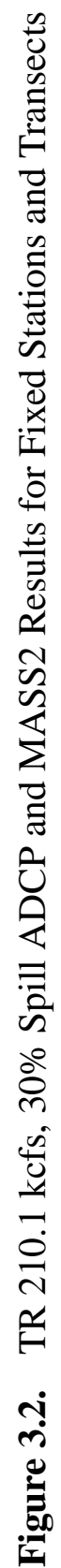




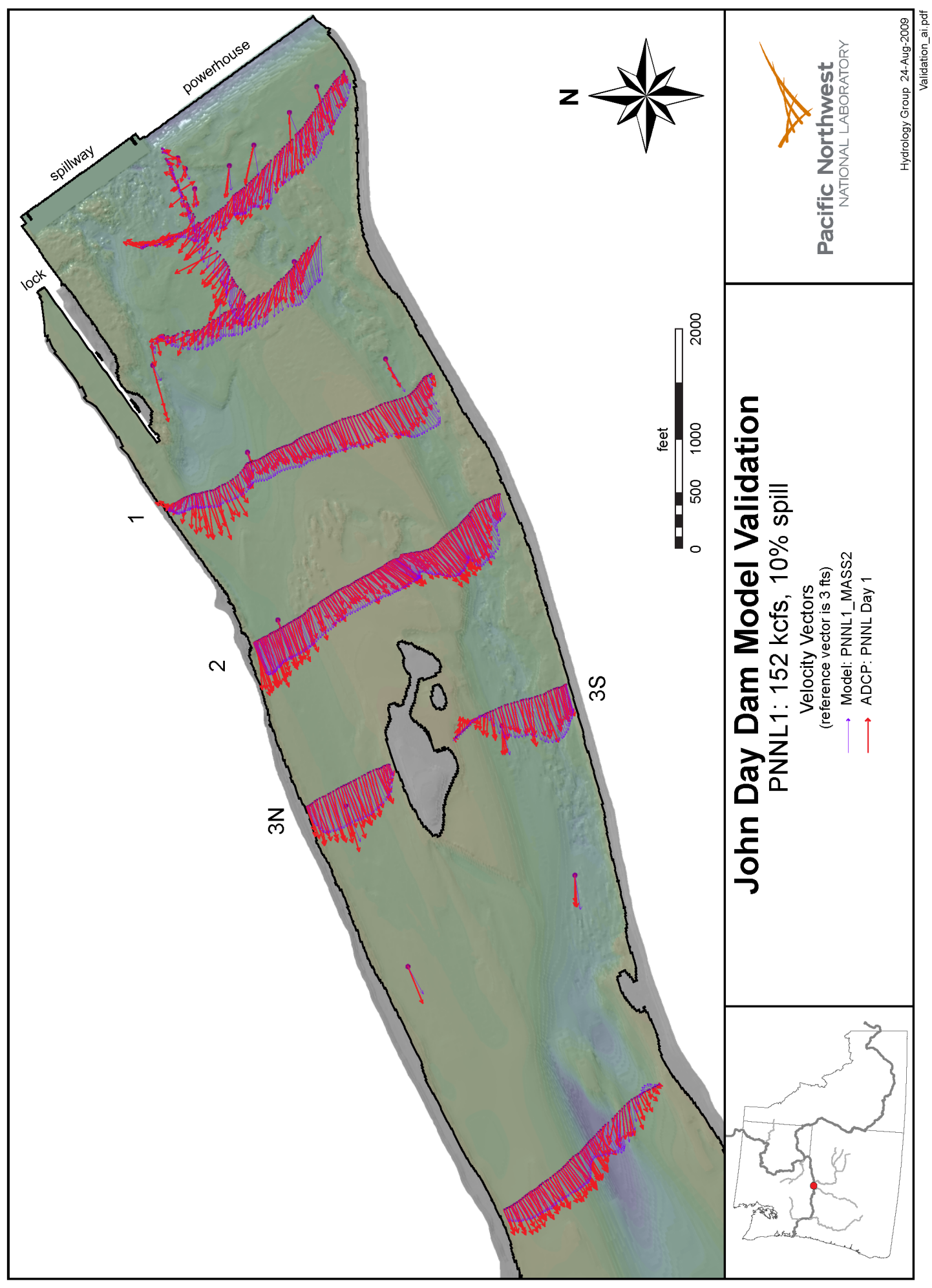

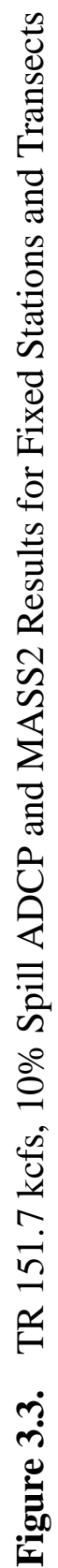




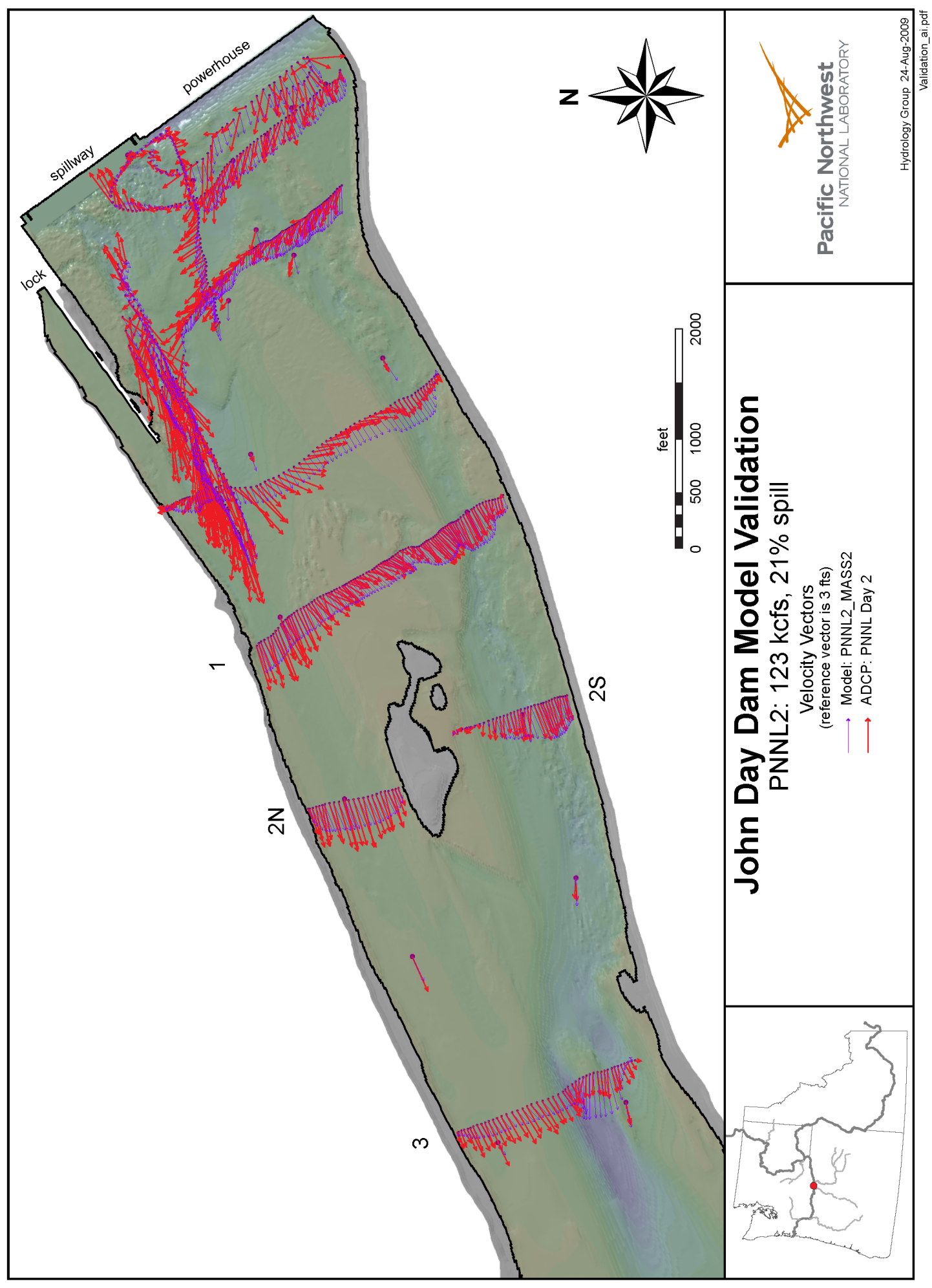

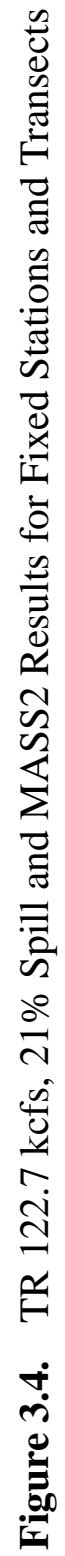




\subsubsection{MASS2 Scenarios, TR $250 \mathrm{kcfs}$}

The validation results indicated that the MASS2 model results should be used with caution near the project, but could be used to understand general trends in flow patterns resulting from channel modifications. Figures 3.5 to 3.9 show model results for the scenarios detailed in Table 2.4 . The figures show (from top to bottom) the depth-averaged velocity magnitude and vectors, velocity criteria, depth criteria, and (in all but the baseline model) a vector comparison of the alternative to the baseline. Biologically significant criteria provided by CENWP were 1) velocities less than $2 \mathrm{ft} / \mathrm{s}$ or greater than $4 \mathrm{ft} / \mathrm{s}$ and 2) depths less than $30 \mathrm{ft}$. Areas with velocities less than $2 \mathrm{ft} / \mathrm{s}$ are likely predator habitat, and areas with velocities greater than $4 \mathrm{ft} / \mathrm{s}$ tend to exclude predators.

The results for the depth criteria change little except in the case of the shoreline removal scenario. The other excavation scenario, the island removal, does not create areas greater than $30 \mathrm{ft}$ deep.

In the two cases with modeled material excavation, the island and shoreline removal cases, the MASS2 results had a reduced area of velocities greater than $4 \mathrm{ft} / \mathrm{s}$ because the cross sectional area of the channel was increased (and hence velocities decreased) where the material was (virtually) excavated.

The spillwall and blockage model results should only be considered for the hydraulic impacts in the vicinity of the dredge spoils island and downstream. However, for these cases, it is not possible to attribute the hydraulic differences to the added structures rather than to the change in spill

pattern. For all 2D cases, the lateral entrainment into the spillway flows was underestimated, and hence the results near the project are less accurate. 

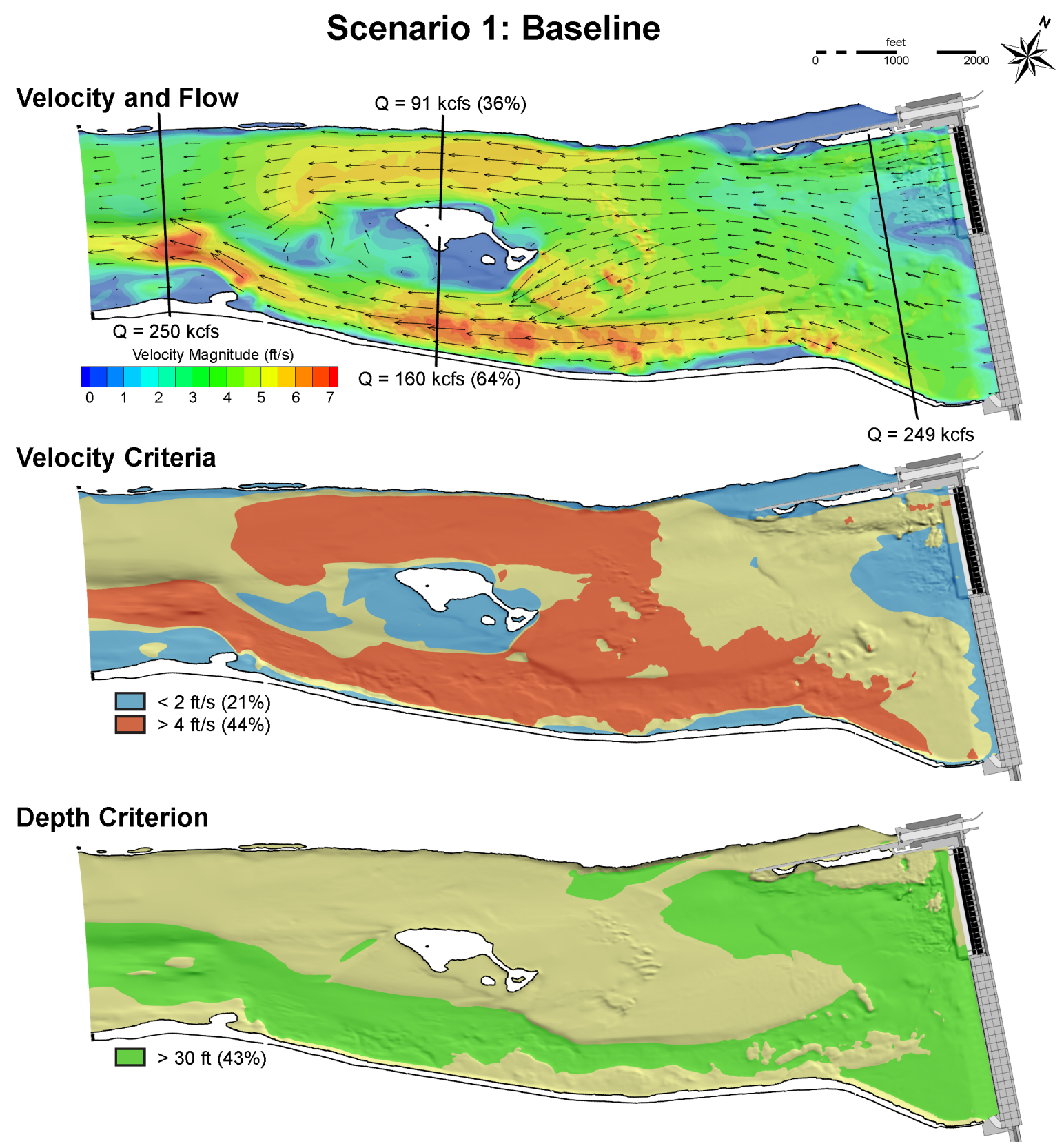

Figure 3.5. MASS2 Results for the Baseline Case, $250 \mathrm{kcfs}, 30 \%$ Spill 

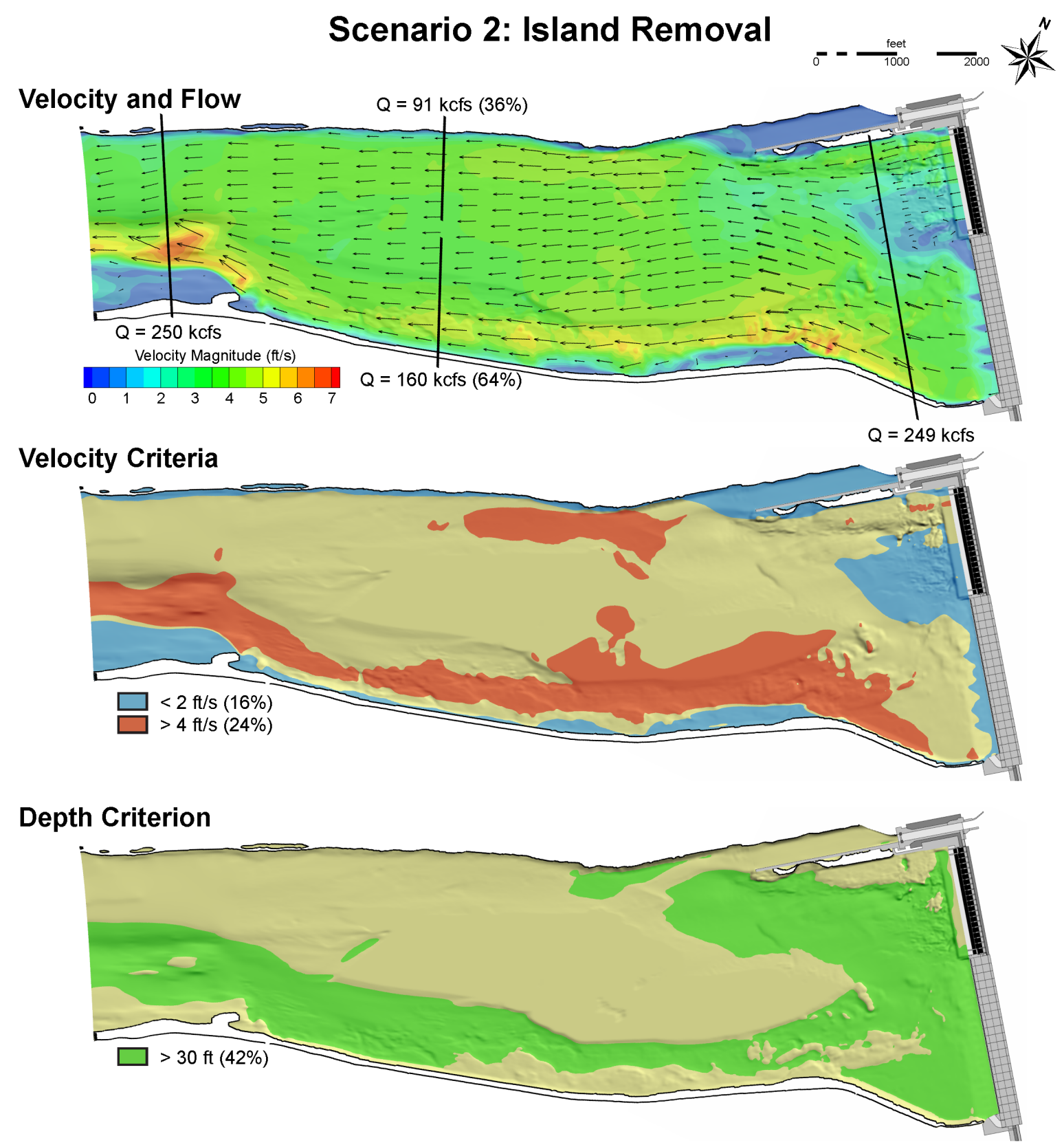

\section{Compare to Baseline}

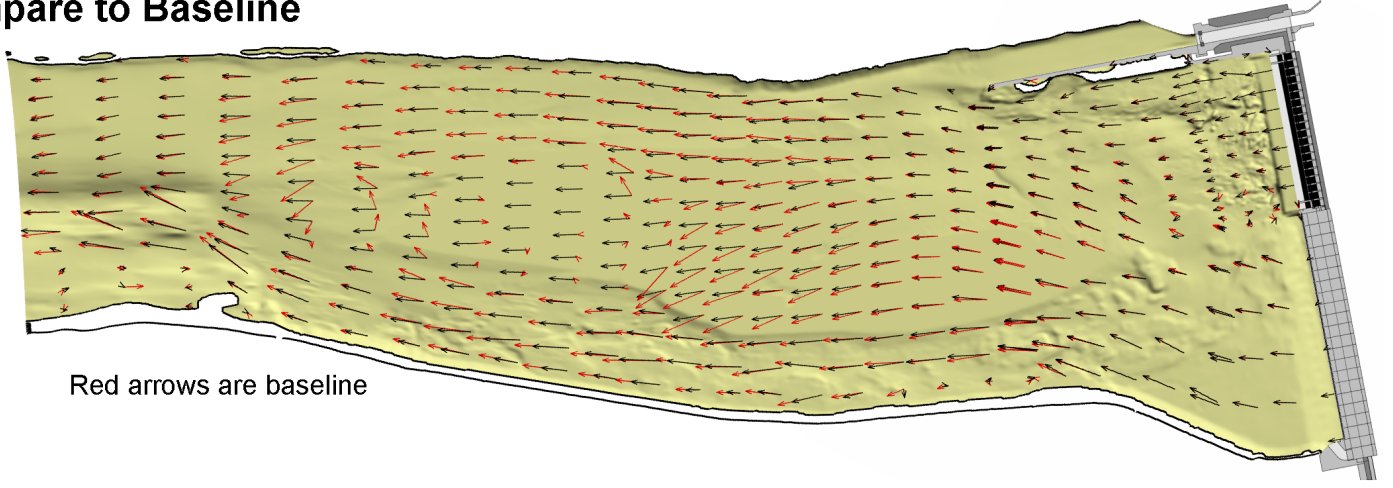

Figure 3.6. MASS 2 Results for the Island Removal Scenario, $250 \mathrm{kcfs}, 30 \%$ Spill 

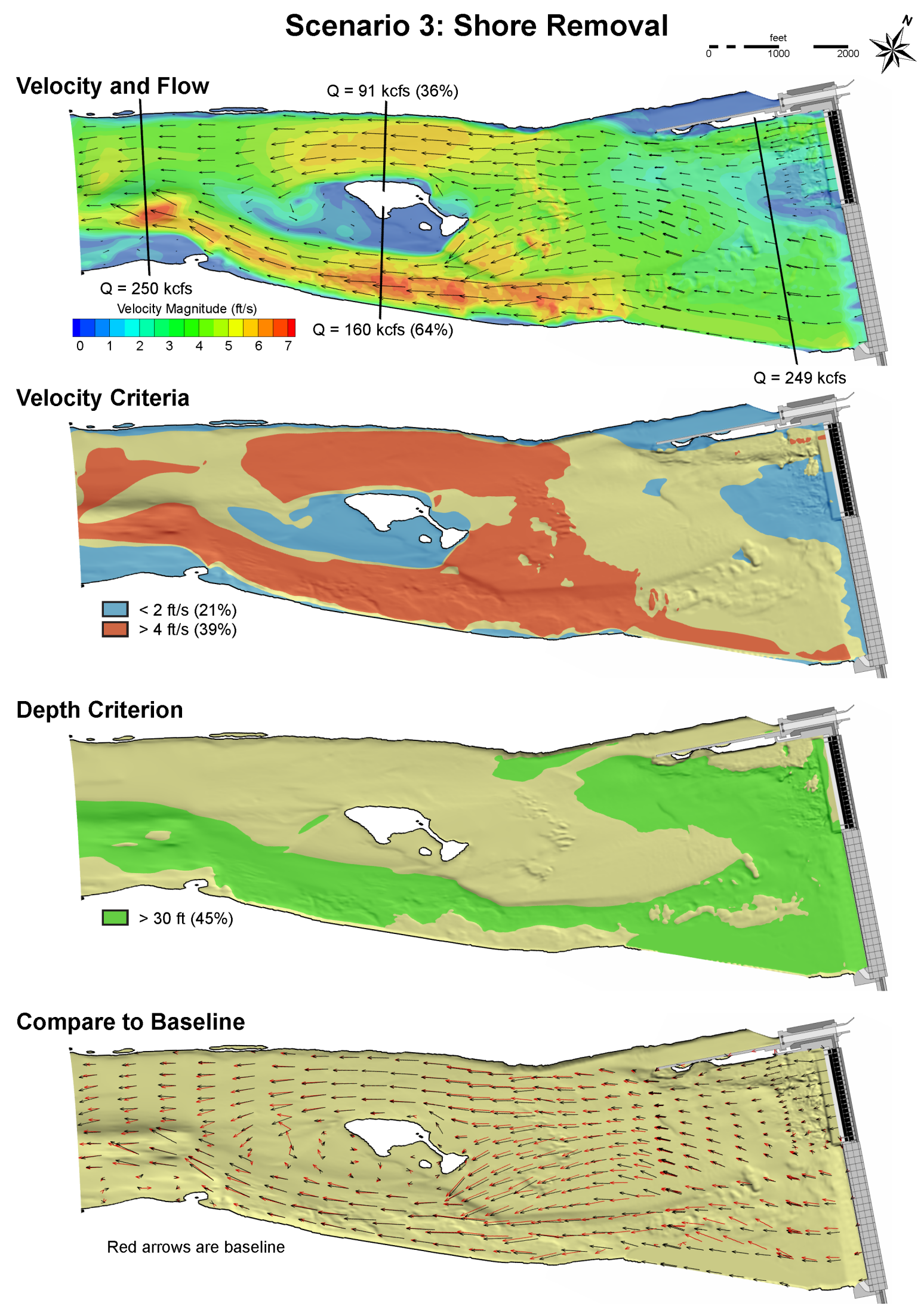

Figure 3.7. MASS2 Results for the Shoreline Removal Scenario, $250 \mathrm{kcfs}, 30 \%$ Spill 

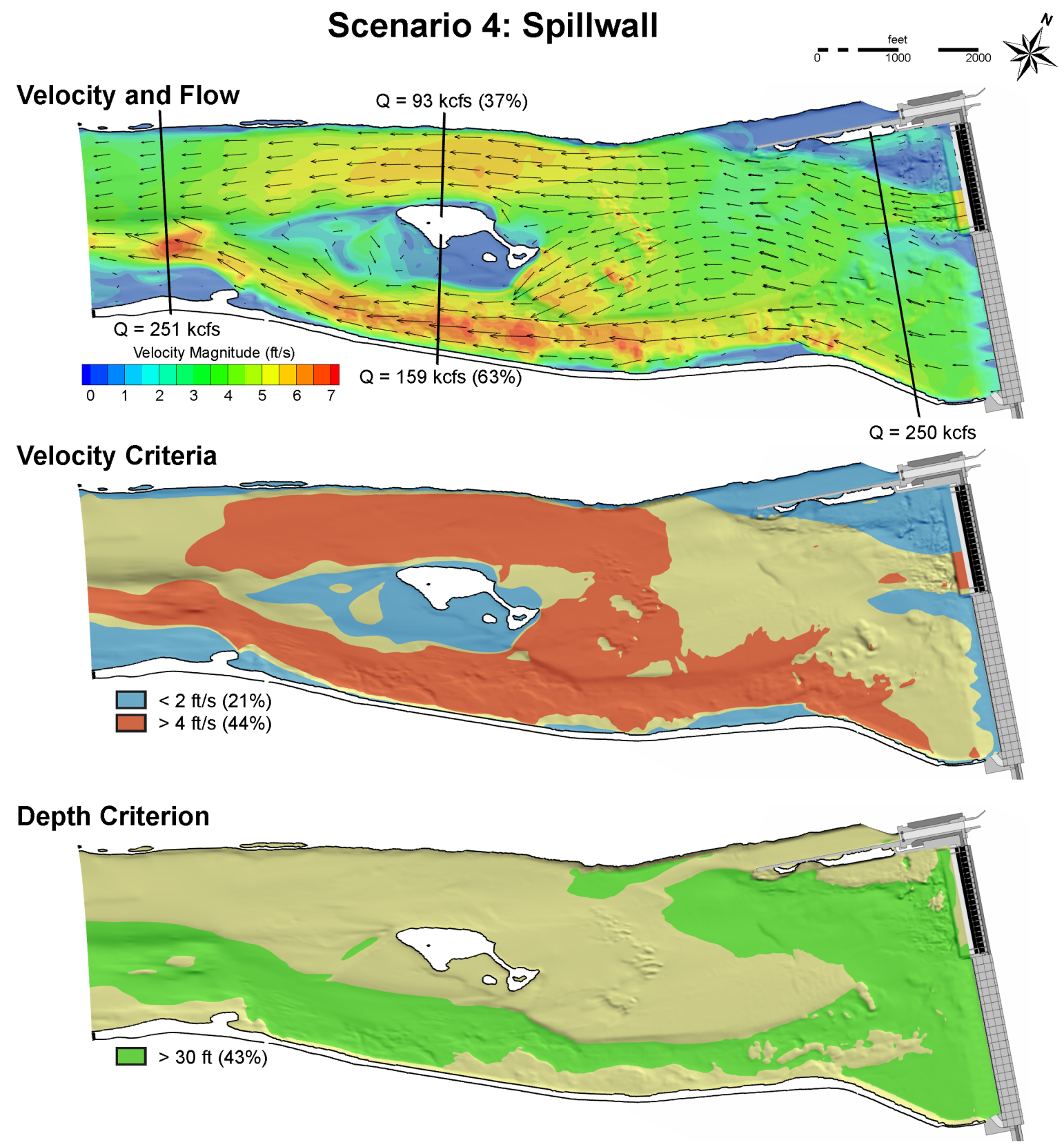

\section{Compare to Baseline}

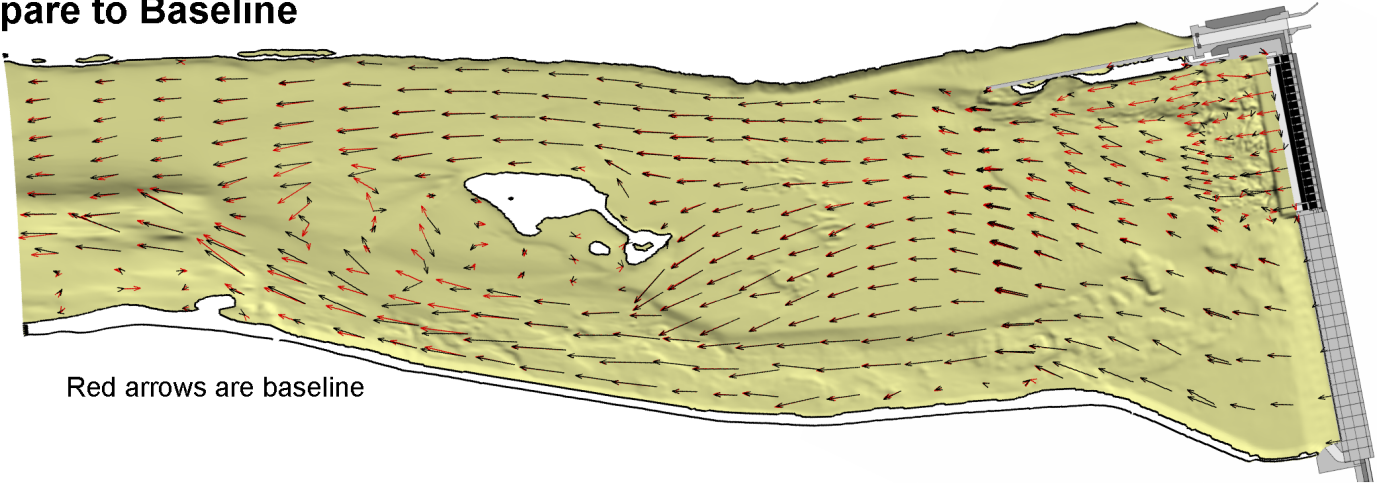

Figure 3.8. MASS2 Results for the Spillwall Scenario, $250 \mathrm{kcfs}, 30 \%$ Spill 

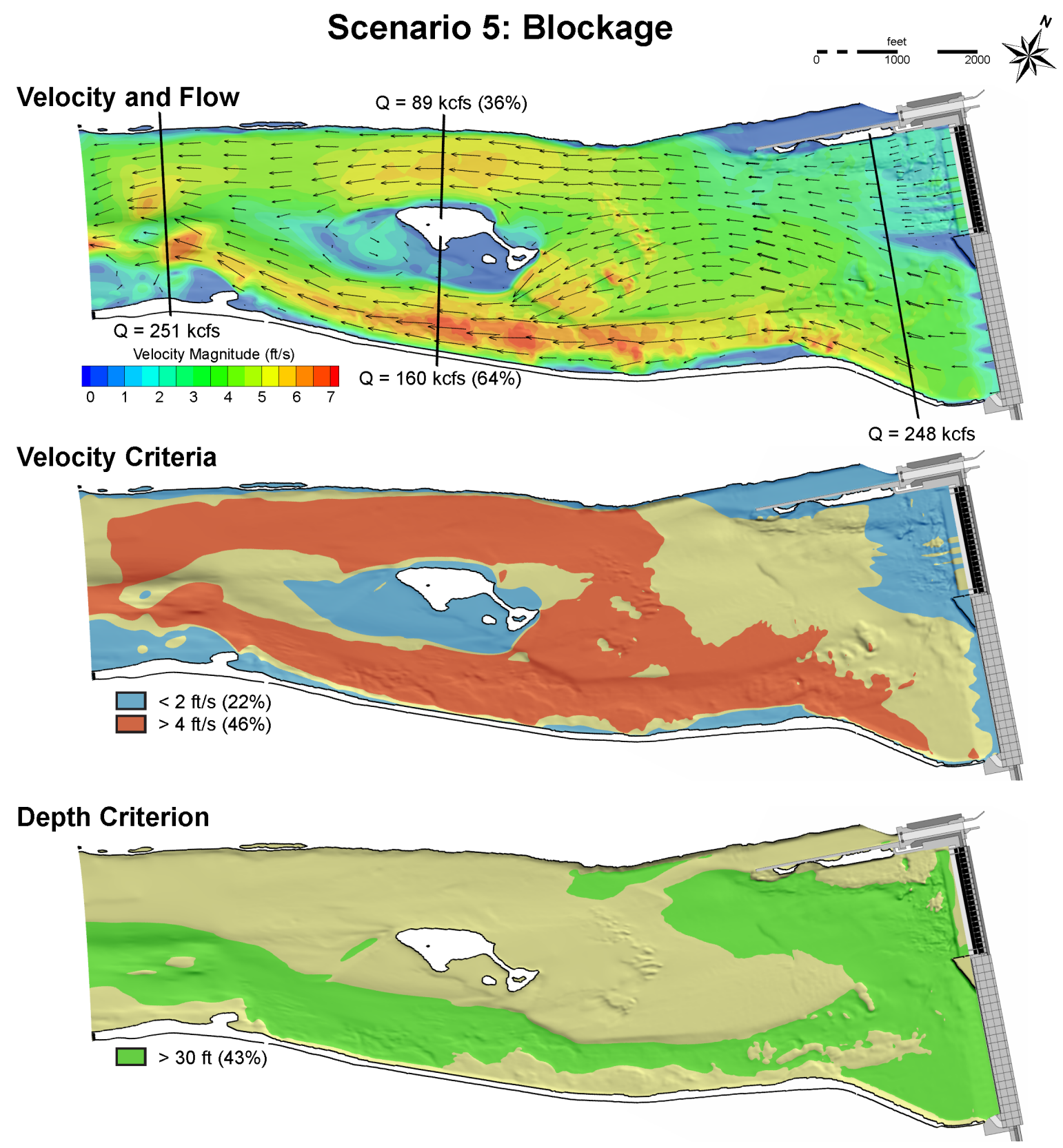

\section{Compare to Baseline}

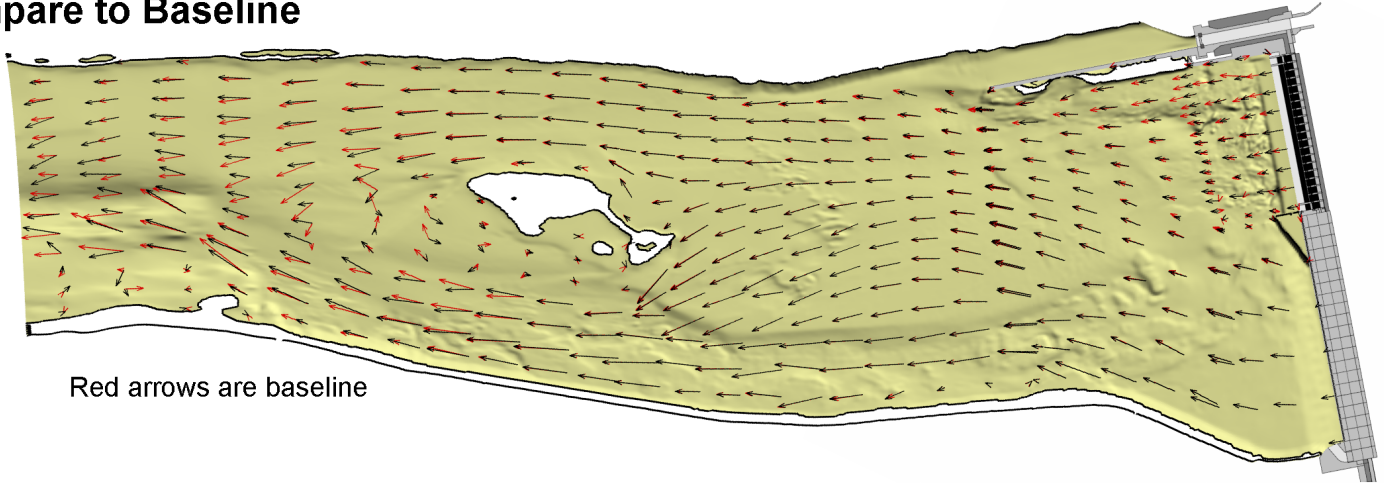

Figure 3.9. MASS2 Results for the Skeleton Bay Blockage Scenario, $250 \mathrm{kcfs}, 30 \%$ Spill 


\subsection{Tailrace 3D CFD Model}

\subsubsection{Need for a 3D Model for Near-Project Alternatives}

Although we knew from the outset that the flows near the project were very three dimensional, we had hoped that useful data and trends could be found in the 2D model results. However, the $2 \mathrm{D}$ results showed that they were not as representative as needed near the project. As this project moved forward and the proposed alternatives evolved, the near-project alternatives emerged as the better options. Given that the area of concern and the alternative location were now both near the project, a 3D numerical model was required.

\subsubsection{STAR-CD 3D VOF Model Validation}

The three validation cases that were run for MASS2 were also run for the 3D VOF model. The initial model extents were approximately $6.9 \mathrm{~km}$ downstream from the project. Although the downstream boundary of the model was sufficiently far from the area of interest, the run times for a quasi-steady state to be achieved were excessive for the large domain and its run configuration. There were several factors contributing to the large run times. A large contributor was the very large spatial domain. The real-world time to start the model from zero velocity everywhere to obtain a quasi-steady solution was large. As part of the settling process as the run progresses, the model "sloshes" (as can be seen in model outflow volumes in Figure 3.10), and that sloshing period is related to the physical extent of the model. Note in the figure that the period of sloshing is about $4000 \mathrm{~s}$ for the long model whereas the period for the shortened model is about 2000 s. Another factor was that, theoretically, the most correct solution of the model uses a second order differencing scheme, such as the monotone advection and reconstruction scheme (MARS). However, the use of MARS greatly slowed convergence. The reason was two-fold: each iteration took more computational time, and a smaller time step was required to achieve convergence with the same number of inner iterations per time step. The first-order upwind differencing (UD) scheme was used to speed it to a quasi-steady solution and yields appropriate results.

The TR $151.7 \mathrm{kcfs}, 10 \%$ spill case will be used to illustrate the iterative process used to arrive at the final model and its configuration and its validation. The validation results will be shown for the final model and run parameters for the additional two validation data sets. Complete validation results are in Appendix B.

\section{Determining Model Extent and Configuration}

In the best of all worlds, the numerical model would be run for a very long time period for a very large extent with second-order schemes for greater accuracy. The initial model was for a 6.9-km domain, and the model was run with a second-order differencing scheme (e.g., MARS). The run times for this configuration were too long for obtaining solutions in a timely manner. Consequently, we looked at ways to reduce the run times. Common approaches to achieving reduced run times are to reduce the number of cells in the model, to decrease the spatial extent of the model (as waves have to propagate through the model domain), and, for transient models, to assess ways to increase the time step while maintaining model stability. 

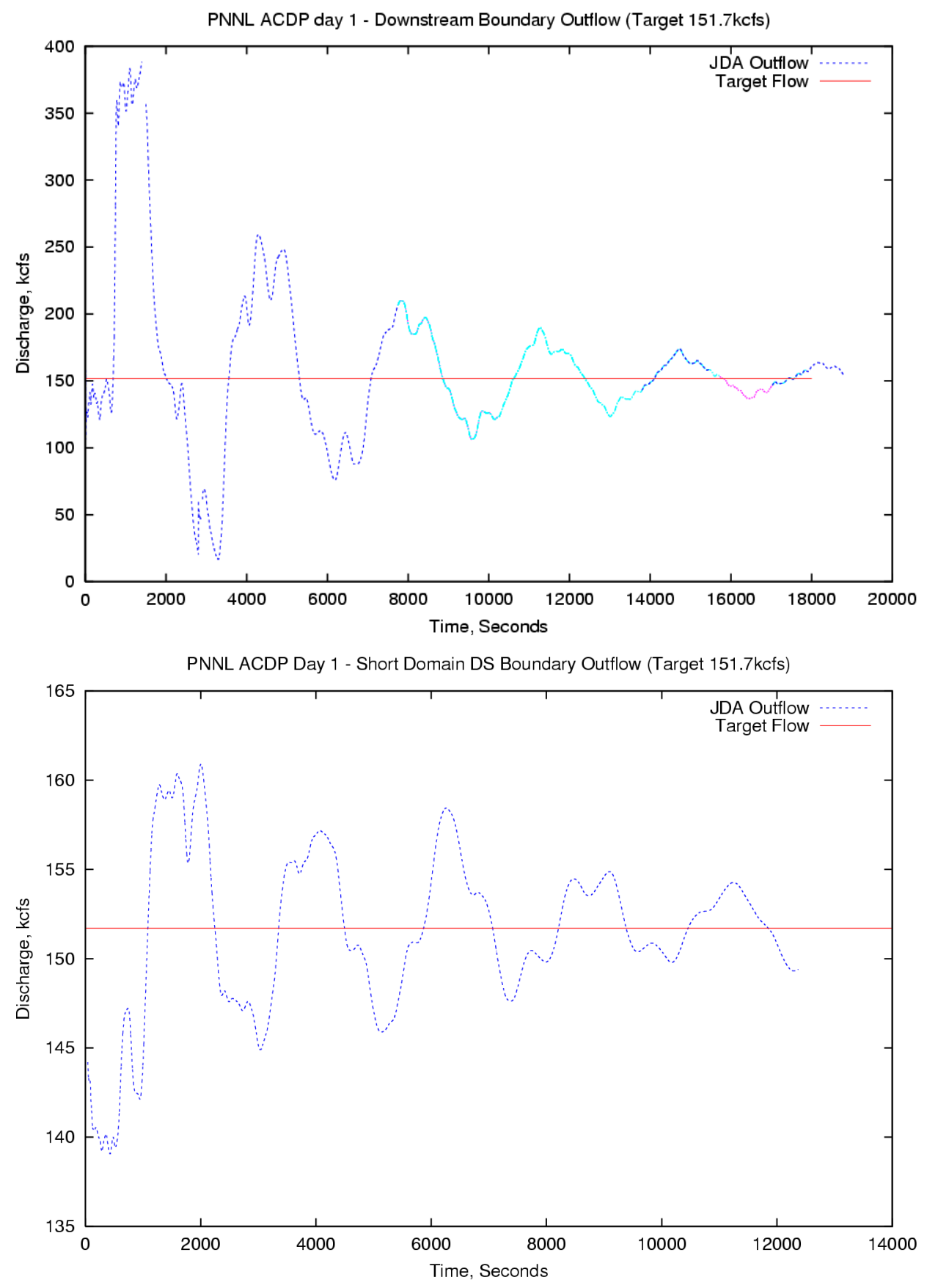

Figure 3.10. Downstream Boundary Discharge for the TR $151.7 \mathrm{kcfs}, 10 \%$ Spill Case. The upper figure is for the 6.9-km domain, and the lower figure is for the shortened model domain. 
To confirm that the solution quality was not compromised by changes, the impacts of model changes were assessed for each change individually. We started by shortening the model domain $3 \mathrm{~km}$ so that the downstream boundary was below the flow-constricting island in an area of converging flow. Both models were run for the TR $151.7 \mathrm{kcfs}, 10 \%$ Spill flow conditions with upwind differencing until the outflow volume became quasi-steady. Figure 3.11] shows that there was little difference in these solutions for the long and short domains. Figure 3.12 shows the differences that occur between different time slices for the same model configuration. This figure shows that the difference in velocities between the long and short models was on the same order of the variability as the velocity fields for different time slices. Figure 3.12 shows velocity differences at the ADCP sampled points but at a single elevation. It also shows the differences in the normalized velocity magnitudes that were computed as $A B S\left(V_{1}-V_{2}\right) / V_{1}$. The largest differences were in the cross section below the navigation lock wall and near the stilling basin. The flow distribution near the downstream boundary of the short model is somewhat different. However, these are well within the standard deviation of the measured velocities of the on-station measurements and the time-varying velocity for these unsteady, VOF simulations.

After the shortened model achieved a quasi-steady outflow, the differencing scheme was changed from UD to MARS. The simulation results from MARS were not greatly different from the UD solutions when viewed with contoured data (see Figure 3.13) or for the point ADCP measurements. The UD solutions were more smoothly varying as expected from this more dissipative method. MARS maintained greater coherence and a longer downstream extent for the jet from the spillway, as well as some larger velocities in the stilling basin. In the future, as other uses of the numerical model are identified, revisiting the model parameters would be appropriate. For example, if there were a specific need for modeling the spillway jet near the navigation lock entrance, MARS might be a more appropriate solver setting.

The differences in the simulation results for the UD and MARS differencing schemes would be expected to be largest for the lower flow volumes and higher spill percentages. These flow conditions were expected to have larger areas of recirculation and larger velocity gradients. The spillwall configuration with TR $125 \mathrm{kcfs}$ was chosen for an additional comparison (Table 2.6). Figure 3.14 shows several ways to look at the differences in the simulation results for the MARS and UD models for the 125-kcfs spillwall simulation. Both differencing schemes had lateral entrainment of flow from the powerhouse, and the results were very similar to the flow patterns observed in the physical model for the same flow conditions and spillwall configuration. Contours of velocity show very similar patterns at elevation $157 \mathrm{ft}$, although the UD model had more dissipation in the jet from the spillway. The detail of vectors shows differences in the spillway flows, but those differences are on the order of time slice variability. Iso-surfaces of velocity difference (left side of Figure 3.14) show that larger differences in velocity magnitude (greater than $1.5 \mathrm{ft} / \mathrm{s}$ ) are limited to the downstream boundary and the stilling basin and its downstream jet from the spill flow being concentrated between the spillwall and skeleton bays. Differences less than $1.5 \mathrm{ft} / \mathrm{s}$ are within the variability found from time step to time step. The MARS results have higher velocities in the spillway flows and a slightly stronger recirculation zone between the spillwall and Washington shore.

Given the minimal differences and the computational costs, it was determined that upwind differencing in the short model would be appropriate to assess the general trends in hydraulic conditions for proposed operational and structural changes for the John Day tailrace. 


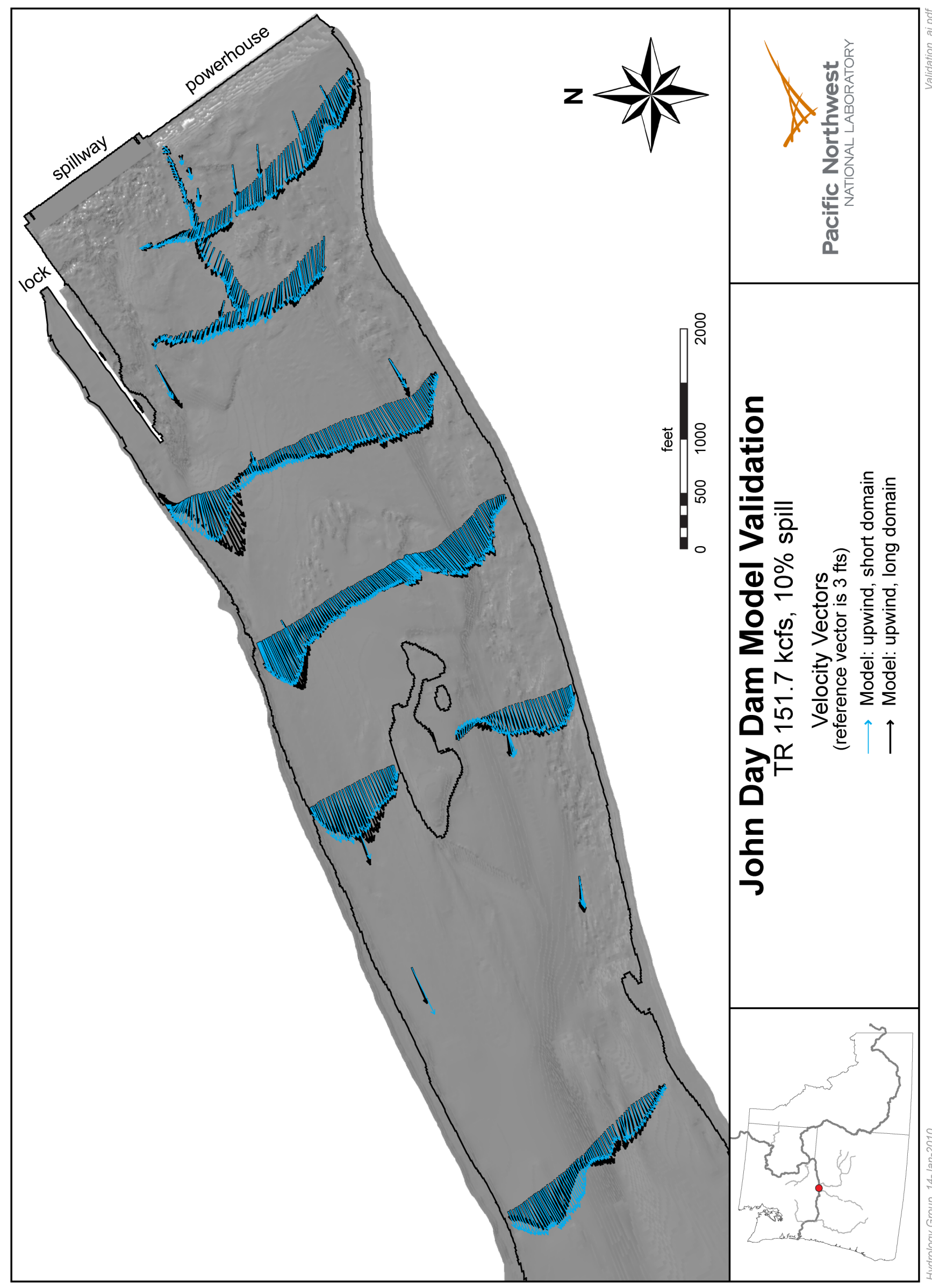

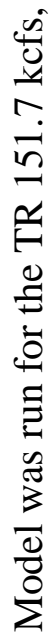

$\stackrel{\dot{\theta}}{\overrightarrow{0}}$

兽

휴

胥

光

के

.

ํㅗㅇ

흥

ज

를

on

ธิ

I

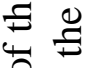

훈

荬

잉

$\ddot{7}$ 


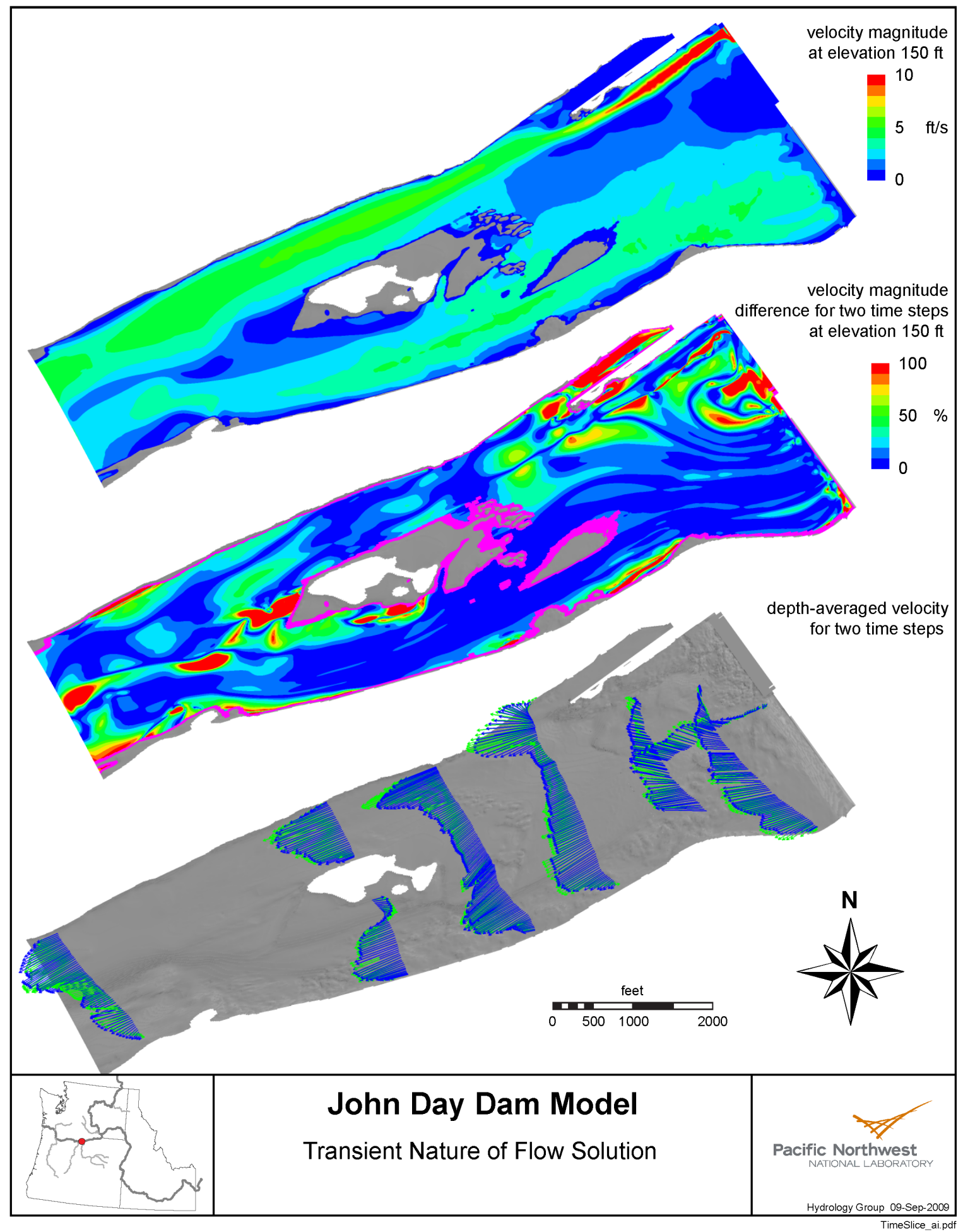

Figure 3.12. Comparison of Different Time Slices (a minute apart) for the TR $151.7 \mathrm{kcfs}$, $10 \%$ Spill Validation Simulation Results at an Elevation of $150 \mathrm{ft}(46 \mathrm{~m})$. The top graphic shows depth-averaged velocities extracted at the ADCP transecting locations. The middle graphic shows contours of the normalized difference in velocity magnitude at elevation $150 \mathrm{ft}$. The lower graphic shows the comparison of velocity vectors at the points which ADCP velocities were collected. These graphics indicate the transient nature of the CFD flow solution. 


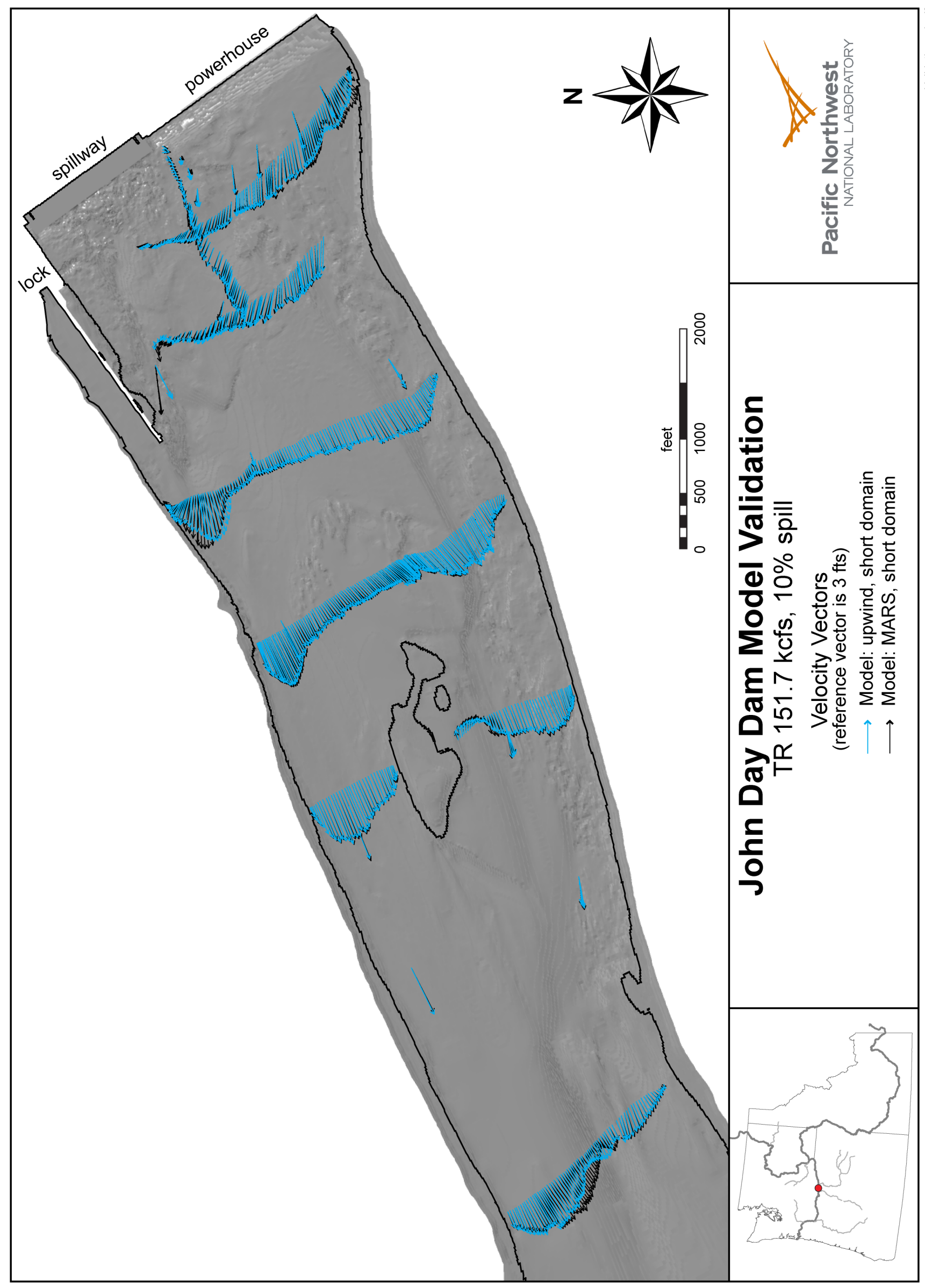

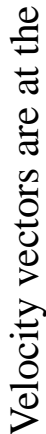

है

응

$\frac{w}{2}$

I

든

午

ํㅡ

节

虫

둥

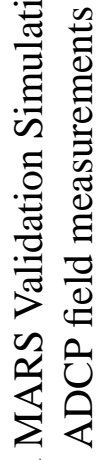

로.

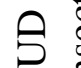

प艹 증

둥

สิ

苂

மூ7 


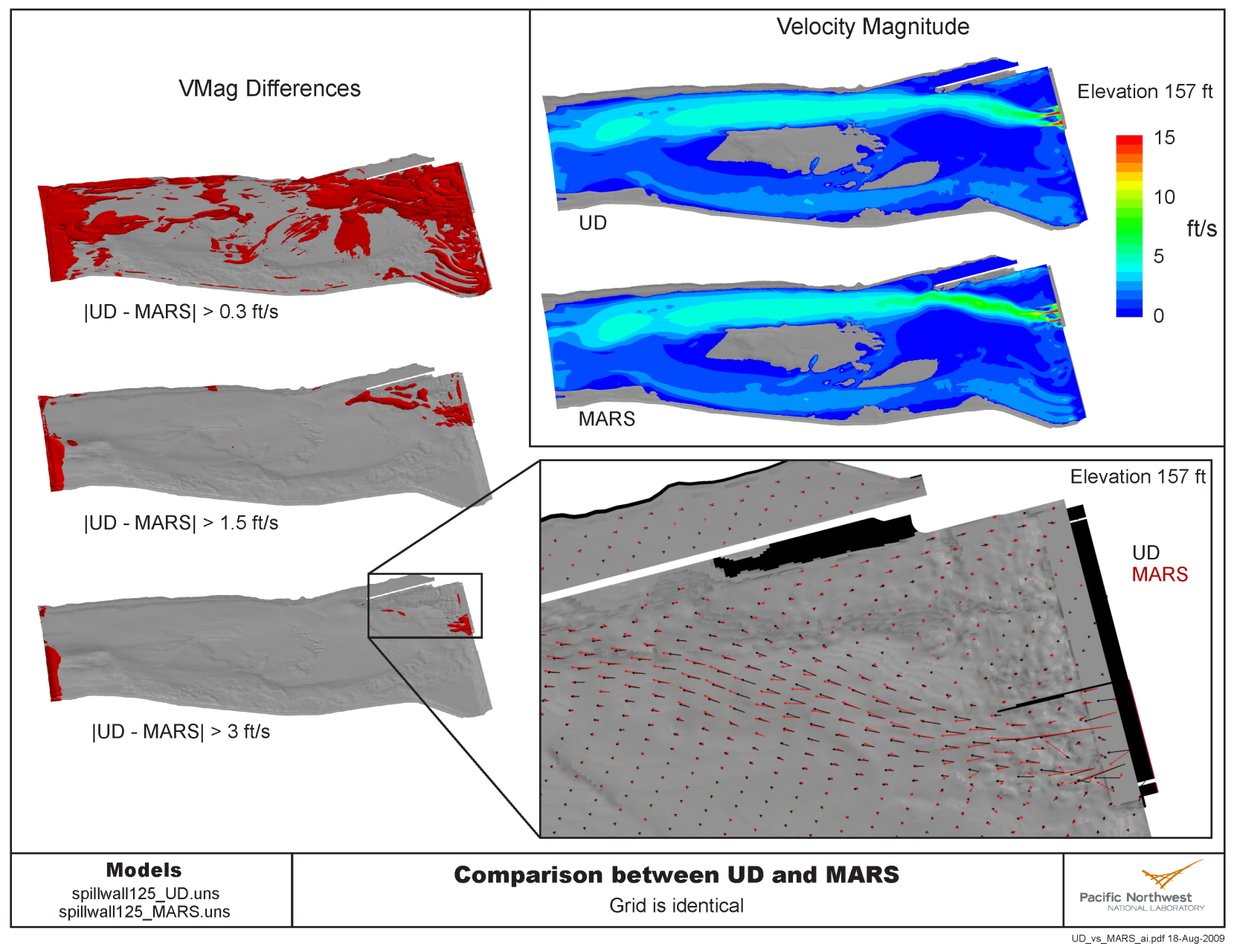

Figure 3.14. Comparison of UD and MARS Simulation Results for $125 \mathrm{kcfs}$ at $30 \%$ Spill. The left side shows the isosurface of velocity magnitude differences. For these unsteady runs, differences on the order of $0.3 \mathrm{ft} / \mathrm{s}$ are on the order of time variations in the unsteady results. The $157-\mathrm{ft}$ elevation is near the expected watersurface elevation of the tailrace. 


\section{Model Validation for Final Configuration}

The shortened model was run with UD for the three validation cases (Table 2.3). Figure 3.15 shows the UD simulation vectors (transecting points are depth averaged) and the ADCP fieldmeasured velocity vectors for the TR $151.7 \mathrm{kcfs}, 10 \%$ Spill case. This figure shows that the 3D CFD results, relative to the MASS2 results, had much more lateral entrainment from the powerhouse into the spillway flows and an area of higher velocity near the Washington shore downstream of the spillway. These features are shown in the field measurements. The TR 210.1 kcfs, 30\% Spill and TR $122.7 \mathrm{kcfs}, 21 \%$ Spill vector comparisons are in Appendix B. Table 3.4 has the flow splits around the dredge spoils island for all three validation cases. This table shows that the 3D model reproduced the flow splits measured in the field to within a few percent. The larger percentage of flow (in the simulations) on the north side of the island resulted from lateral entrainment of powerhouse flow into the spillway jet.

Table 3.4. Observed and 3D CFD Modeled Flow Splits for the ADCP Validation Cases. See Figures 3.2 to 3.4 for cross section locations.

\begin{tabular}{lccccc}
\hline \hline Case & XS-1 & XS-2 & XS-3N & XS-3S & Sum XS-3 \\
\hline TR 210.1 kcfs, 30\% Spill measurement & 220 & 197 & $107(46 \%)$ & $125(54 \%)$ & 232 \\
TR 210.1 kcfs, 30\% Spill STAR-CD Model & 206.5 & 207.3 & $90.7(43 \%)$ & $117.7(57 \%)$ & 208 \\
Percent difference & $-6.1 \%$ & $5.2 \%$ & $-15.2 \%$ & $-5.8 \%$ & $10.2 \%$ \\
from field & & & & & \\
\hline TR 151.7 kcfs, 10\% Spill measurements & 146 & 148 & $64(42 \%)$ & $87(58 \%)$ & 151 \\
TR 151.7 kcfs, 10\% Spill STAR-CD Model & 148.8 & 141.9 & $66.0(45 \%)$ & $79.1(55 \%)$ & 145.1 \\
Percent difference & $2 \%$ & $4 \%$ & $3 \%$ & $9 \%$ & $4 \%$ \\
from field & & & & & XS-3 \\
\hline & $\mathbf{X S - 1}$ & $\mathbf{X S - 2 N}$ & $\mathbf{X S - 2 S}$ & $\mathbf{S u m ~ X S - 2}$ & 125 \\
\hline TR 122.7 kcfs, 21\% Spill measurements & 125 & $64(52 \%)$ & $60(48 \%)$ & 124 & 126.9 \\
TR 122.7 kcfs, 21\% Spill STAR-CD & 121.5 & $66.8(53 \%)$ & $59.2(47 \%)$ & 126.0 & 1.6 \\
Percent Difference & -2.8 & 4.4 & -1.3 & & 1.5 \\
from field & & & & & \\
\hline
\end{tabular}

The extracted point data were used to create 1:1 plots comparing field data on-station and transecting ADCP measurements to the simulation results. Figure 3.16 shows the 1:1 comparison for the TR $151.7 \mathrm{kcfs}, 10 \%$ Spill on-station measurements; the standard deviations are included on the lower graphic. Although no standard deviations were available for the transecting data, we know these to be noisier than the on-station data, which were collected for a 10 minute period. This difference is shown in Figure 3.17. The transecting data have lower $\mathrm{R}^{2}$ values than the on-station data. The sub-optimal field conditions (wind and waves) and samples below the spilling bays with the entrained bubbles for the TR $210.1 \mathrm{kcfs}, 30 \%$ Spill data (conditions documented in Mannheim and Sweeney 2003) probably contribute to the lower $\mathrm{R}^{2}$ values for those data. The on-station data had a much better fit than the transecting data. These on-station data, while averaging the flow conditions over time, more accurately characterize the overall tailrace flows. 


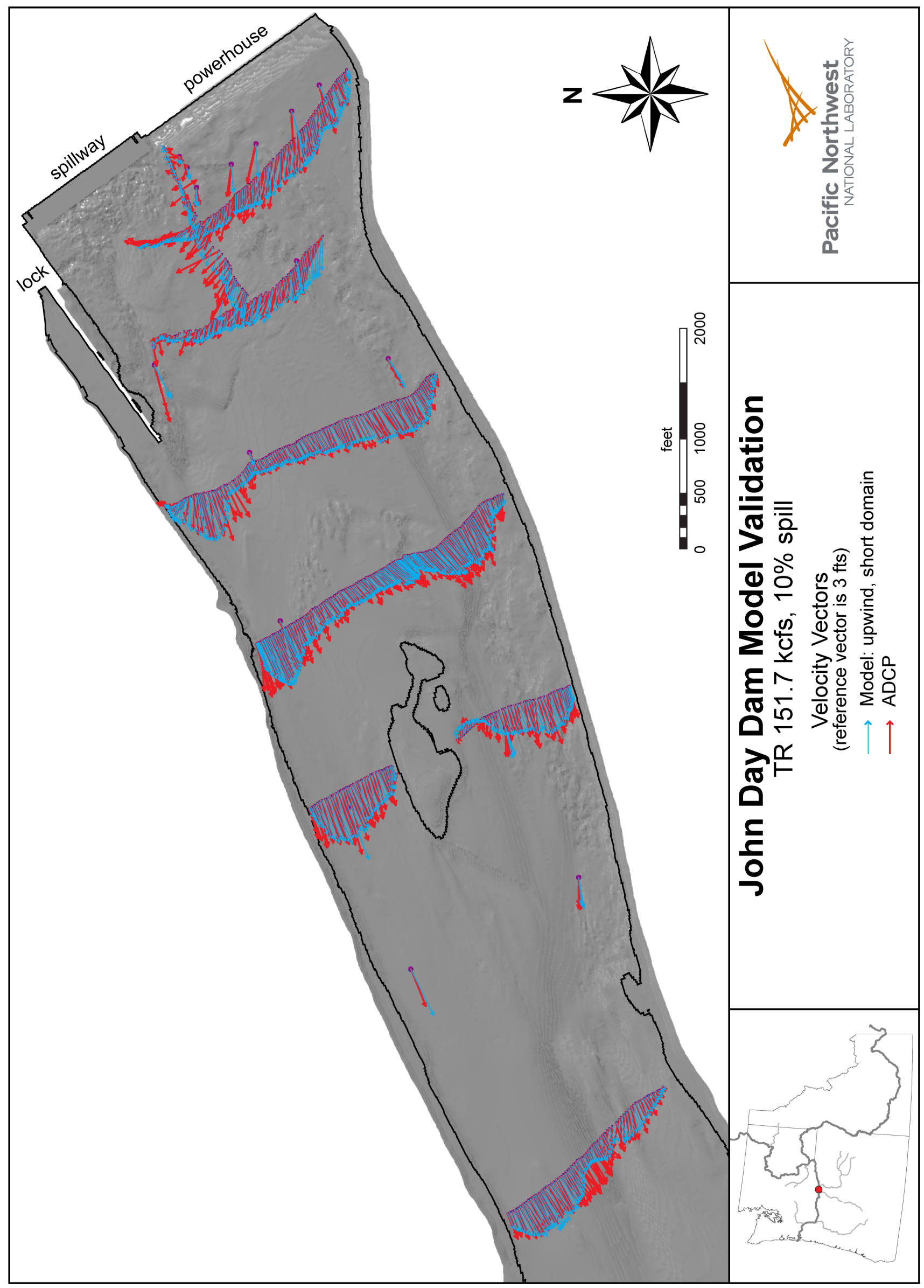

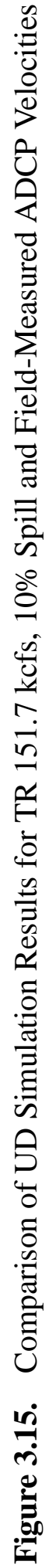




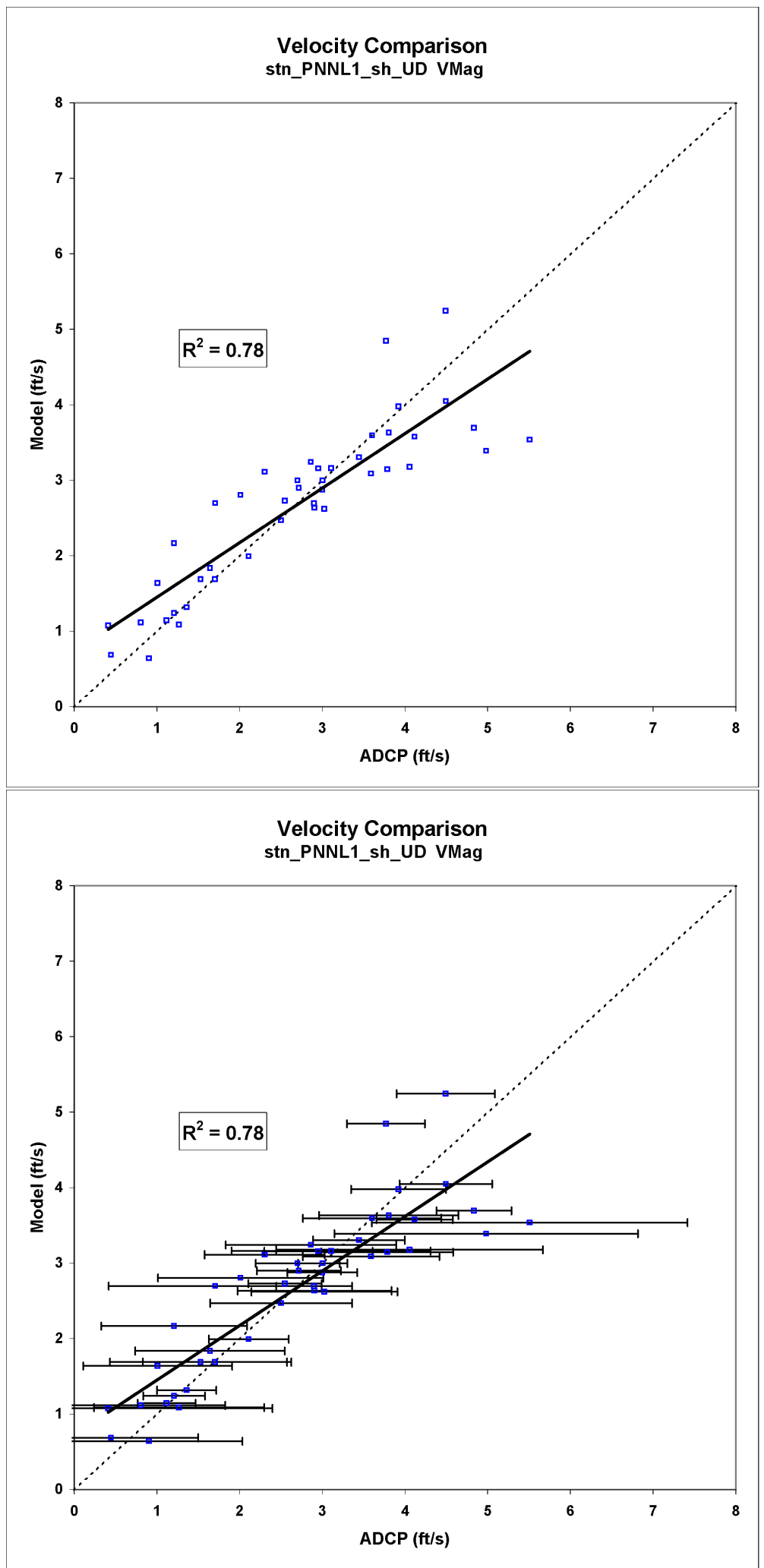

Figure 3.16. Simulated and Field-Measured Velocity Magnitude for the On-Station TR 151.7 kcfs, $10 \%$ Spill model with Shorter Extents and Upwind Differencing. The bottom graphic shows the same data, but with the standard deviation (SD) bars included. The large SDs are an indication of the transient and turbulent character of the system. 

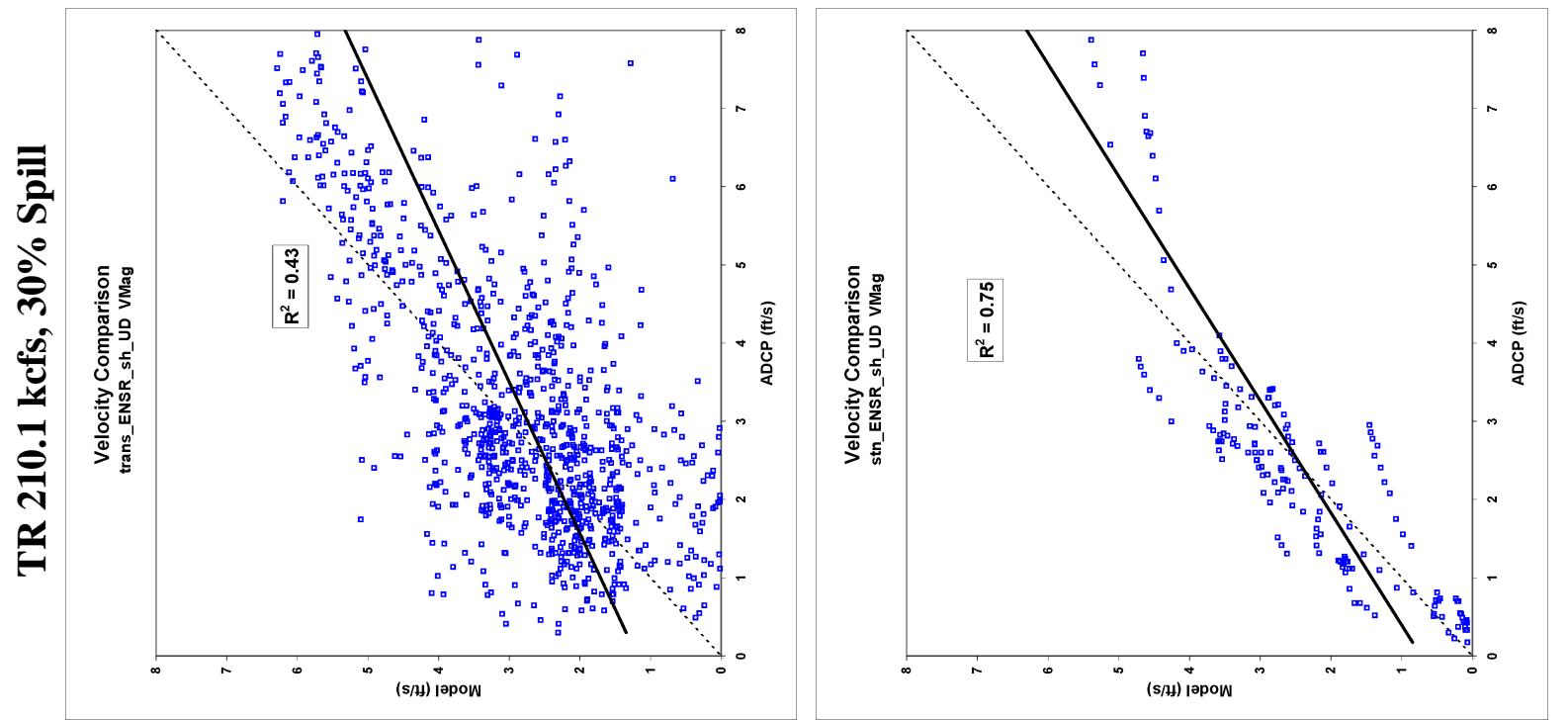

ปี่
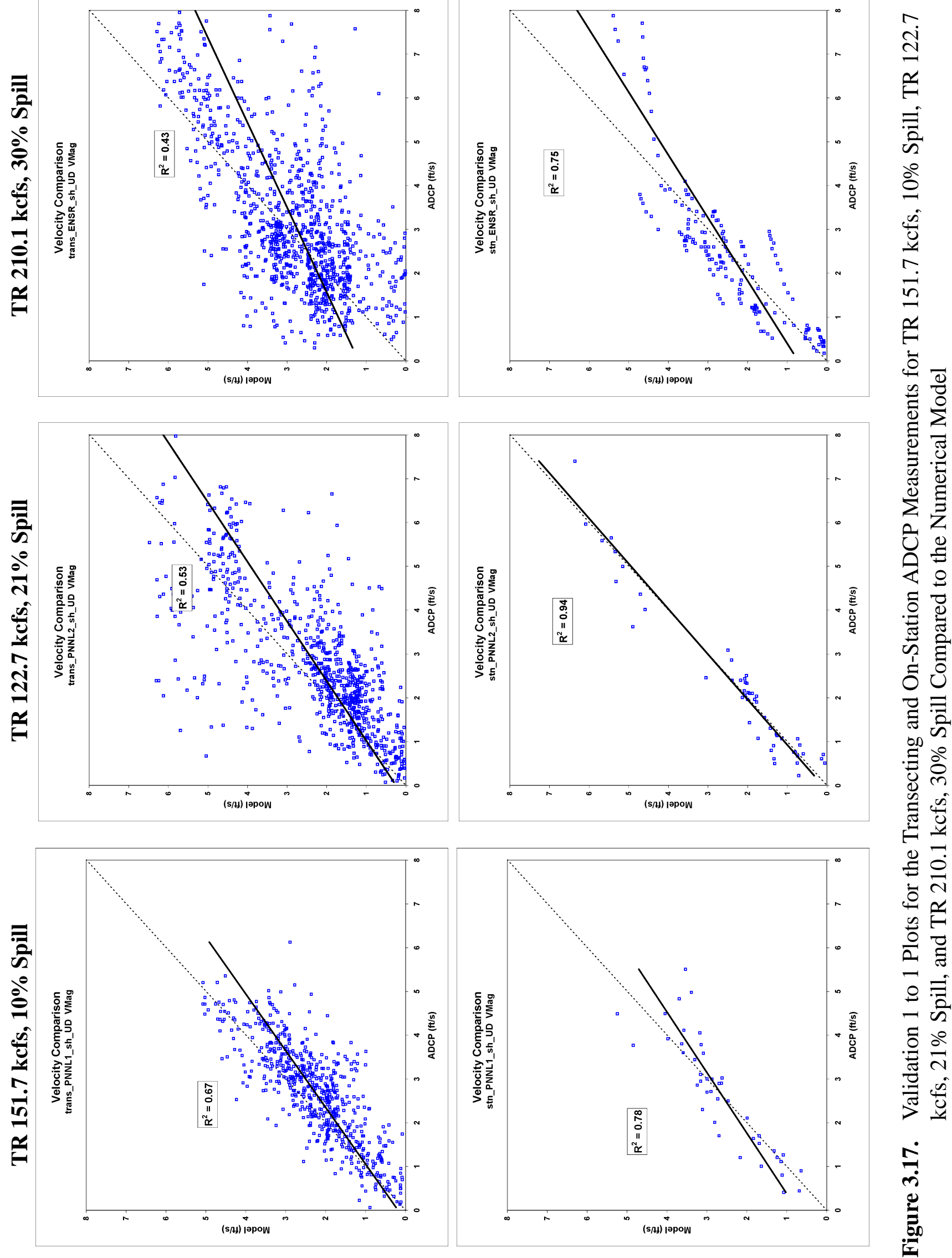
Figure 3.17 shows the 1:1 plots for the transecting and on-station measurement for the three validation simulations. Based on these graphics and the capability of the 3D numerical model to more accurately reproduce the lateral entrainment and flow splits around the dredge spoils island, the 3D numerical model was deemed an appropriate tool to evaluate John Day tailrace hydraulics near the project and further downstream for the objectives of this study.

\subsubsection{Additional Validation Information}

Drogues were released in the John Day tailrace by U.S. Geological Survey (USGS) during the same period in which the TR $210.1 \mathrm{kcfs} 30 \%$ Spill ADCP measurements were collected. These drogue data were made available to PNNL by CENWP personnel. The release locations provided were used as seed locations to generate streamlines in the CFD model. Figure 3.18 shows the drogue paths and the streamlines for the drogue release locations. Although the overall agreement is good, there are larger differences between the CFD streamlines and the drogues for the afternoon releases. The reasons for these larger differences are most likely attributable to changes in the field conditions: winds and spillway flows. Weather data and observations from that day indicate that the winds were strong, blowing downstream in the morning, but shifted to strong winds in the upstream direction in the afternoon (Mannheim and Sweeney 2003). The drogues extend to $2 \mathrm{~m}$ deep and thus are influenced by wind-driven surface flows. It was noted that afternoon upstream winds increased the wave height and frequency. The drogue paths in Figure 3.18 use the path color to show the time of day the drogue was released.

These results are further evidence that the CFD model results are similar to flows at the prototype; however, there are additional processes at the prototype, such as wind-driven surface features, that are not included in the CFD model.

\subsubsection{D Flow Scenarios}

The 3D simulations, as demonstrated by the validation runs, better represent the lateral entrainment and near-project flows than the 2D runs. The recirculation and lateral entrainment seen in the physical model and supported by the limited number of field measurements of velocity are reproduced in the 3D numerical model. Hence, we have much more confidence using the model results near the powerhouse and spillway. The numerical model was used to predict tailrace hydrodynamics for operational and structural scenarios and to characterize the probable egress times. The egress times, past a near- and far-field cross section, were quantified using the PNNL particle tracking software for streamlines and neutrally buoyant and buoyant spheres.

\section{Spillwall Case: TR 250 kcfs with $30 \%$ Spill}

The 3D VOF model was run for two cases with TR $250 \mathrm{kcfs}$ with $30 \%$ spill. One was for the existing conditions (Baseline, Figure 3.19), and one was with the spillwall in place (Figure 3.20). The baseline simulation was run with the current operational rules for comparison of tailrace egress times. It should be noted that there was a higher velocity area simulated downstream of the spillway near the Washington shore. This was consistent with the field measurements from the validation data and field observations. 


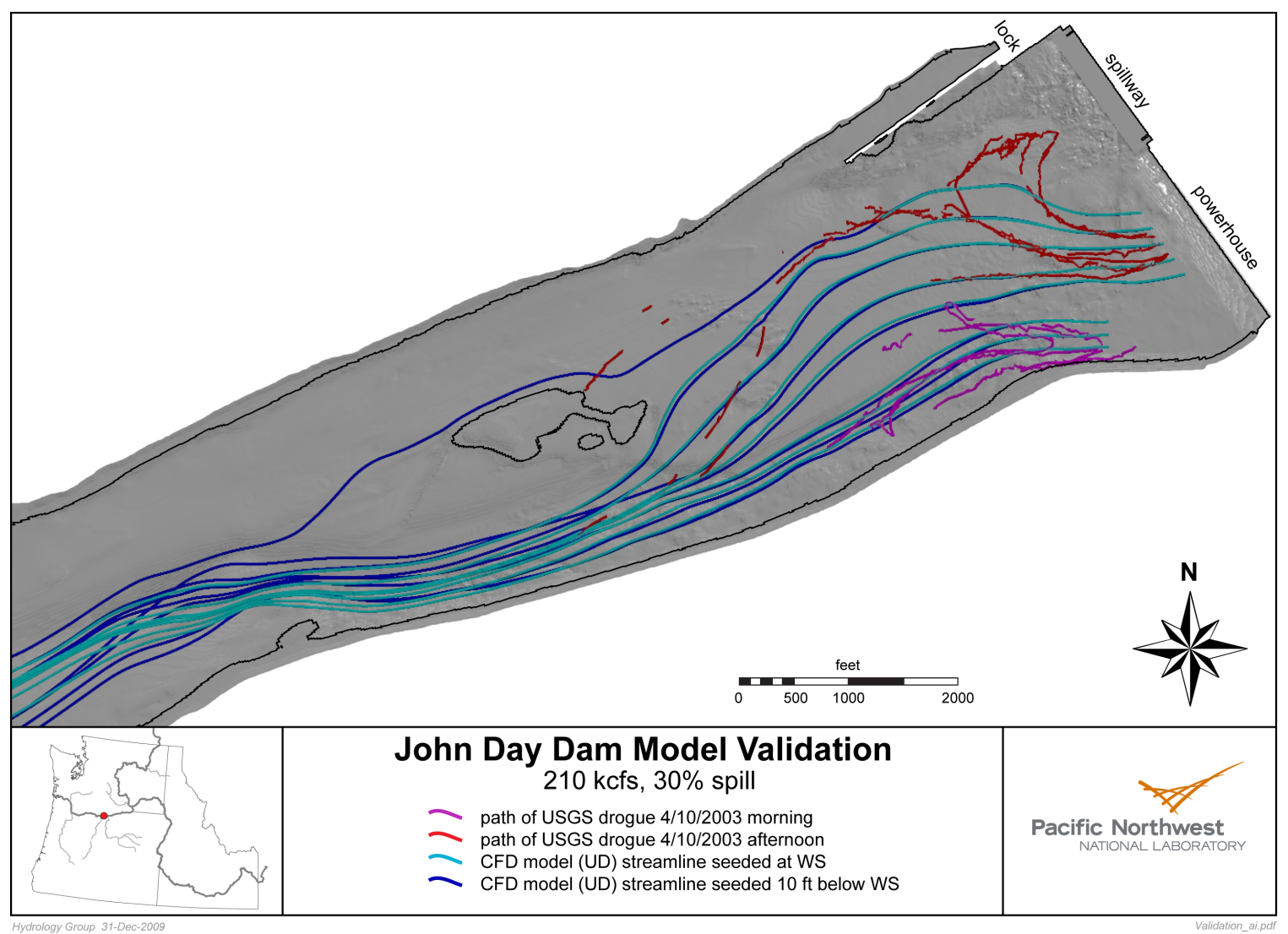

Figure 3.18. Particle Tracks Seeded at the Start Location of USGS Released Drogues in 2003

Streamlines and neutrally buoyant particles behave somewhat differently, especially in CFD results for turbulent environments such as the John Day tailrace. The streamlines go with the flow and do not disperse or respond to turbulence. The neutrally buoyant particles have mass and do disperse in response to turbulence-it can be considered to be a "numerical dye."

Streamlines (Figure 3.21), showed that particles that traveled in the south channel tended to have larger egress times than those that passed through the north channel. Neutrally buoyant particles were used to more realistically simulate the particle spreading in response to turbulence. Figure 3.22 shows that, unlike the streamlines, the neutrally buoyant particles that passed through the north channel had longer egress times. To understand the differences and origin of the longer egress times, the streamlines and particle tracks were separated into those with seed locations originating in the spillway (Figure 3.23) and in the powerhouse (Figure 3.24). It should be noted that equal numbers of particles were released in each inflow boundary, independent of the flow volume through that boundary. For the spillway-released particles, the baseline case had many more slow particles along the north shore of the dredge spoils island. In the spillwall simulation, egress times were reduced, even though some spillway particles passed on the south side of the dredge spoils island.

For the powerhouse-released neutrally buoyant particles (Figure 3.24), the particles spread across the river and were entrained into the spillway flows. From this figure, it appeared that the egress 


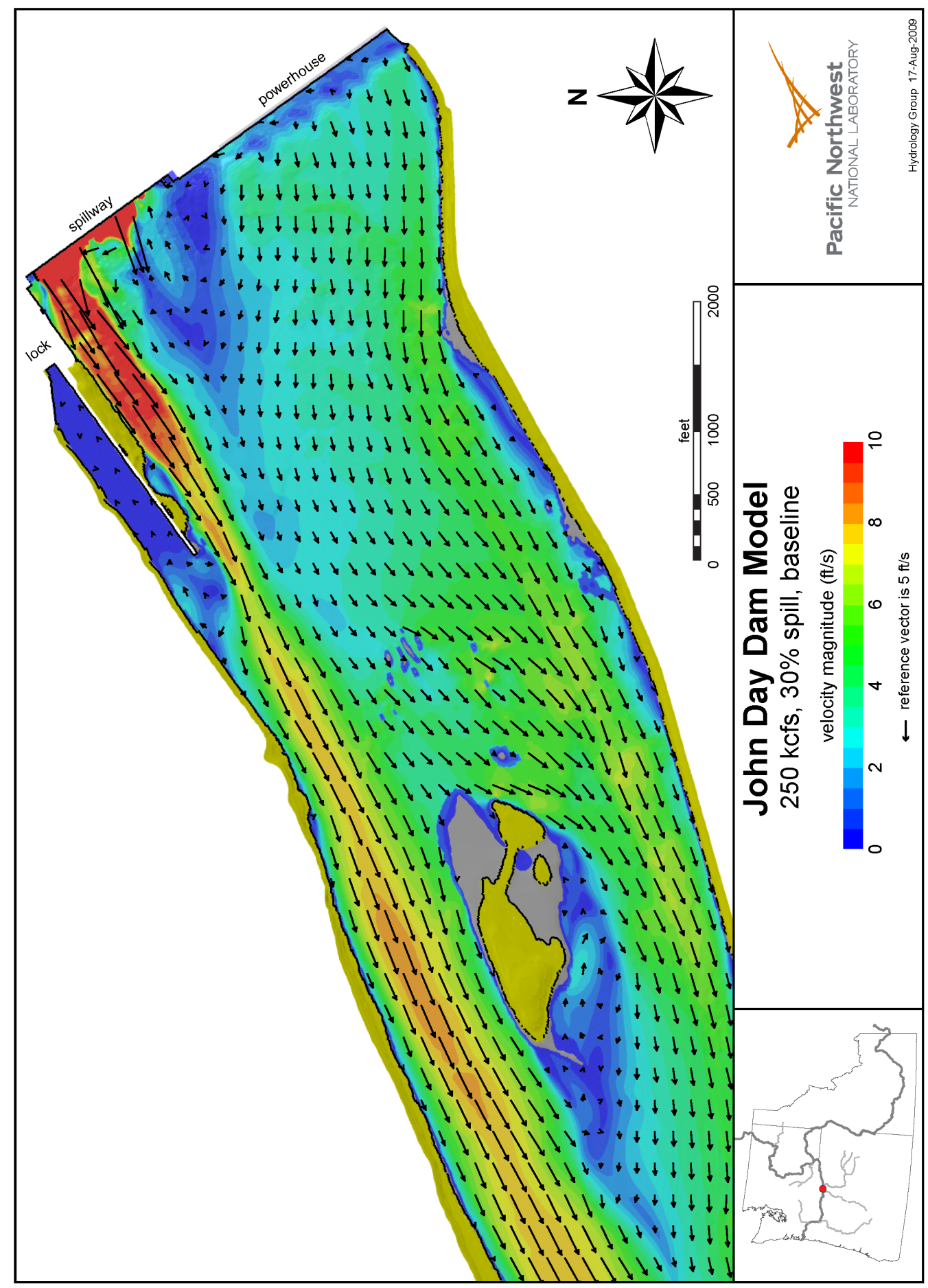

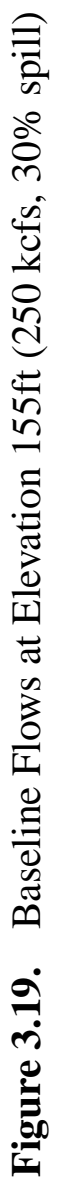




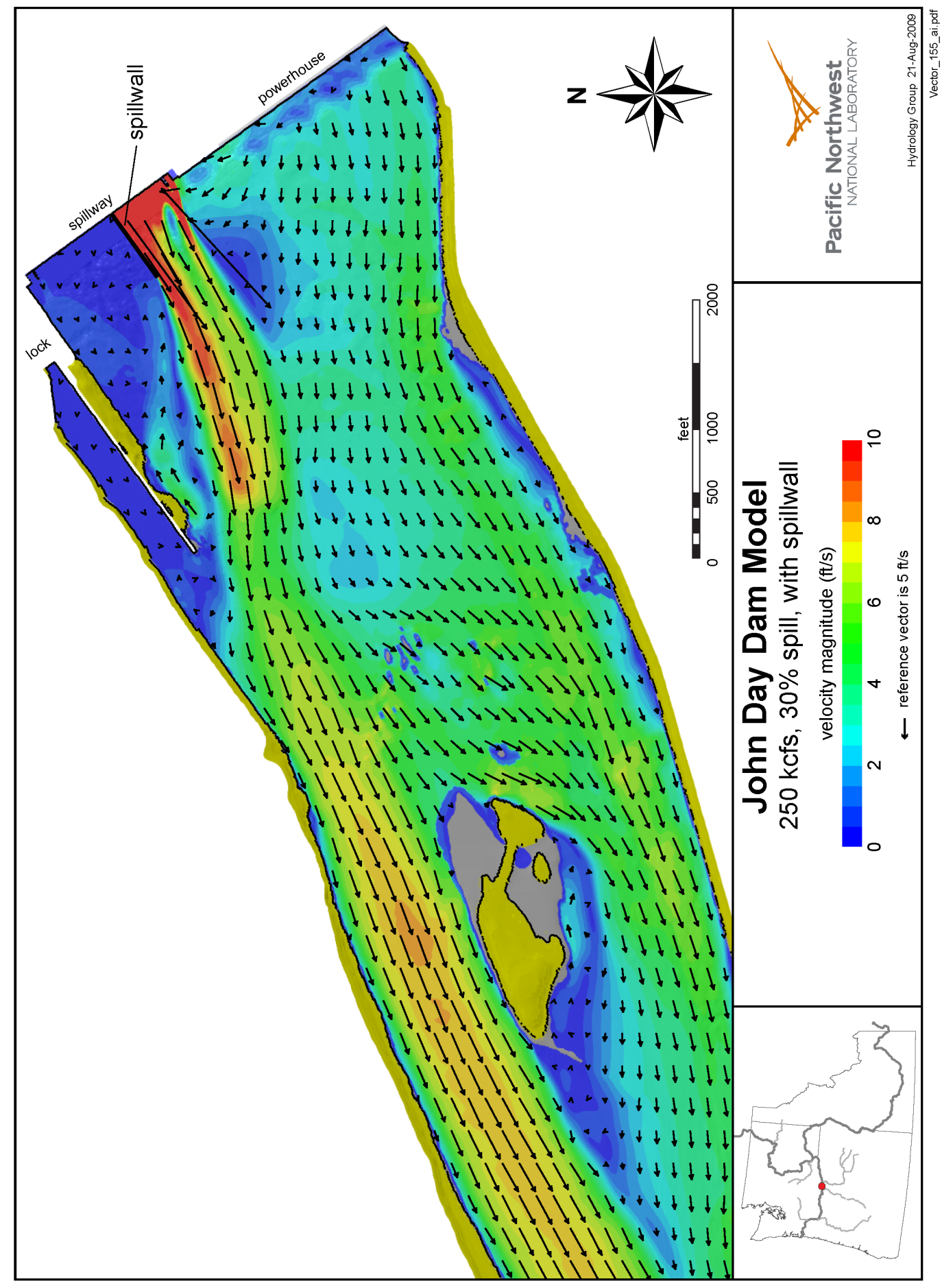

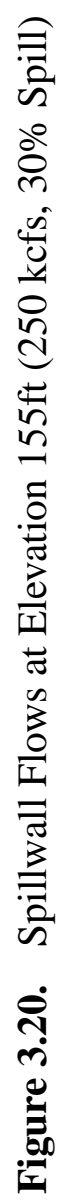


times were reduced for the spillwall case. The reduction had two sources. The spillway flow was confined to fewer bays in the spillwall case, so egress from those fewer bays was more rapid. When probing the flow details for the baseline case, there were backrollers in the stilling basin that greatly slowed egress times for particles passing through the stilling basin. The powerhouse flows that were entrained in the spill flows for the spillwall case traveled a shorter distance before being entrained in the spill flow and rapidly moved downstream. Histograms quantifying these differences are discussed below. 


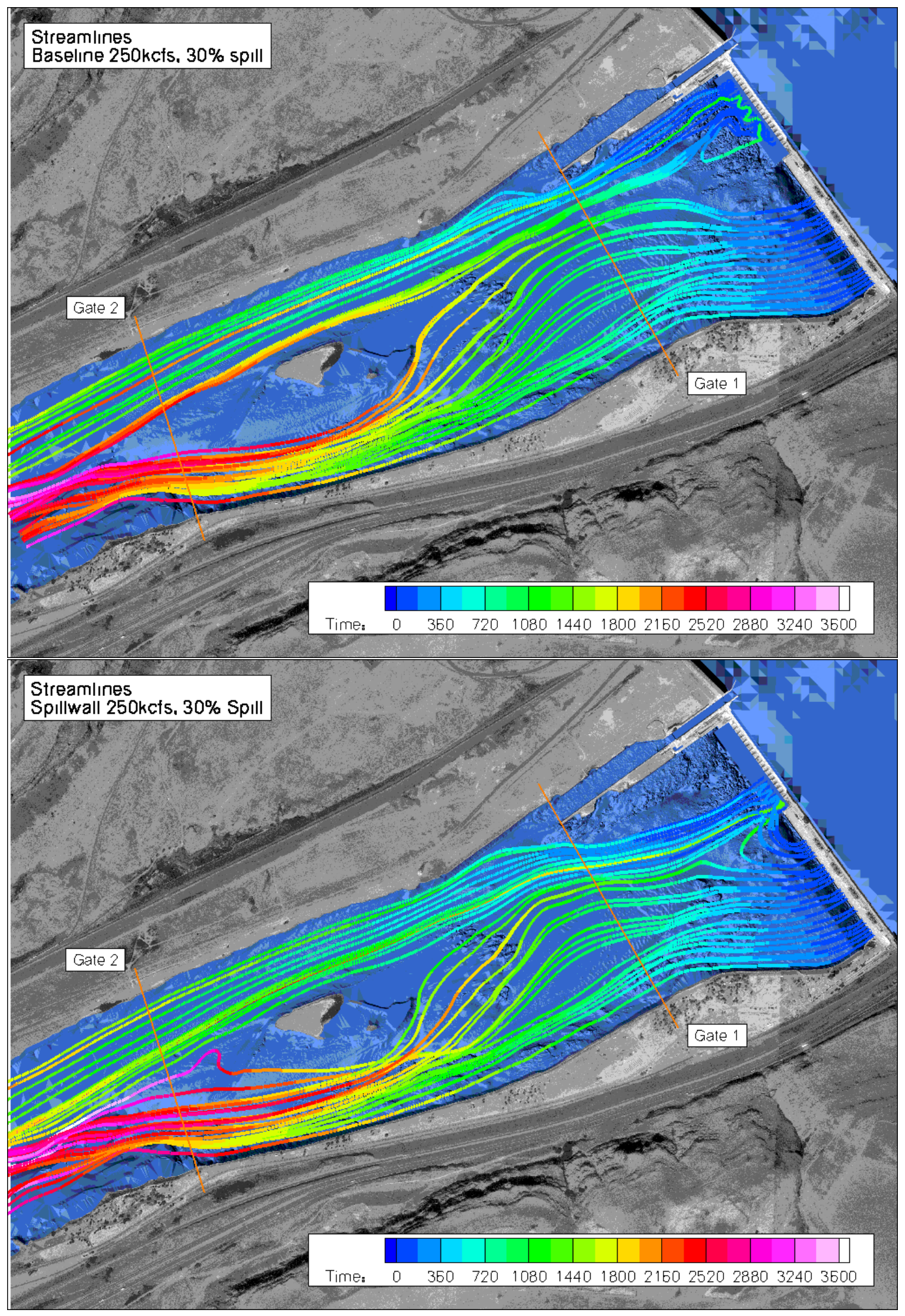

Figure 3.21. The Baseline FPP (upper) and Spillwall (lower) ( $250 \mathrm{kcfs}, 30 \%$ spill) Streamline Particle Tracks 


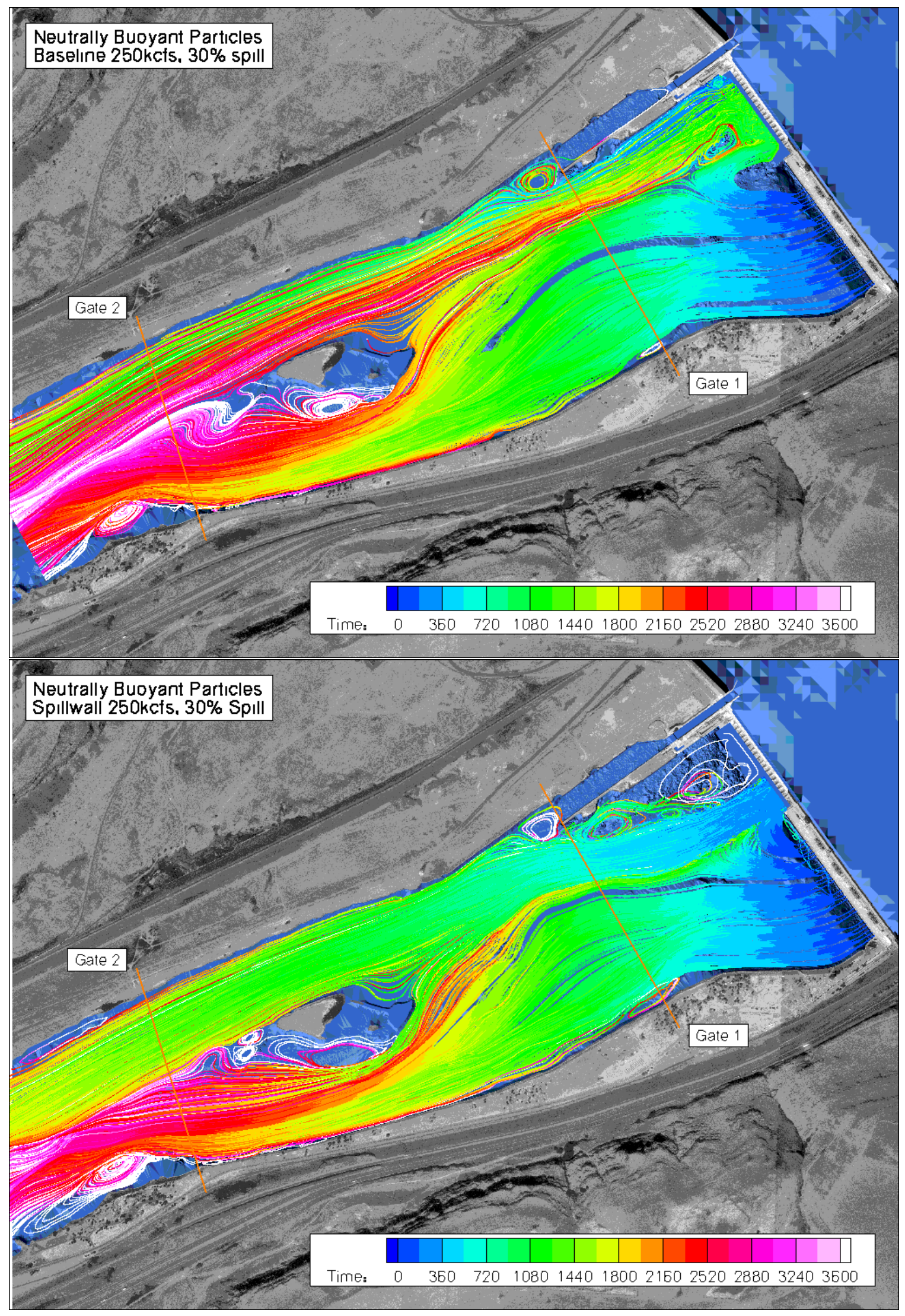

Figure 3.22. The Baseline FPP (upper) and Spillwall (lower) ( $250 \mathrm{kcfs}, 30 \%$ spill) Neutrally Buoyant Particle Tracks 


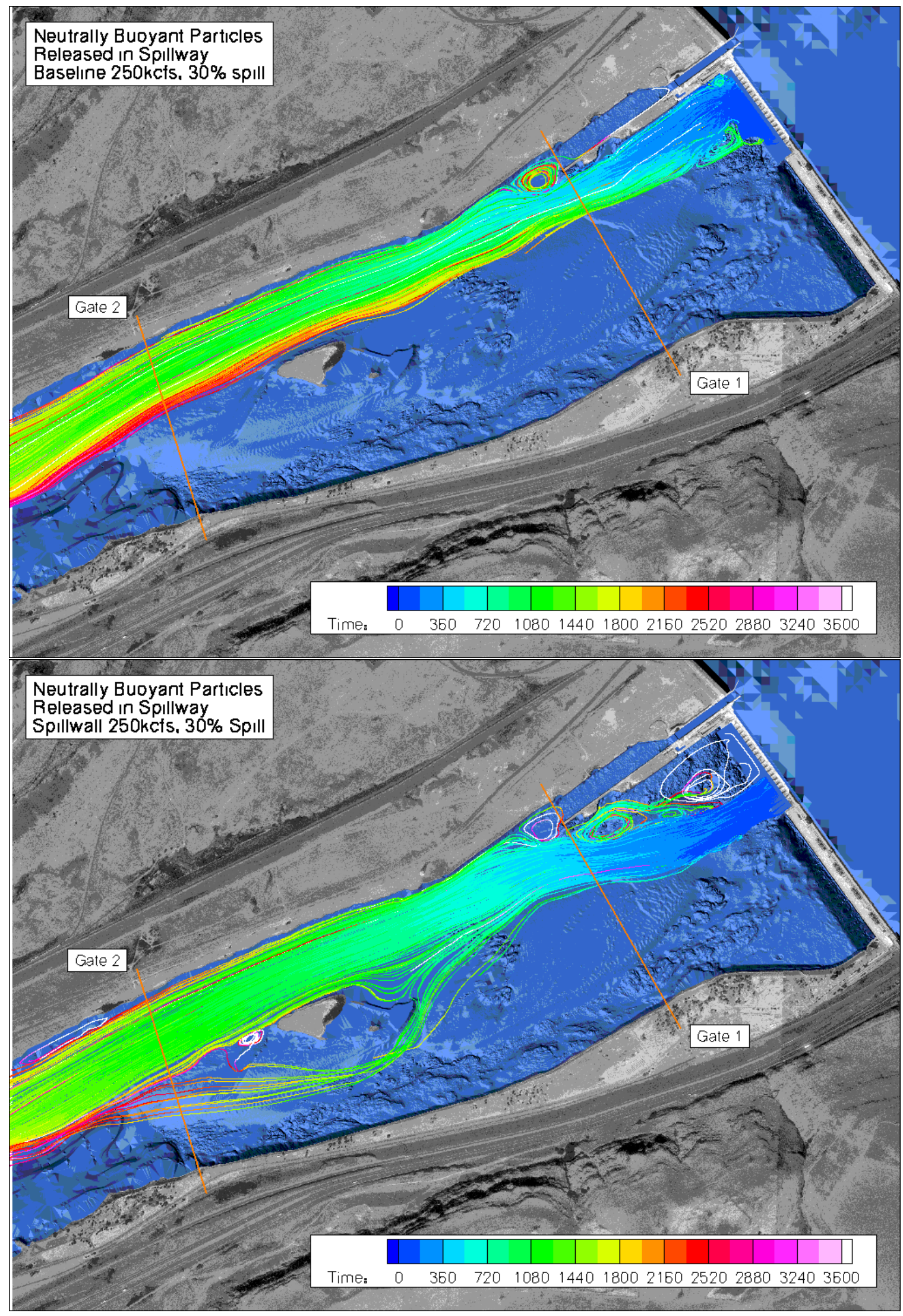

Figure 3.23. The Baseline FPP (upper) and Spillwall (lower) (250 kcfs, $30 \%$ Spill) Neutrally Buoyant Spillway Seeded Particle Tracks 


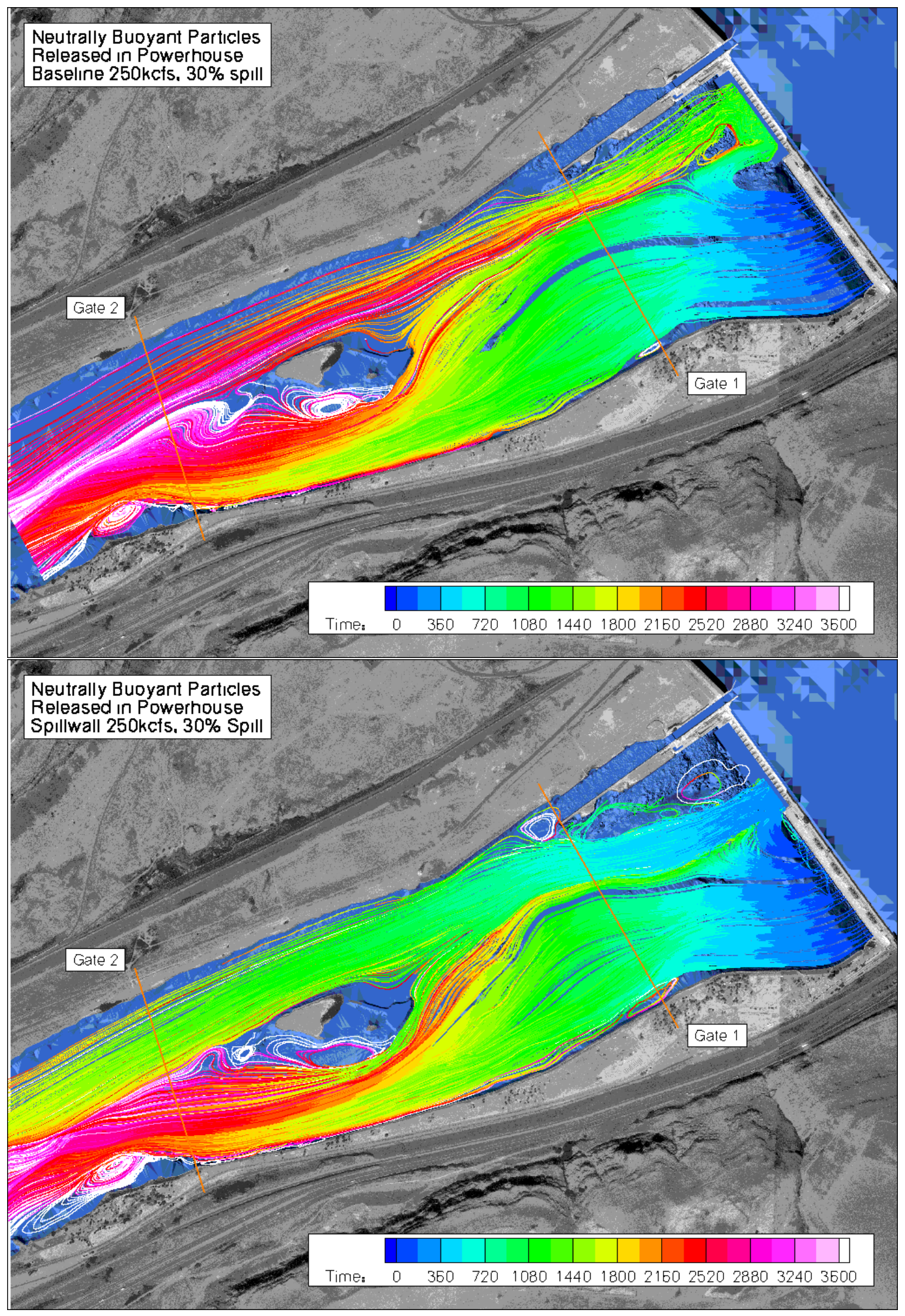

Figure 3.24. The Baseline FPP (upper) and Spillwall (lower) ( $250 \mathrm{kcfs}, 30 \%$ spill) Neutrally Buoyant Powerhouse Seeded Particle Tracks 
The PNNL particle tracker was run, and histograms were produced. These histograms quantified the times of passage ("residence time") at cross-section locations (Gate 1 and Gate 2, shown in the particle track plots) for 25,50 , and $75 \%$ of the particle populations. These residence time plots were used to compare the relative potential impact on retention time of the proposed spillwall. It should be noted that these are neutrally buoyant particles, not fish. These particles elucidate flow paths and are derived from velocities and turbulence quantities. The histogram data should be viewed in terms of time distribution of the particles, the median times, and the width of the 25 to $75 \%$ bands.

Residence time plots for Gates 1 and 2 are shown in Figures 3.25 to 3.27. The overall retention times for all particles for the baseline and spillwall simulations were very similar for TR 250 kcfs (Figure 3.25). There are, however, differences in retention times for the spillway-released particles (Figure 3.26) with longer times for the baseline case. Detailed examination of the tracks for the spillway particles reveal particles recirculating in the backrollers within the stilling basin rather than the more direct exit resulting from the larger flows in fewer individual bays. For the baseline case, the same flow volume was spread across 16 bays rather than being confined to the 8 bays of the spillwall case. It should be noted that the same number of particles were released in each open bay rather than a distribution of particles weighted by flow volume. The powerhouse-released particles (Figure 3.27) had very similar mean residence times; however, the tail of the distribution of tracked particles times was truncated somewhat for the spillwall case. The time for $50 \%$ of the particles to pass Gate 2 was functionally the same, but the $75 \%$ arrival time was reduced in the spillwall simulation compared to the baseline. Overall, for these TR 250 kcfs simulations, the addition of the spillwall does not greatly alter particle arrival times for Gate 1 or Gate 2.

Table 3.5 and Figure 3.28 compare the changes in passage time for 25,50 , and $75 \%$ of the particles to pass Gate 2 for a TR of $250 \mathrm{kcfs}$. It should be noted that equal numbers of particles were seeded at each boundary with flow. Future work could include weighting the particles by flow volumes or by the observed percentage of fish passing at each location. Weighting could result in very different distributions. For particles seeded at both powerhouse and spillway locations, the mean residence time is little changed, although the tail of the distribution, represented by the time for $75 \%$ of the particles to pass Gate 2, is reduced by 150 to 374 seconds.

Table 3.5. TR $250 \mathrm{kcfs}$ Gate 2 Residence Times (in seconds) for 25,50 , and $75 \%$ of the Tracked Particle Populations for the FPP and for the Spillwall

\begin{tabular}{l|cc|cc|cc}
\hline Percent & \multicolumn{2}{c}{ All } & \multicolumn{2}{c}{ Powerhouse } & \multicolumn{2}{c}{ Spillway } \\
Population & FPP 250 & Spillwall 250 & FPP 250 & Spillwall 250 & FPP 250 & Spillwall 250 \\
\hline 0.75 & 2569 & 2416 & 2734 & 2478 & 1754 & 1380 \\
0.5 & 2118 & 2122 & 2249 & 2204 & 1307 & 1239 \\
0.25 & 1773 & 1608 & 2053 & 1925 & 1118 & 1162 \\
\hline
\end{tabular}


Gate 1
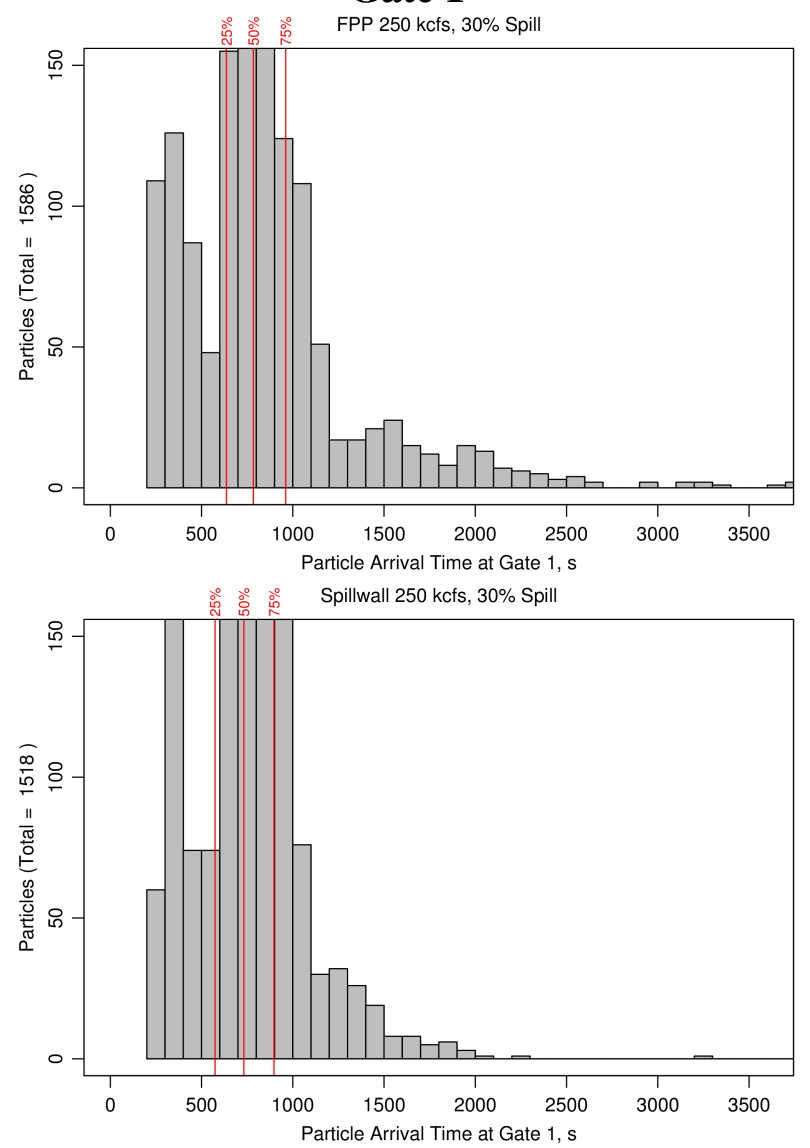

Gate 2
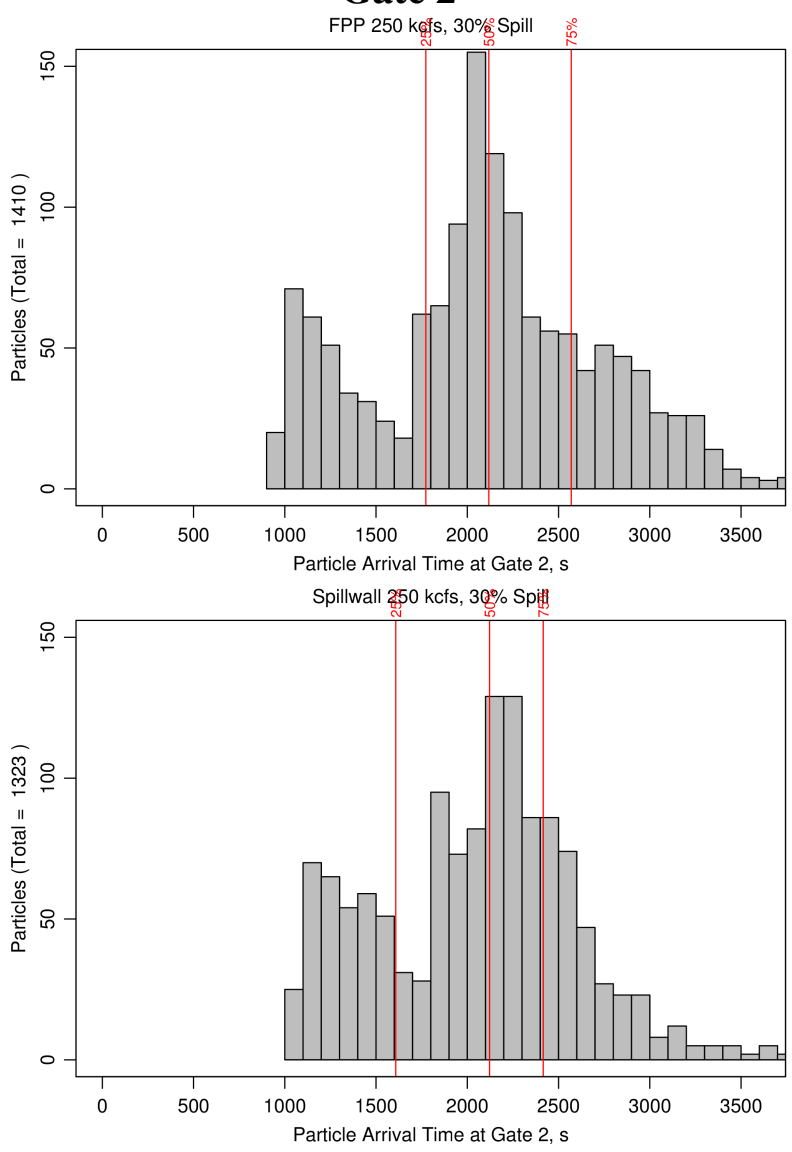

Figure 3.25. Residence Times for TR $250 \mathrm{kcfs}$ for all Particles. Baseline FPP is on the top, with the spillwall on the bottom. 
Gate 1
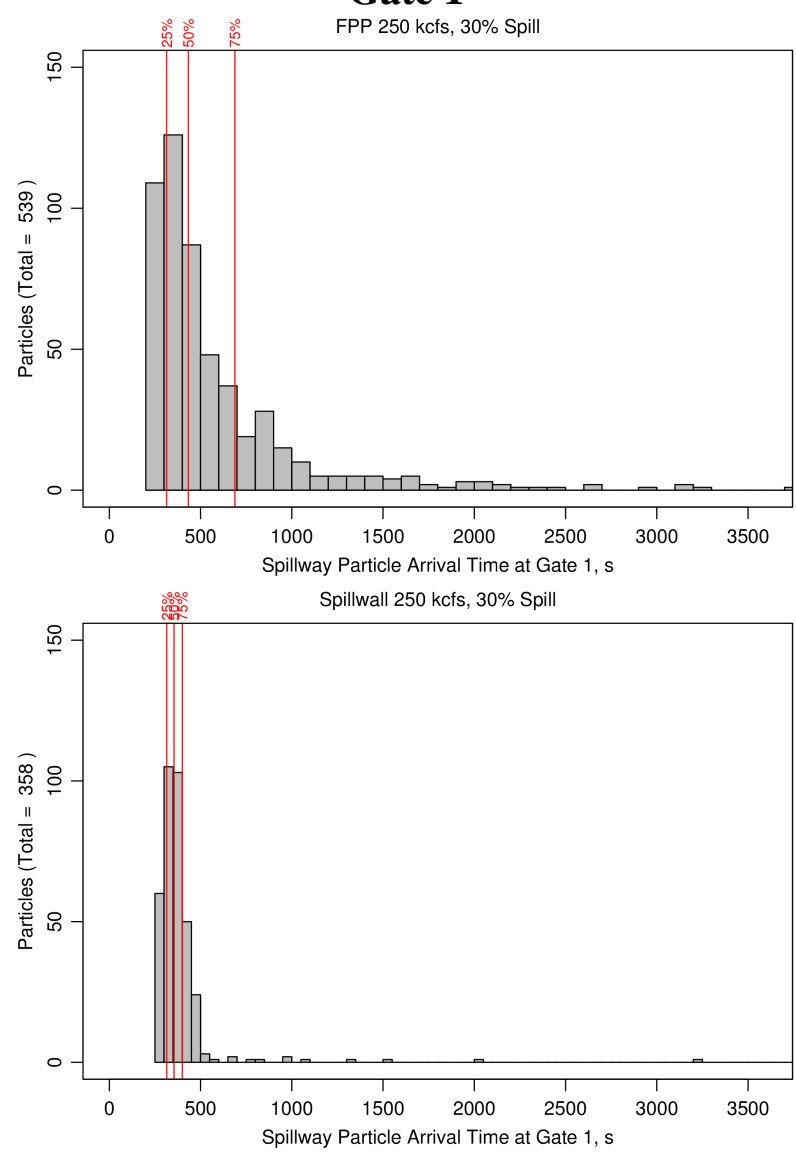

Gate 2

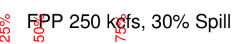

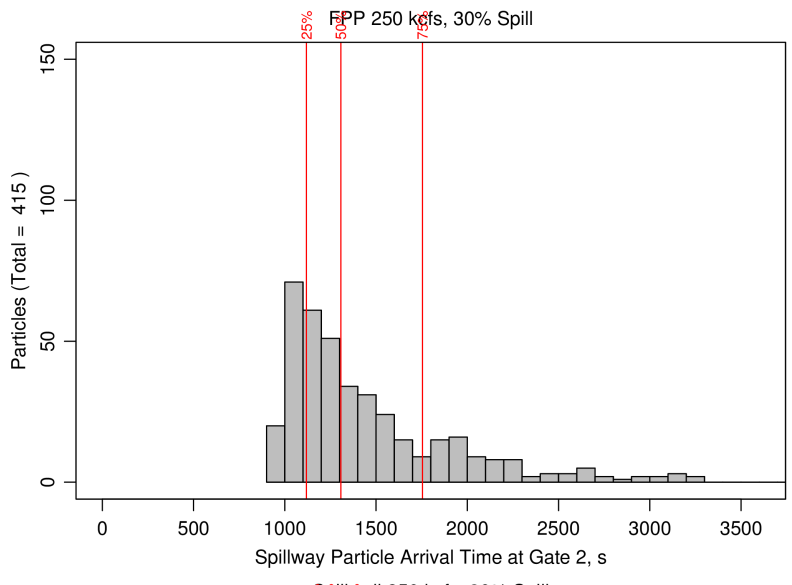

Șbillwall $250 \mathrm{kcfs}, 30 \%$ Spill

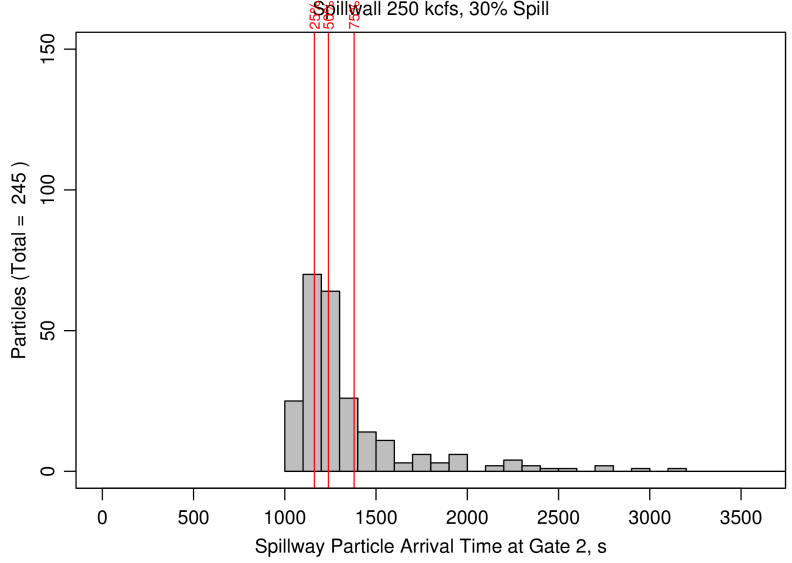

Figure 3.26. Residence Times for TR $250 \mathrm{kcfs}$ for Spillway Particles. Baseline FPP is on the top, with the spillwall on the bottom. 
Gate 1
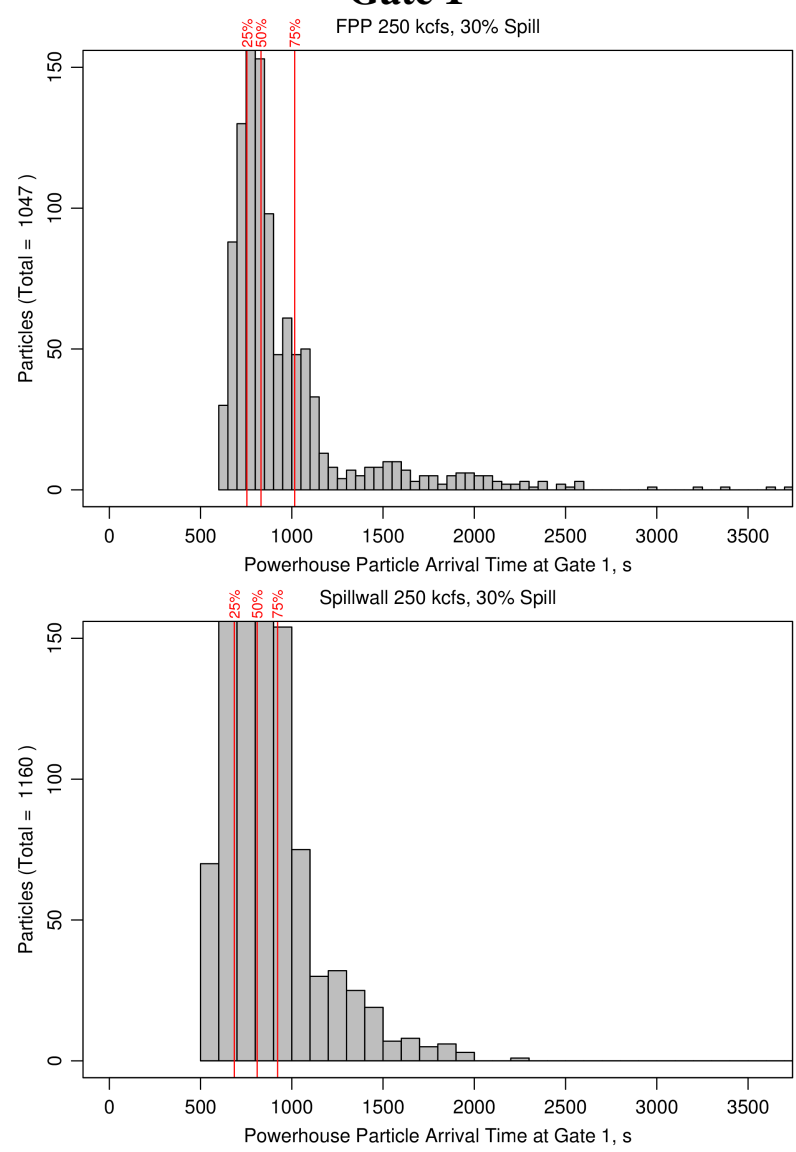

Gate 2
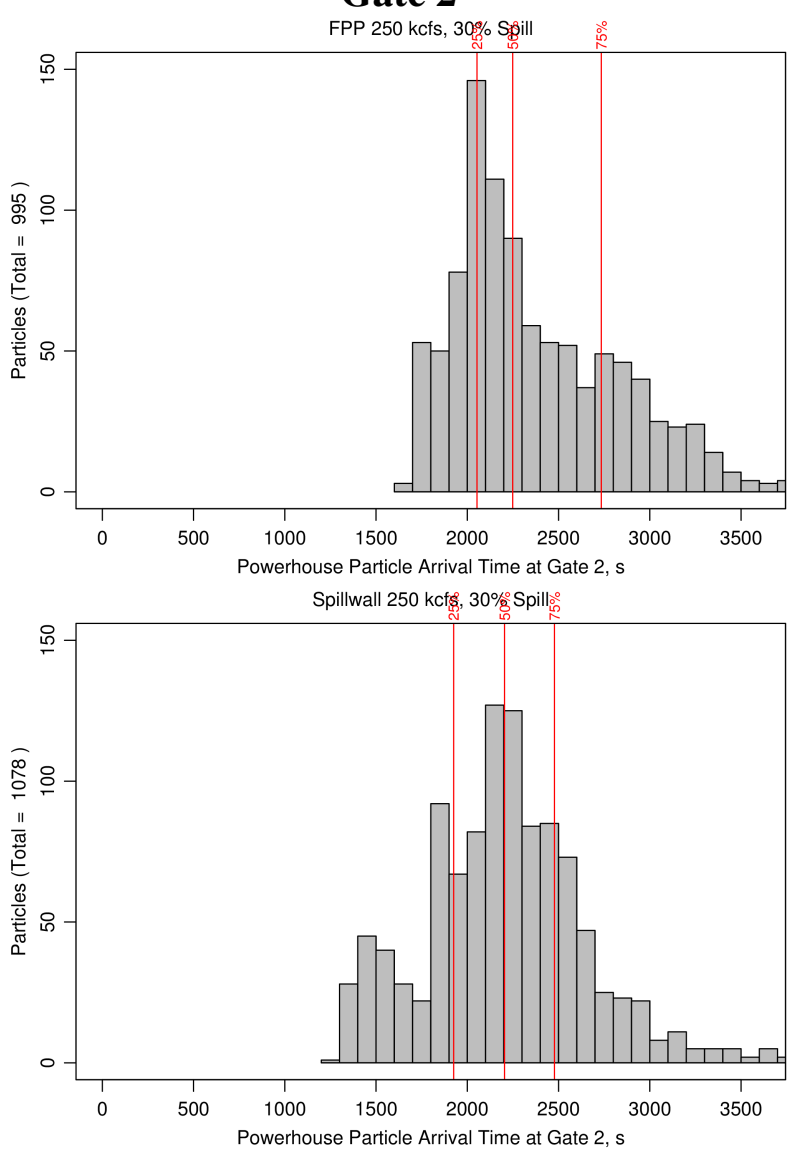

Figure 3.27. Residence times for TR $250 \mathrm{kcfs}$ for Powerhouse Particles. Baseline FPP is on the top, with the spillwall on the bottom. 


\section{Residence Times}

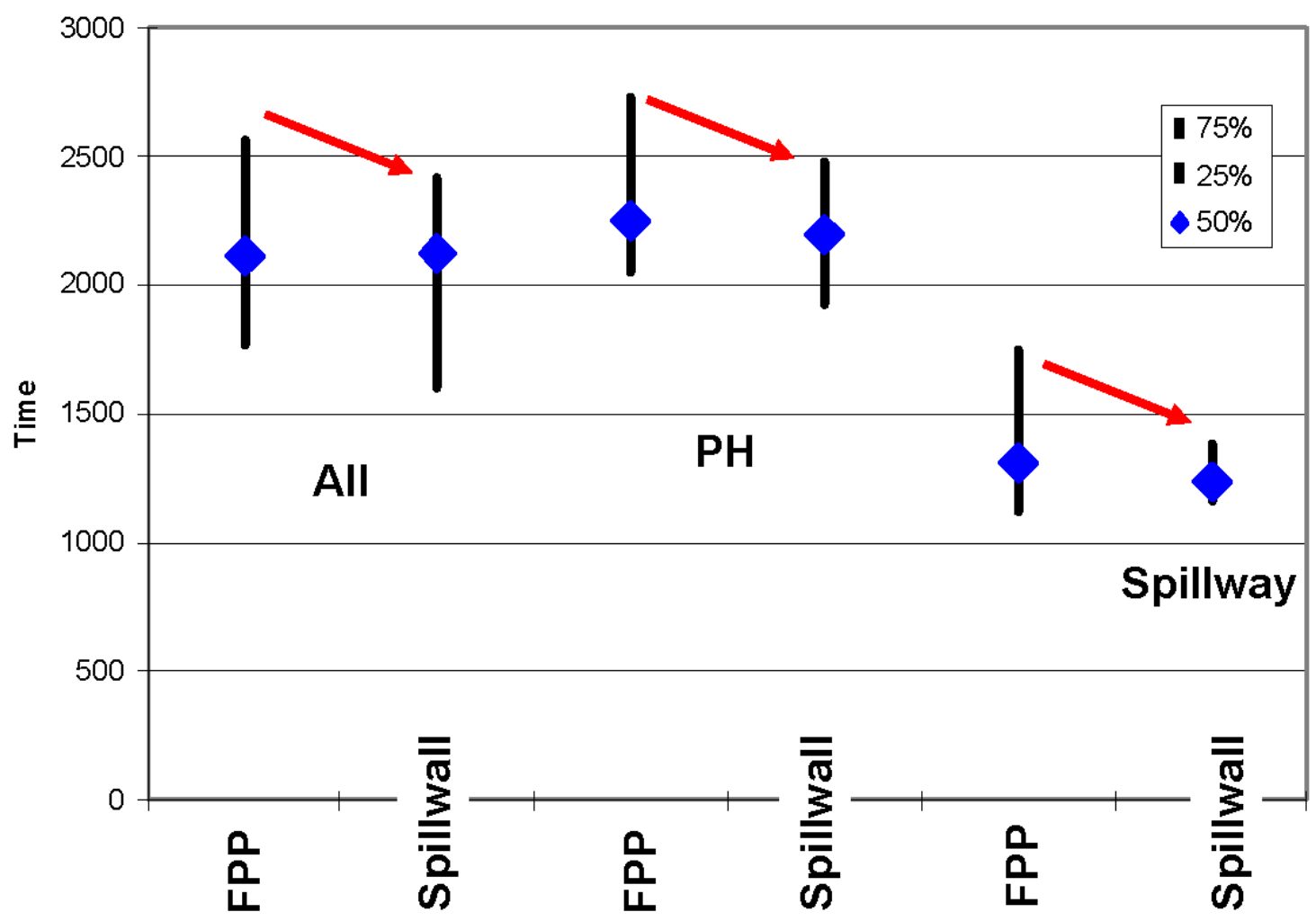

Scenario

Figure 3.28. Particle Population Gate 2 Residence Times for the FPP and Spillwall ( $250 \mathrm{kcfs,}$ $30 \%$ spill) Neutrally Buoyant Powerhouse Seeded Particle Tracks. The blue diamond shows the time for $50 \%$ of the particles to pass, the vertical black line the times for $25 \%$ and $75 \%$ of the particle population to pass. The red arrows show the decrease in time for $75 \%$ of the particle population to pass the Gate 2 location. 


\section{Spill Wall Cases: TR 125 kcfs with $30 \%$ Spill and $25 \%$ Spill}

Three simulations were run for TR $125 \mathrm{kcfs}$. The TSW case represented a baseline and current operational conditions (pers.comm., Sean Askelson, CENWP August 2009). For this baseline run, TSWs were deployed in bays 15 and 16 for this simulation (Table 2.6). The spillwall cases were run for $30 \%$ and $25 \%$ spill for flow conditions that included a pair of TSWs in spillway bays 15 and 18 . The TR $122.7 \mathrm{kcfs}, 21 \%$ spill results are also presented as they represented a similar total river for an operational pattern more consistent with the fish passage plan.

Overall flow patterns at an elevation of $155 \mathrm{ft}$ (near the water surface) are shown in Figures 3.29 to 3.31. For the baseline TSW case (Figure 3.29), there was a very large area of very low velocity or recirculating flow downstream of the powerhouse that extended across about 3/4 of the river near the end of the navigation lock wall. With the addition of a spillwall (Figure 3.30), the plan view area of very low velocities was reduced, and velocities near the Oregon shore increased. To reduce the recirculation and stagnation areas downstream of the powerhouse, a simulation with $25 \%$ spill was run. The choice of $25 \%$ spill was based on flow patterns observed in the physical model. The numerical model results show that the flow pattern at $25 \%$ spill reduced, but did not eliminate, areas of recirculation and stagnation (Figure 3.31). Additional graphics for the spillwall with $25 \%$ spill are included in Appendix C

The TR $122.7 \mathrm{kcfs}, 21 \%$ Spill operations were very different from the baseline; the spillway was loaded to the north (i.e., the spill bays nearest the Washington shore were opened), but the total river flow is similar (122 kcfs vs. $125 \mathrm{kcfs}$ ). Consequently, the flow pattern is very different with a low spill percentage $(21 \%)$. Figure 3.32 shows the general flow pattern at elevation 155 $\mathrm{ft}$. Note that the powerhouse flow near the spillway travels downstream and then turns back upstream to be entrained across the stilling basin and into the spillway jet. Although there is downstream flow near the Oregon shore, there is a large low velocity area in the center of the river downstream of the spillway and skeleton bays. 


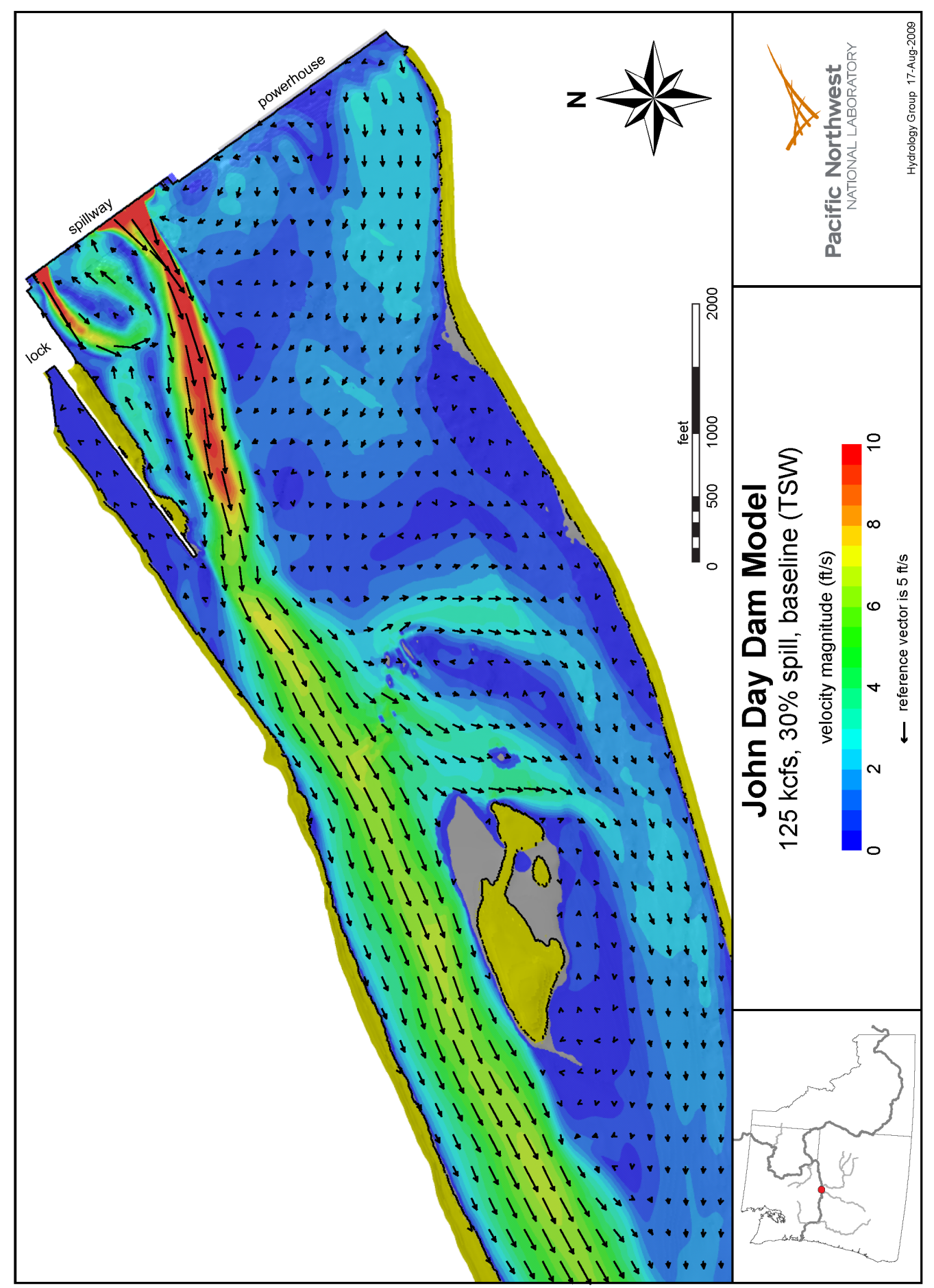

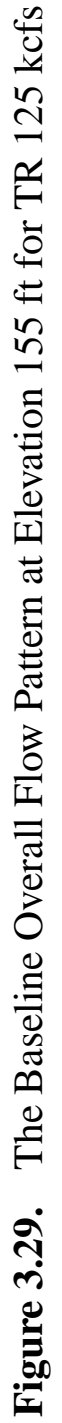




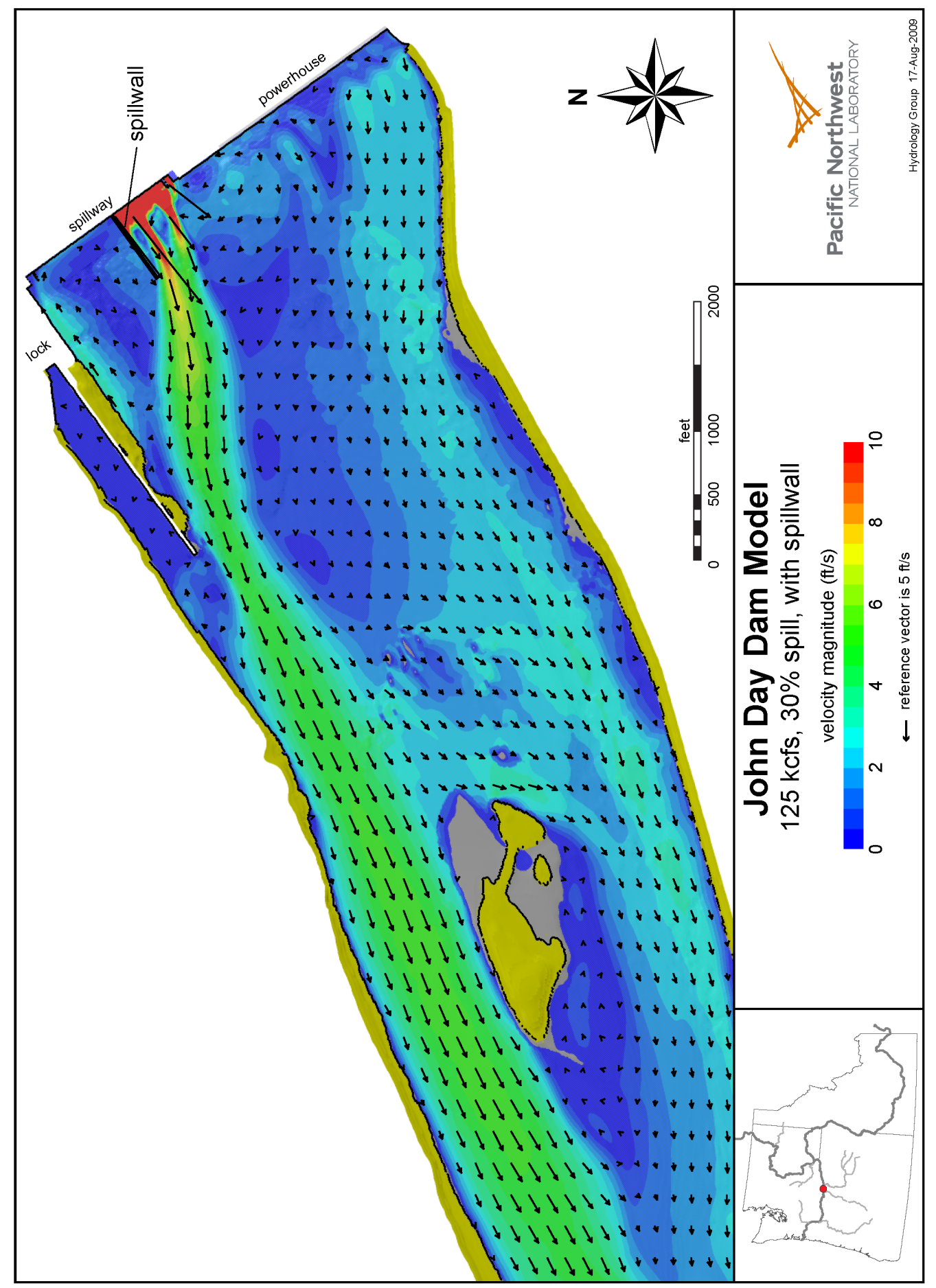

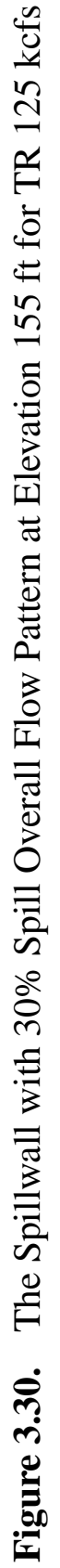




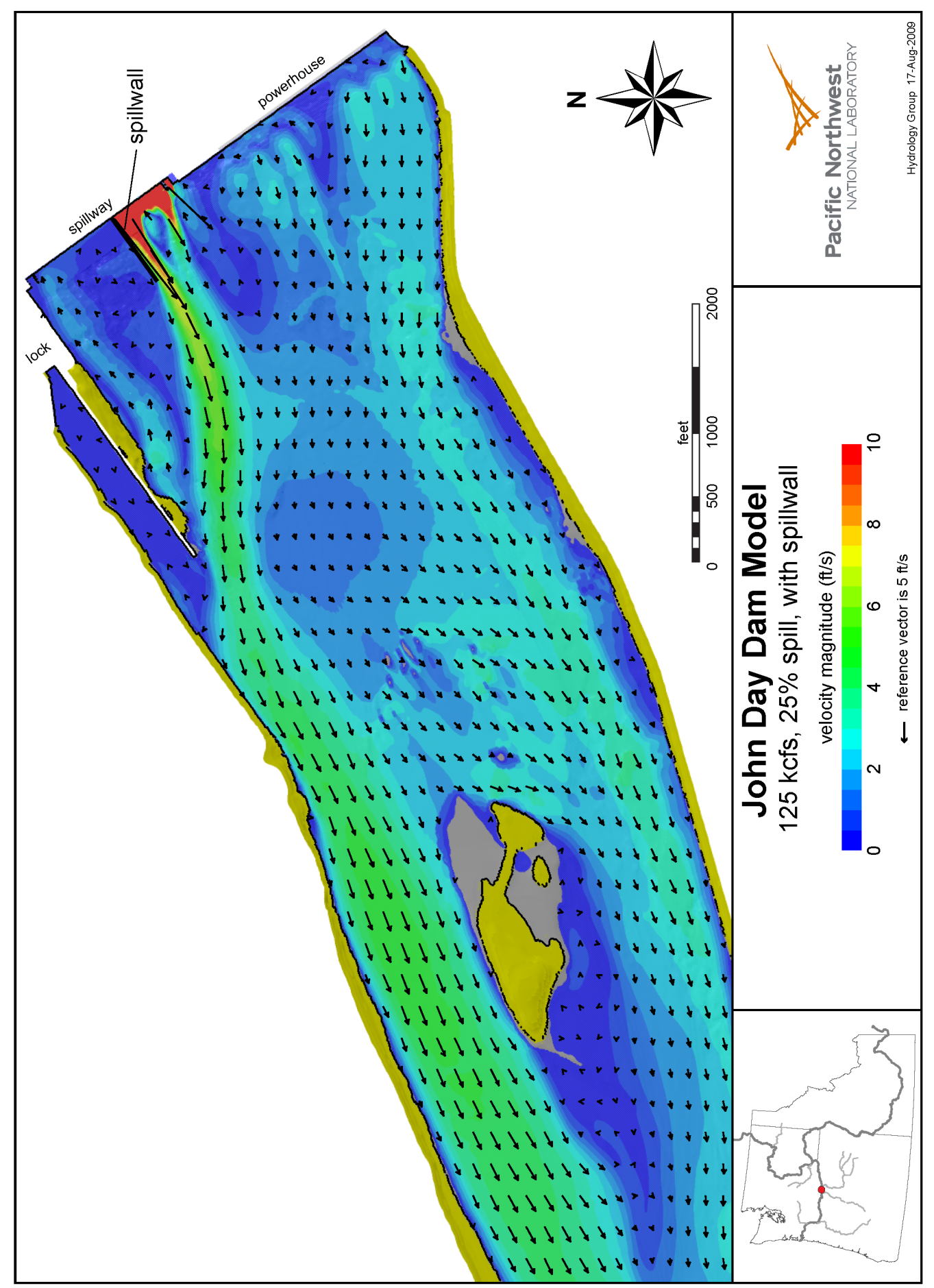

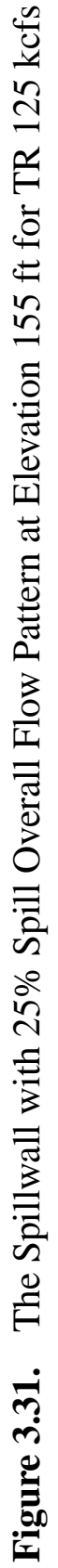




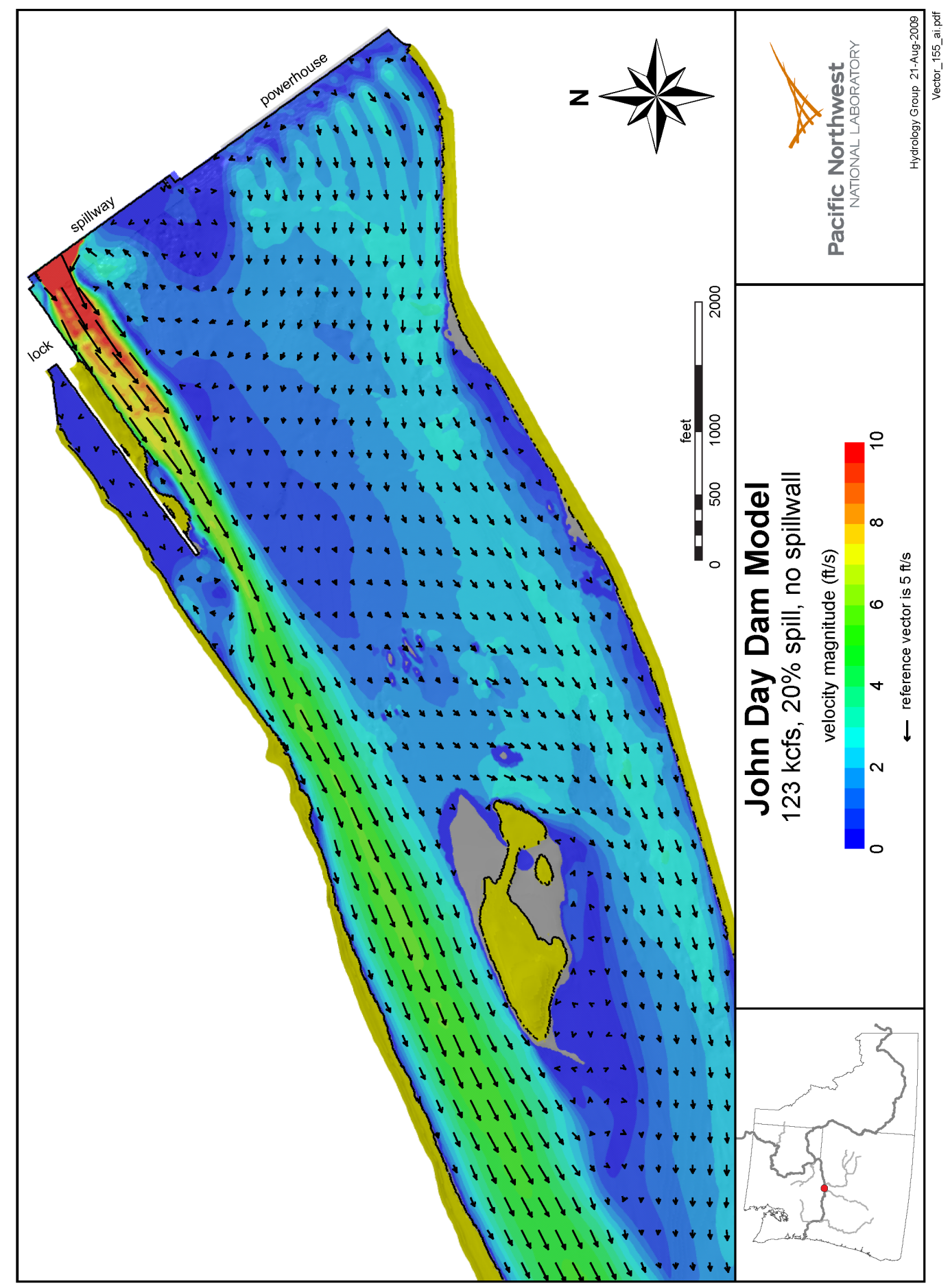

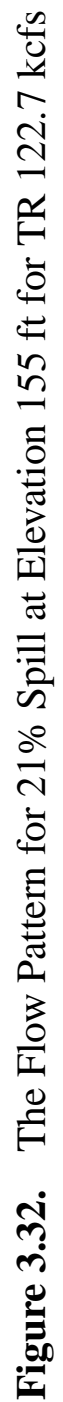


The PNNL tracking data were used in two ways for these TR $125 \mathrm{kcfs}$ scenarios. First, the simulation results for these different runs were compared for neutrally buoyant particles as was done for the $250 \mathrm{kcfs}$ case. The histograms of neutrally buoyant-particle egress times past the gates were created for comparison. Second, the particle tracker was run on the baseline results for neutrally buoyant, slightly buoyant, and more buoyant particles.

The particle tracking data were plotted on a base map, coloring the particle path by time. Figure 3.33 shows the streamlines for particles seeded in the middle of the draft tube or spillway bay. The streamlines for the baseline case show the lateral movement from powerhouse particles (and spillway entrainment for some) and their increased retention times. As before, the neutrally buoyant particles (Figure 3.34) show more spillway entrainment and complex motion than the streamlines. For the baseline case, the powerhouse particles (Figure 3.35) all move laterally, and the most efficient egress that occurred for them was by entrainment in the spillway. However, the flow paths were very convoluted with many areas of recirculation. Adding the spillwall decreased areas of recirculation downstream of the powerhouse and improved the overall downstream flow. Figure 3.36 shows that the spillway-released particles for the spillwall case were somewhat slower to pass Gate 2 than in the baseline scenario. 


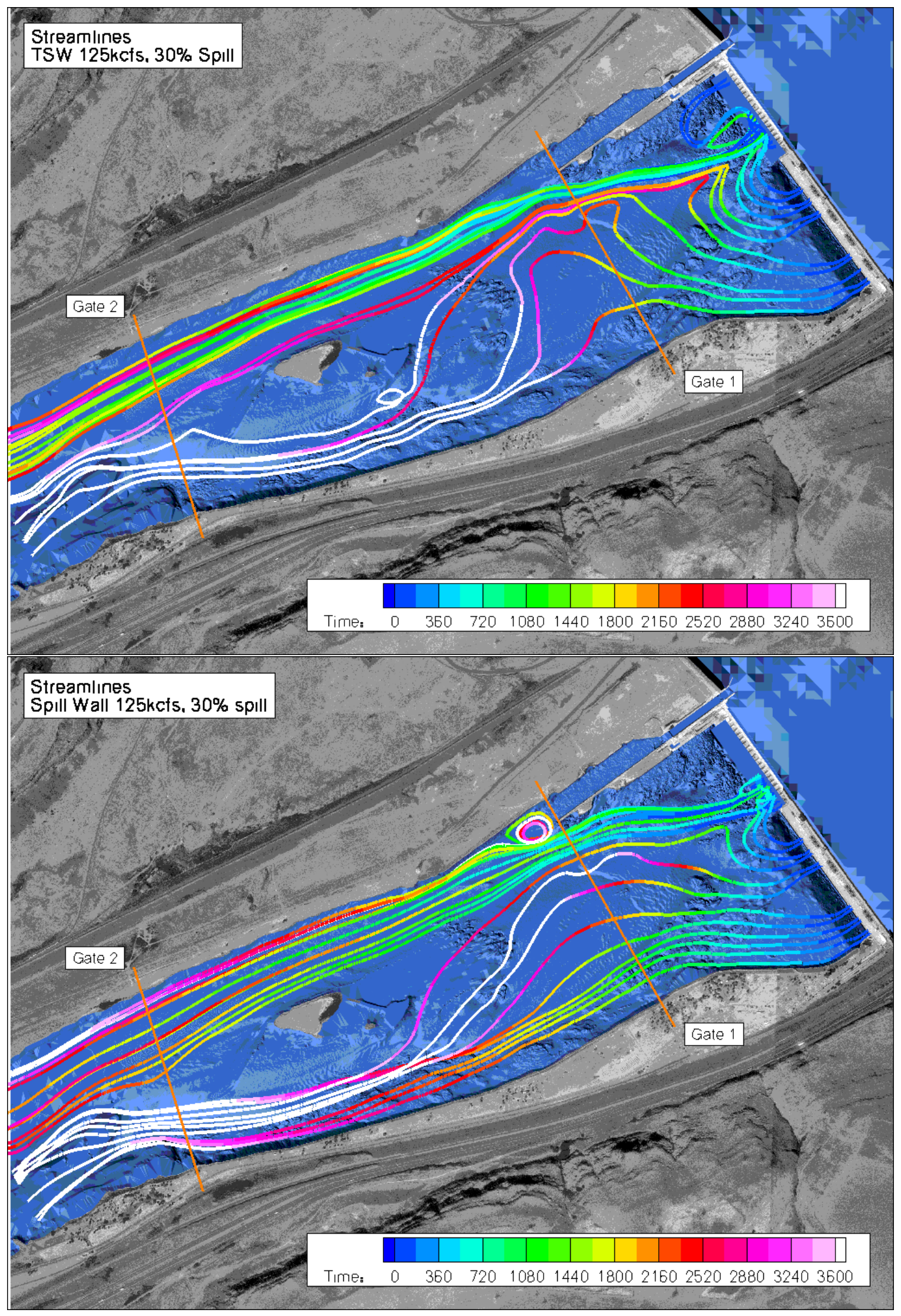

Figure 3.33. The Baseline FPP (upper) and Spillwall (lower) (125 kcfs, 30\% spill) Streamline Particle Tracks 


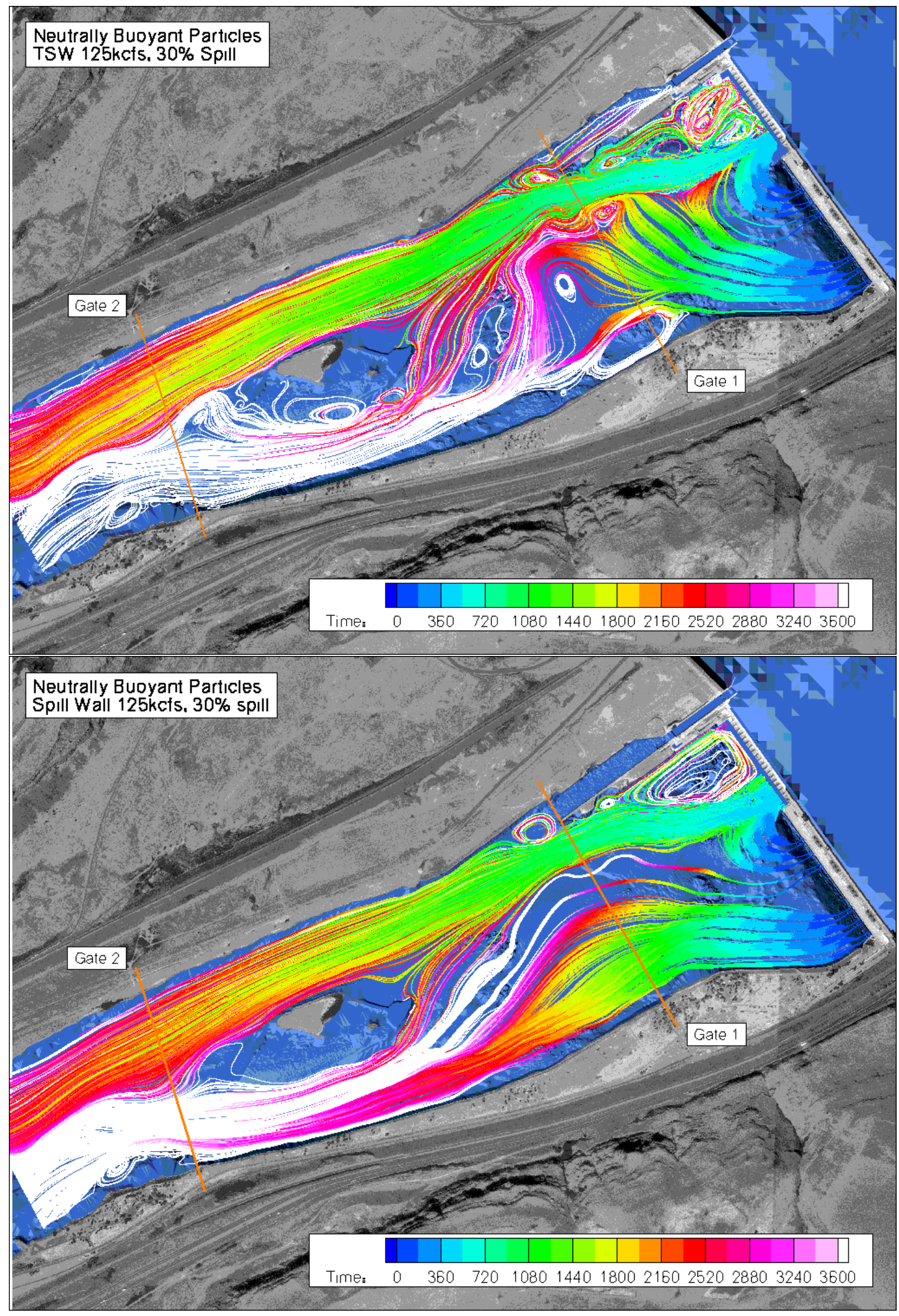

Figure 3.34. The Baseline FPP (upper) and Spillwall (lower) (125 kcfs, $30 \%$ spill) Neutrally Buoyant Particle Tracks 


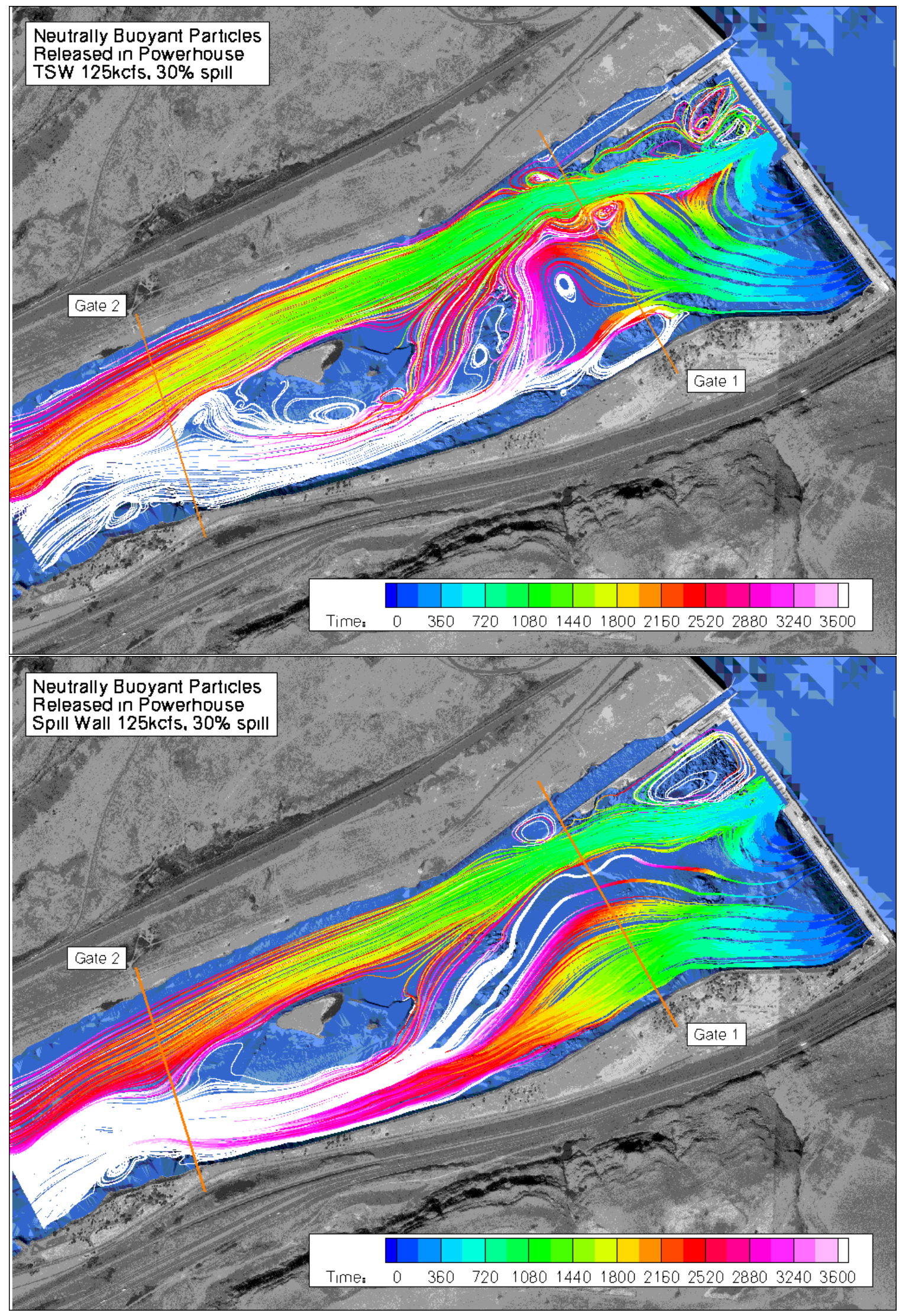

Figure 3.35. The Baseline FPP (upper) and Spillwall (lower) (125 kcfs, 30\% spill) Neutrally Buoyant Powerhouse-Seeded Particle Tracks 


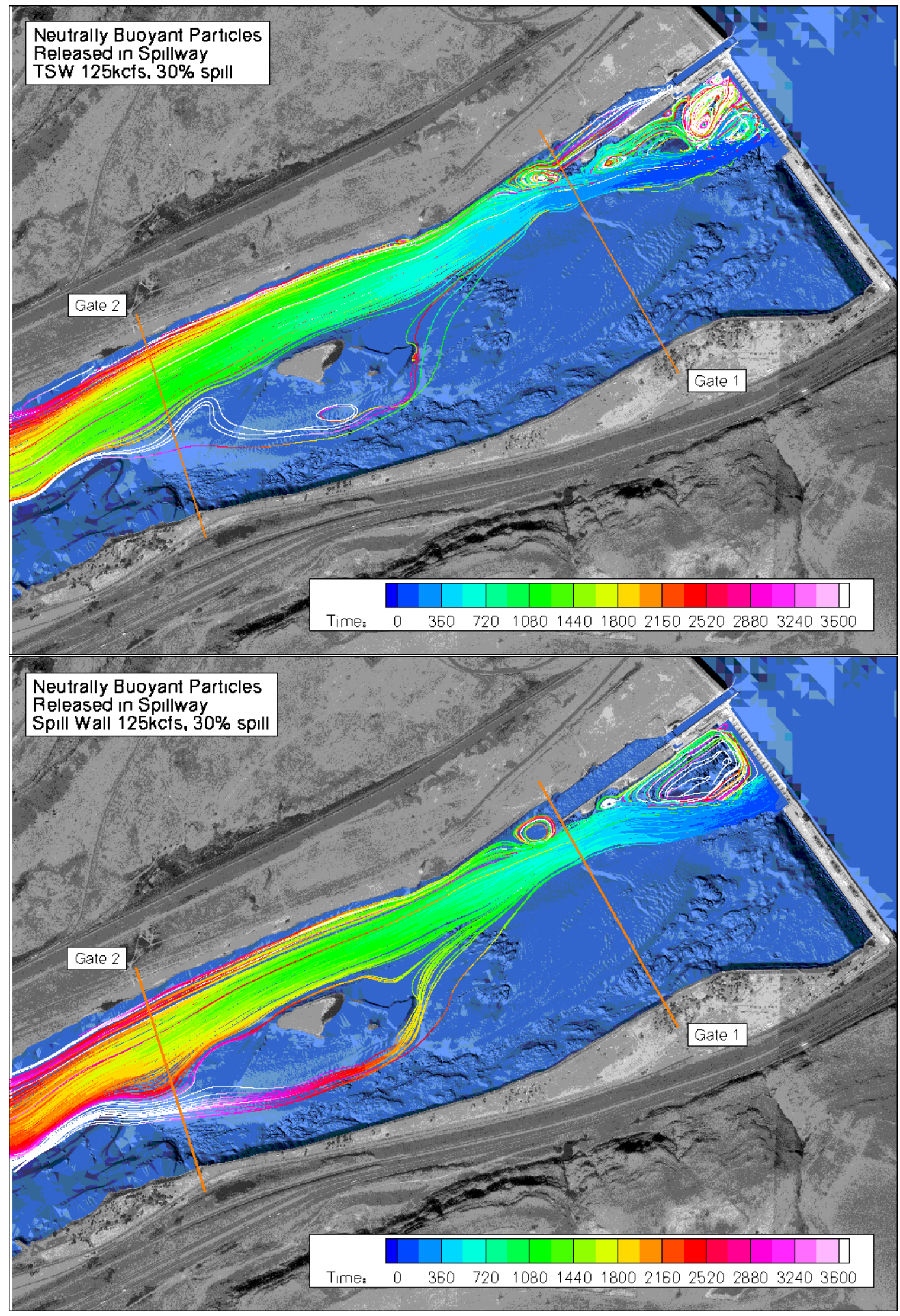

Figure 3.36. The Baseline FPP (upper) and Spillwall (lower) (125 kcfs, 30\% spill) Neutrally Buoyant Spillway-Seeded Particle Tracks 
These hydraulic differences between scenarios are reflected in the particle-tracking histograms. Figures 3.37 to 3.39 show the residence time histograms for the TR $125 \mathrm{kcfs}$ cases. The TR $122.7 \mathrm{kcfs}, 21 \%$ Spill plots are included. Note that the time scale is different than the TR 250 kcfs plots. The curves for all particles (Figure 3.37) were multimodal, with some particles rapidly passing Gate 2, but the bulk of the population took much longer.

The difference between the baseline scenario and the two spillwall scenarios was striking. The simulated median egress times were reduced in the baseline scenario relative to both spillwall and the TR $122.7 \mathrm{kcfs}, 21 \%$ Spill scenario. However, the time for $75 \%$ of the particles to pass Gate 2 was greater as many of particles took a more circuitous downstream path. This overall increase in time for $75 \%$ of the particles to pass Gate 2 is shown in Figure 3.37, right hand side. By comparing Figures 3.38 and 3.39, it is shown that the time difference was largely from the powerhouse-released particles. Figure 3.35 shows the meandering path of the baseline case relative to the spillwall cases. The comparison with the $25 \%$ spill is shown in Figure C. 3 .

To make this work relevant to improving fish passage, a critical question is whether fish movement is more similar to neutrally buoyant or to buoyant particles. There are fisheries biologists who believe that drogues and fish behave similarly (and hence we have many drogue studies at the dams). The PNNL tracker was run for the TSW baseline, $125 \mathrm{kcfs}$-case with neutrally buoyant particles and buoyant particles of $947 \mathrm{~kg} / \mathrm{m}^{3}$ and $972 \mathrm{~kg} / \mathrm{m}^{3}$. Residence time plots are presented in Figures 3.40 to 3.42 . Figure 3.40 shows the comparison for all released particles; the histograms are arranged with neutrally buoyant at the top to most buoyant at the bottom. The addition of buoyancy to the particles reduces the time to pass both gates, although the difference in buoyancy in use here $\left(947 \mathrm{~kg} / \mathrm{m}^{3}\right.$ and $\left.972 \mathrm{~kg} / \mathrm{m}^{3}\right)$ had only a small impact on particle egress time. Figures 3.42 and 3.42 show that the large change in egress time is largely from the population of powerhouse-released particles.

The difference in the powerhouse particle paths is shown in Figure 3.43 . For comparison, neutrally buoyant particles are shown in Figure 3.36. Figure 3.43 shows that the buoyant particles exit the draft tubes and remain near the powerhouse rather than moving downstream as the neutrally buoyant particles do. In three dimensions, the particles move upwards and are entrained in the backroller over the draft tube exits. This flow feature, which is also found in the prototype and the physical model, moves water across the face of the powerhouse and skeleton bays and the flow is entrained into the higher velocity spillway flows. This particle path explains the greatly reduced egress times as seen in the histograms.

Further work is needed given the very large differences in egress times resulting from including buoyancy. Consultation with fish biologists will be needed and, if appropriate data exist, data from existing studies re-evaluated with these models in mind. Although reduction of total egress time is highly desirable, it should also be viewed in light of additional factors such as pathway proximity to predator habitat. 
Gate 1
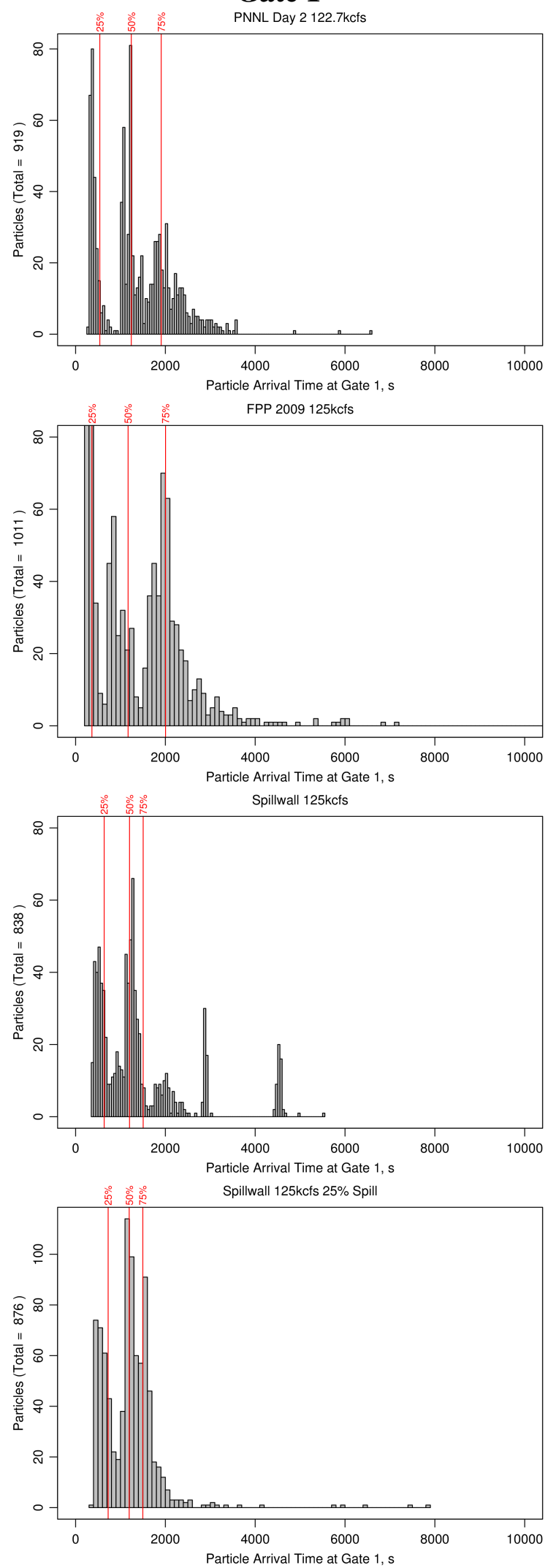

Gate 2
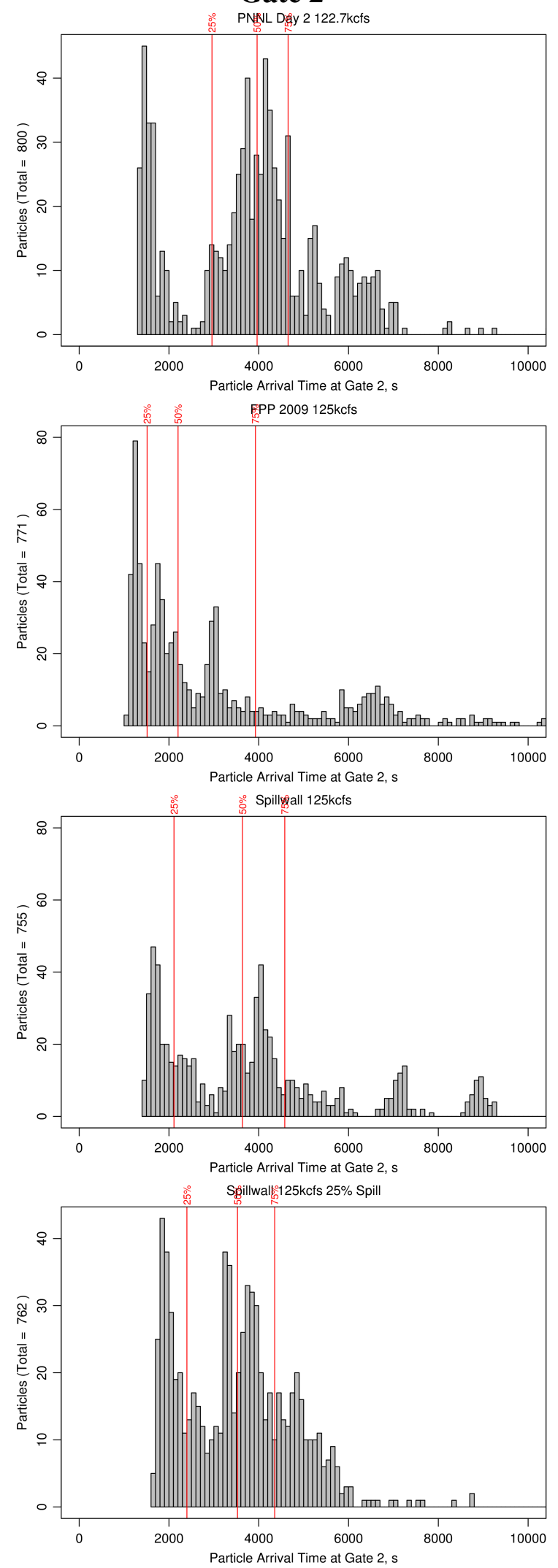

Figure 3.37. Residence Times for TR $125 \mathrm{kcfs}$. From top to bottom, TR $122.7 \mathrm{kcfs}, 21 \%$ Spill, Baseline FPP, the spillwall with $30 \%$ spill, and the spillwall with $25 \%$ spill. 
Gate 1
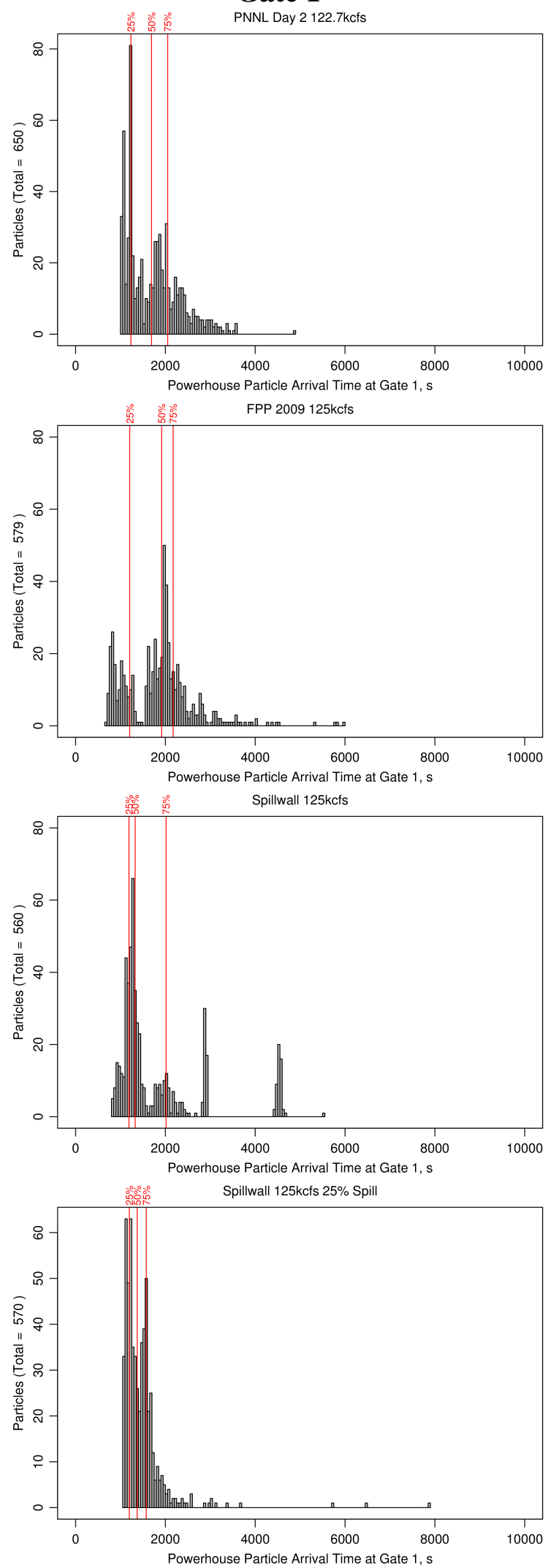

Gate 2
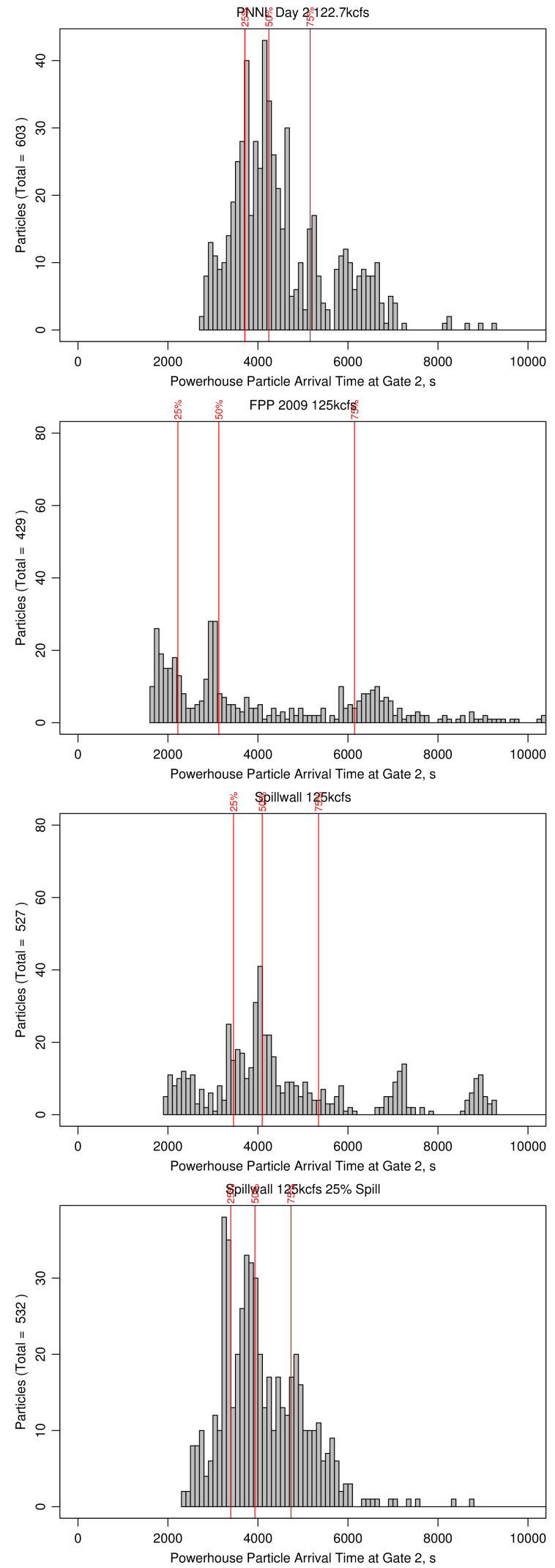

Figure 3.38. Residence Times for TR $125 \mathrm{kcfs}$, Powerhouse Particles. From top to bottom, TR $122.7 \mathrm{kcfs}, 21 \%$ Spill, Baseline FPP, the spillwall with $30 \%$ spill, and the spillwall with $25 \%$ spill. 
Gate 1
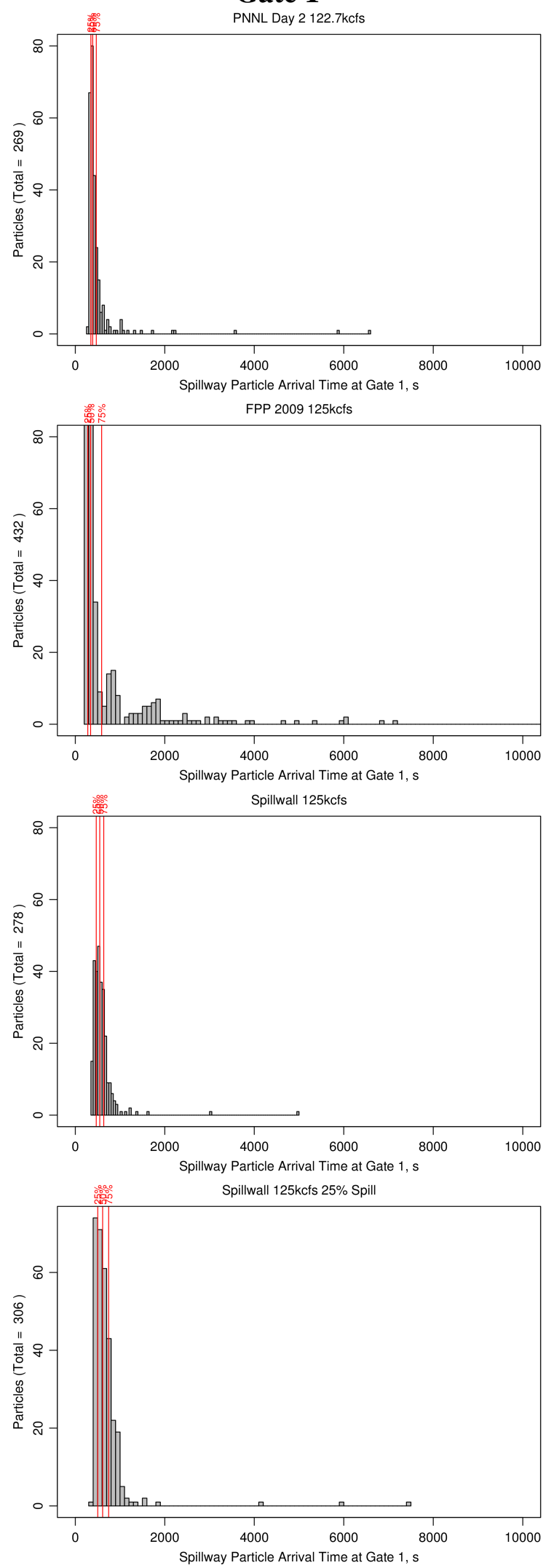

Gate 2
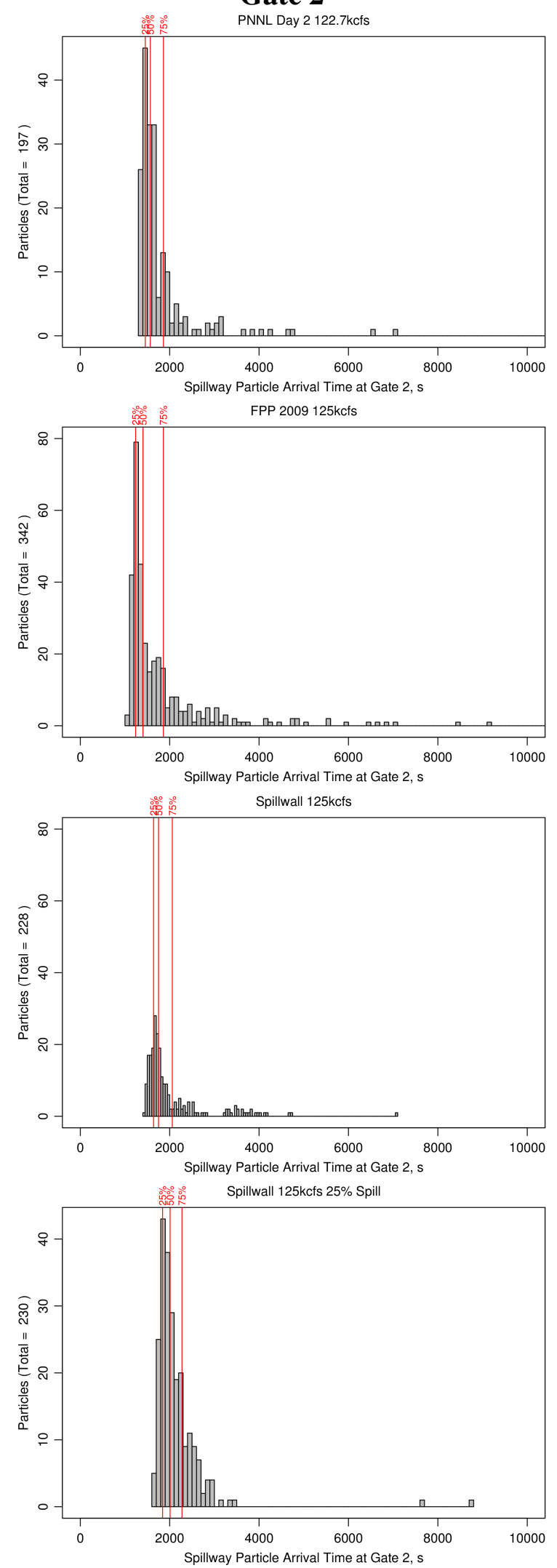

Figure 3.39. Residence Times for TR $125 \mathrm{kcfs}$, Spillway Particles. From top to bottom, TR $122.7 \mathrm{kcfs}, 21 \%$ Spill, Baseline FPP, the spillwall with $30 \%$ spill, and the spillwall with $25 \%$ spill. 
Gate 1
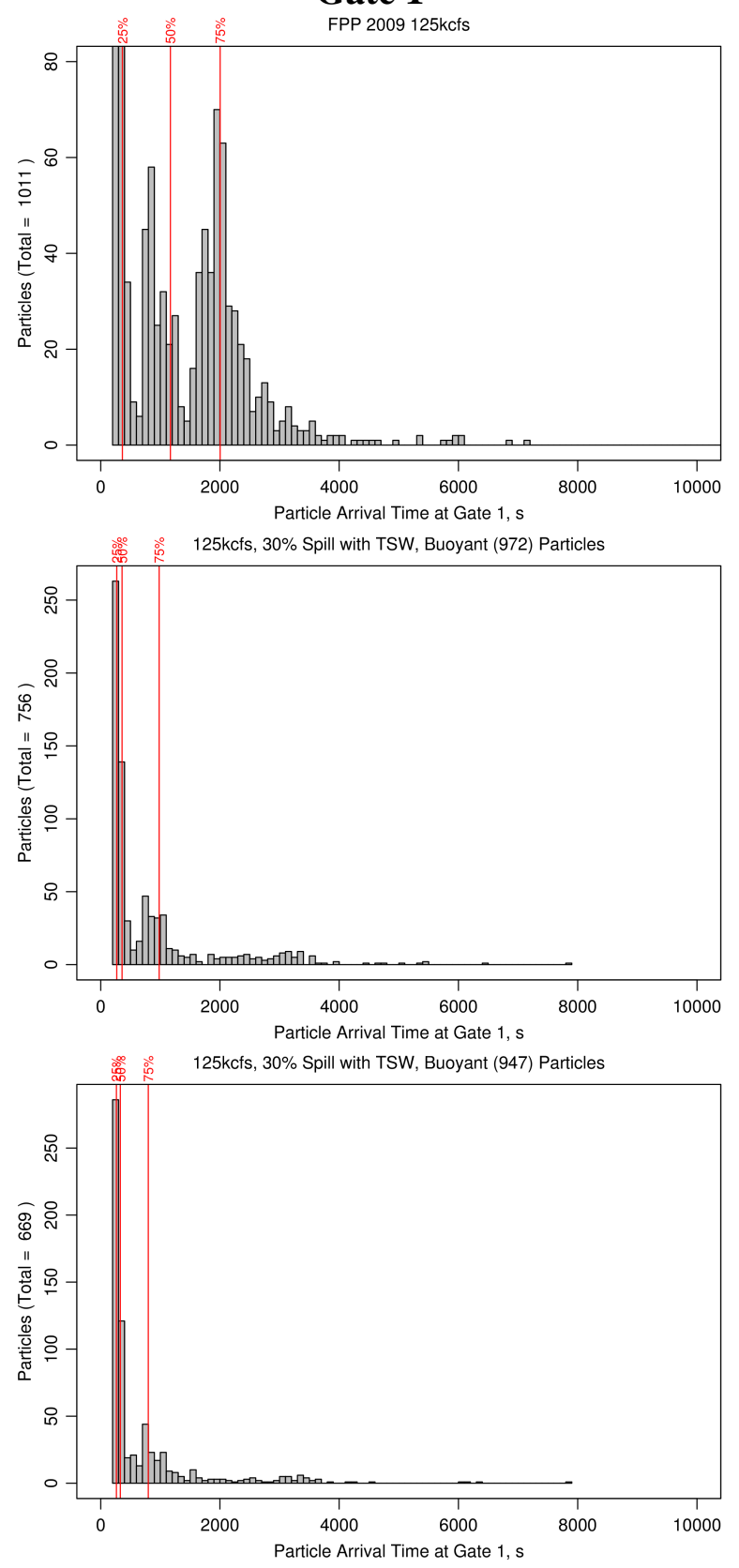

Gate 2
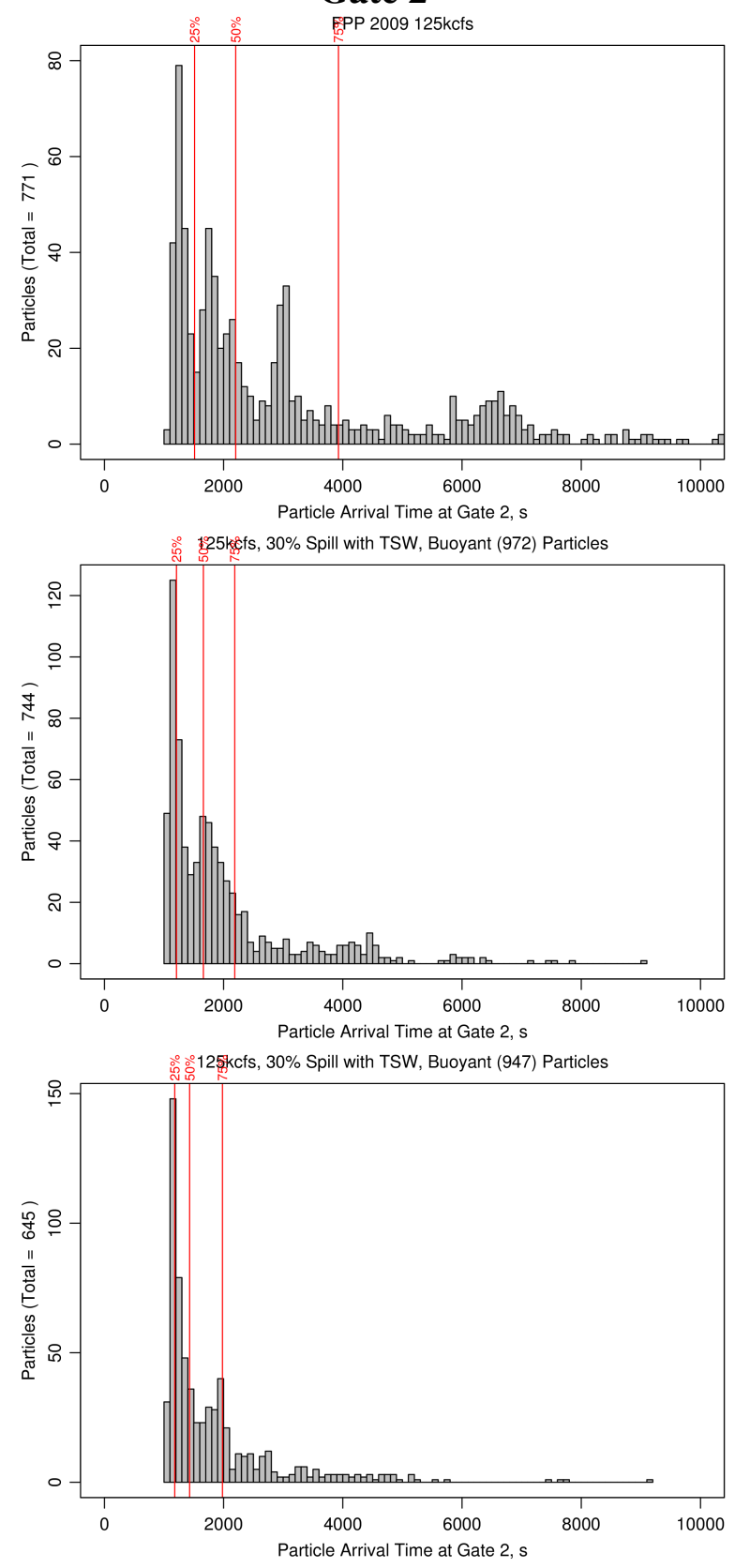

Figure 3.40. Residence Times for the Baseline FPP TR $125 \mathrm{kcfs}$, Particles of Neutral (top), 972 $\mathrm{kg} / \mathrm{m}^{3}$ (middle), and $947 \mathrm{~kg} / \mathrm{m}^{3}$ (bottom) Densities 
Gate 1
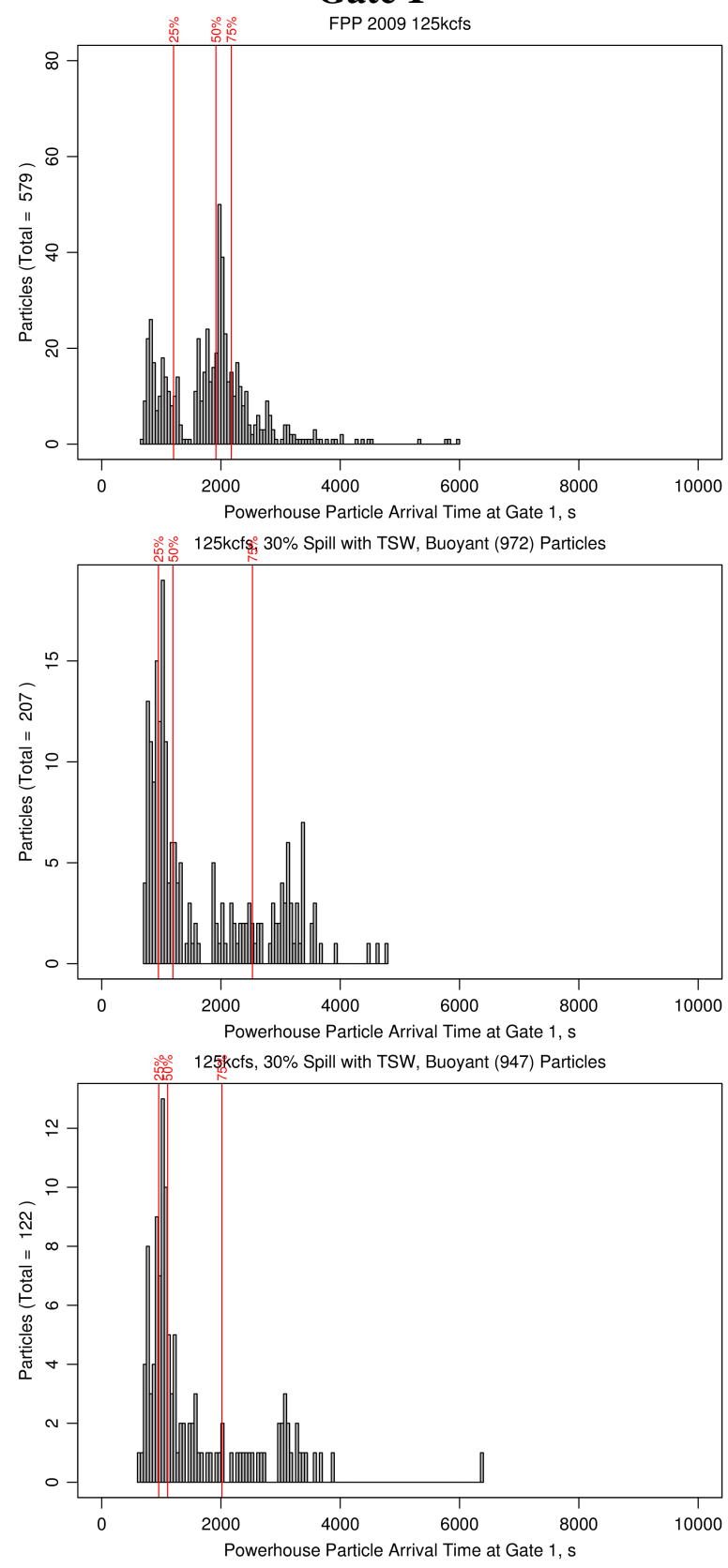

Gate 2
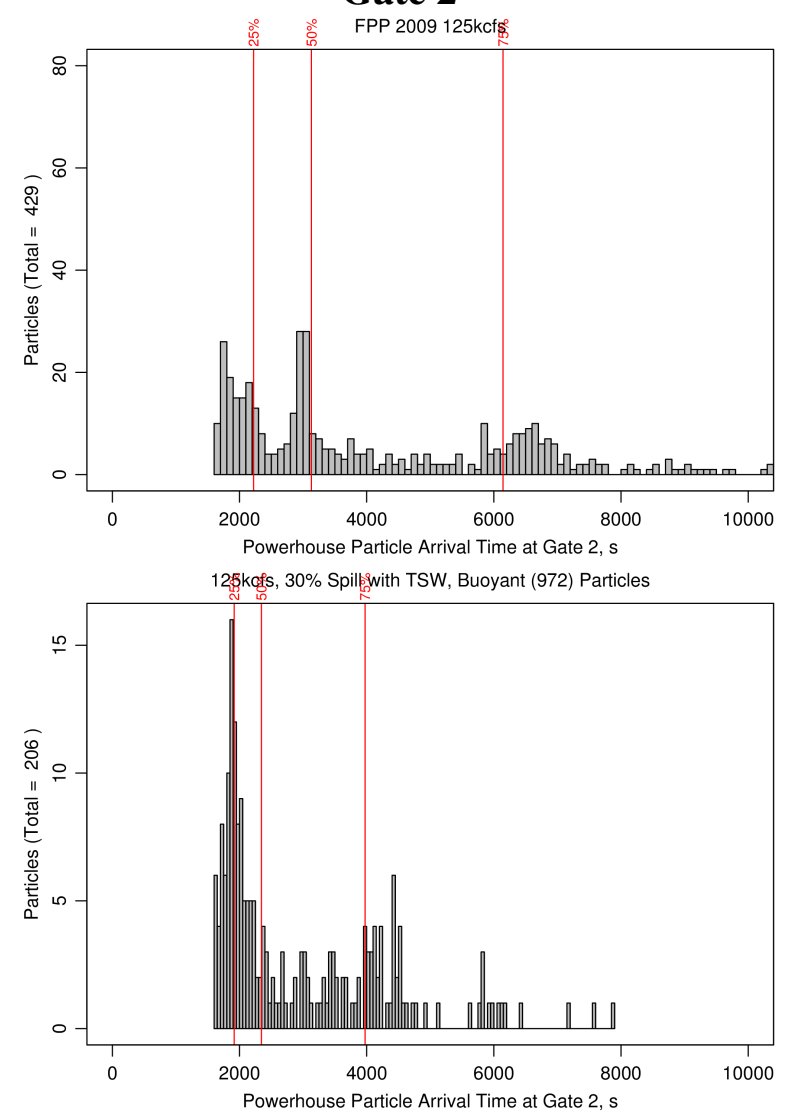

128

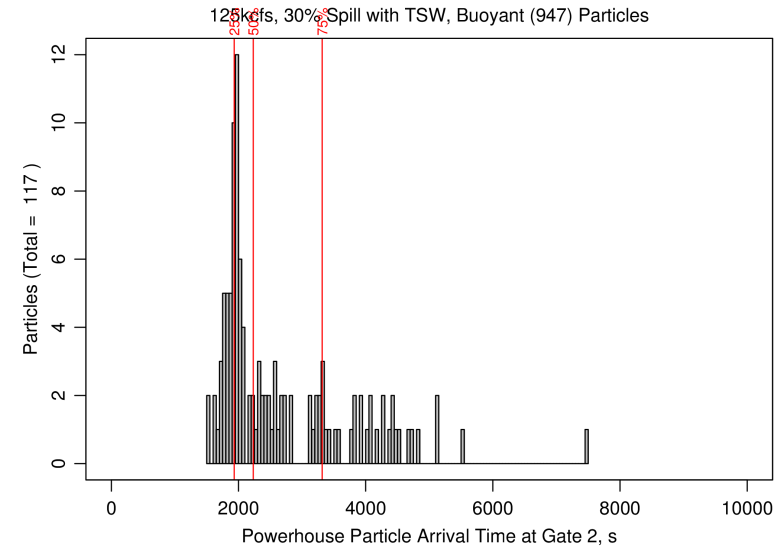

Figure 3.41. Residence Times for the Baseline FPP TR $125 \mathrm{kcfs}$, Powerhouse-Released Particles of Neutral (top), $972 \mathrm{~kg} / \mathrm{m}^{3}$ (middle), and $947 \mathrm{~kg} / \mathrm{m}^{3}$ (bottom) Densities 
Gate 1
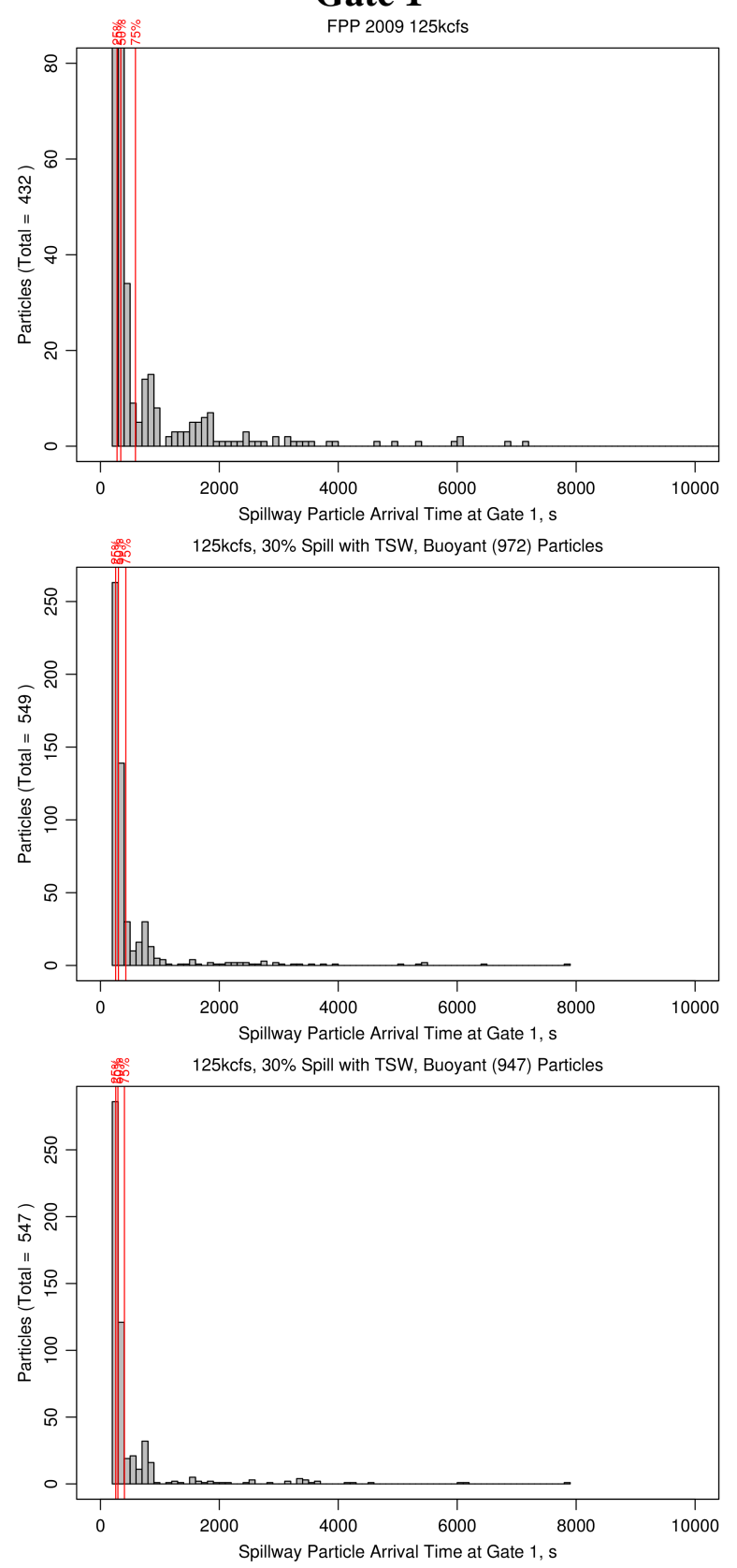

Gate 2
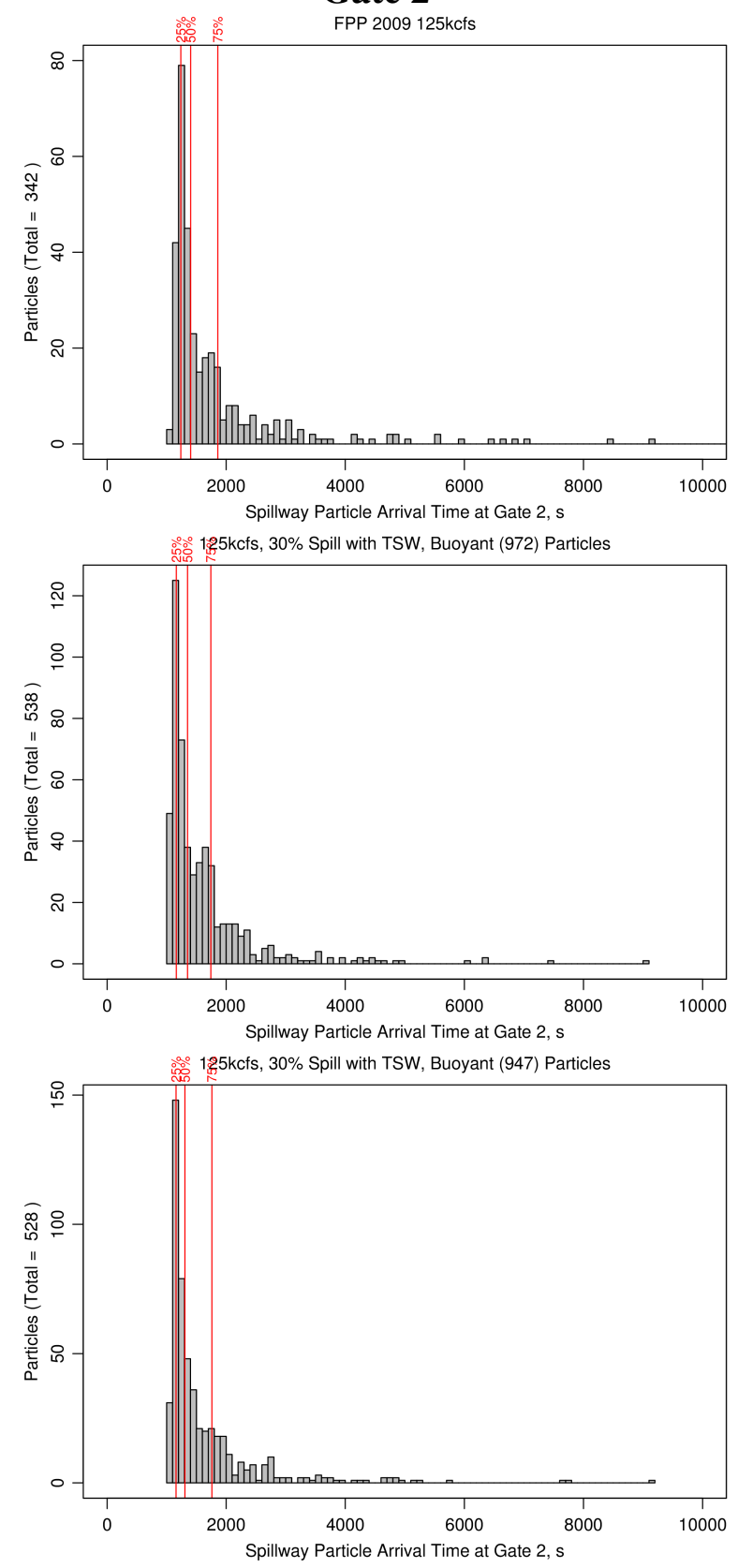

Figure 3.42. Residence times for the Baseline FPP TR $125 \mathrm{kcfs}$, Spillway-Released Particles of Neutral (top), $972 \mathrm{~kg} / \mathrm{m}^{3}$ (middle), and $947 \mathrm{~kg} / \mathrm{m}^{3}$ (bottom) Densities 


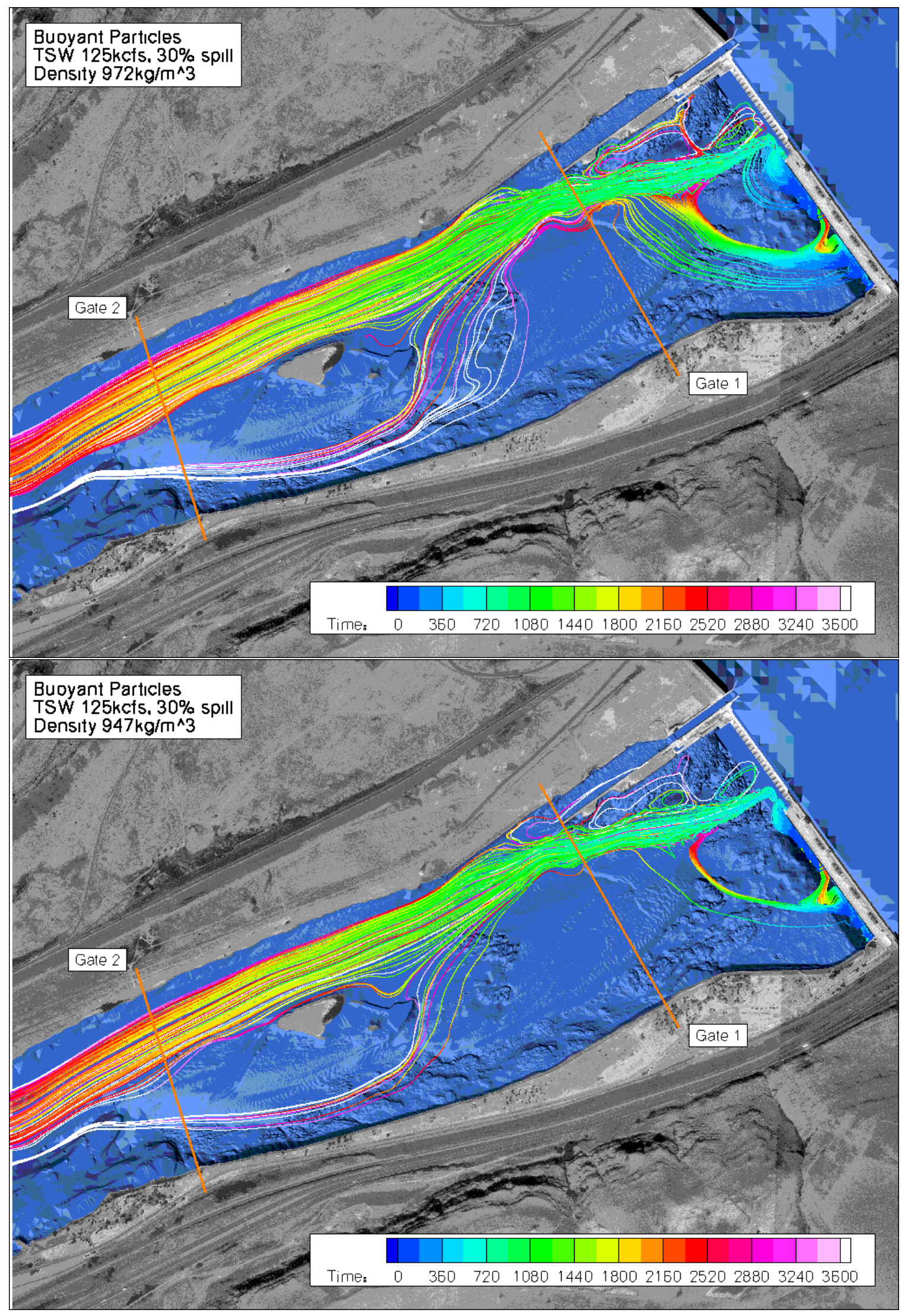

Figure 3.43. The Baseline FPP (125 kcfs, 30\% spill) Tracking Results for PowerhouseReleased Particles of Density $972 \mathrm{~kg} / \mathrm{m}^{3}$ (top), and $947 \mathrm{~kg} / \mathrm{m}^{3}$ (bottom) 
Table 3.6 and Figure 3.44 compare the changes in passage time for 25,50 , and $75 \%$ of the particles to pass Gate 2 for a TR $125 \mathrm{kcfs}$. It should be noted that equal numbers of particles were seeded at each boundary with flow. Future work could include weighting the particles by flow volumes or by the observed percentage of fish passing at each location. Weighting could result in very different distributions. For these flows, there was little difference for particles seeded in the spillway bays. Powerhouse seeded particles had an increased mean residence time (by 965 s), but a reduction in the residence time for $75 \%$ of the particles (797 s). These simulations had almost identical powerhouse operations; however, the spillway flow was distributed in 12 bays for the FPP with TSW and in 8 bays for the spillwall model run. The notable difference was the more downstream and less circuitous route taken by the powerhouse particles for the spillwall model (Figure 3.35). In both cases, particles leave the tailrace on both sides of the dredge spoils island, but it occurs more quickly for the spillwall case.

Table 3.6. TR $125 \mathrm{kcfs}$ Gate 2 Passage Times (in seconds) for 25,50 , and $75 \%$ of the Tracked Particle Populations for the FPP with the TSWs and for the Spillwall

\begin{tabular}{lcccccc}
\hline Percent & \multicolumn{2}{c}{ All } & \multicolumn{2}{c}{ Powerhouse } & \multicolumn{2}{c}{ Spillway } \\
Population & FPP w/ TSW & Spillwall & FPP w/ TSW & Spillwall & FPP w/ TSW & Spillwall \\
\hline 0.75 & 3927 & 4579 & 6144 & 5347 & 1859 & 2059 \\
0.5 & 2203 & 3637 & 3130 & 4095 & 1404 & 1750 \\
0.25 & 1512 & 2112 & 2221 & 3457 & 1238 & 1640 \\
\hline
\end{tabular}




\section{Residence Times}

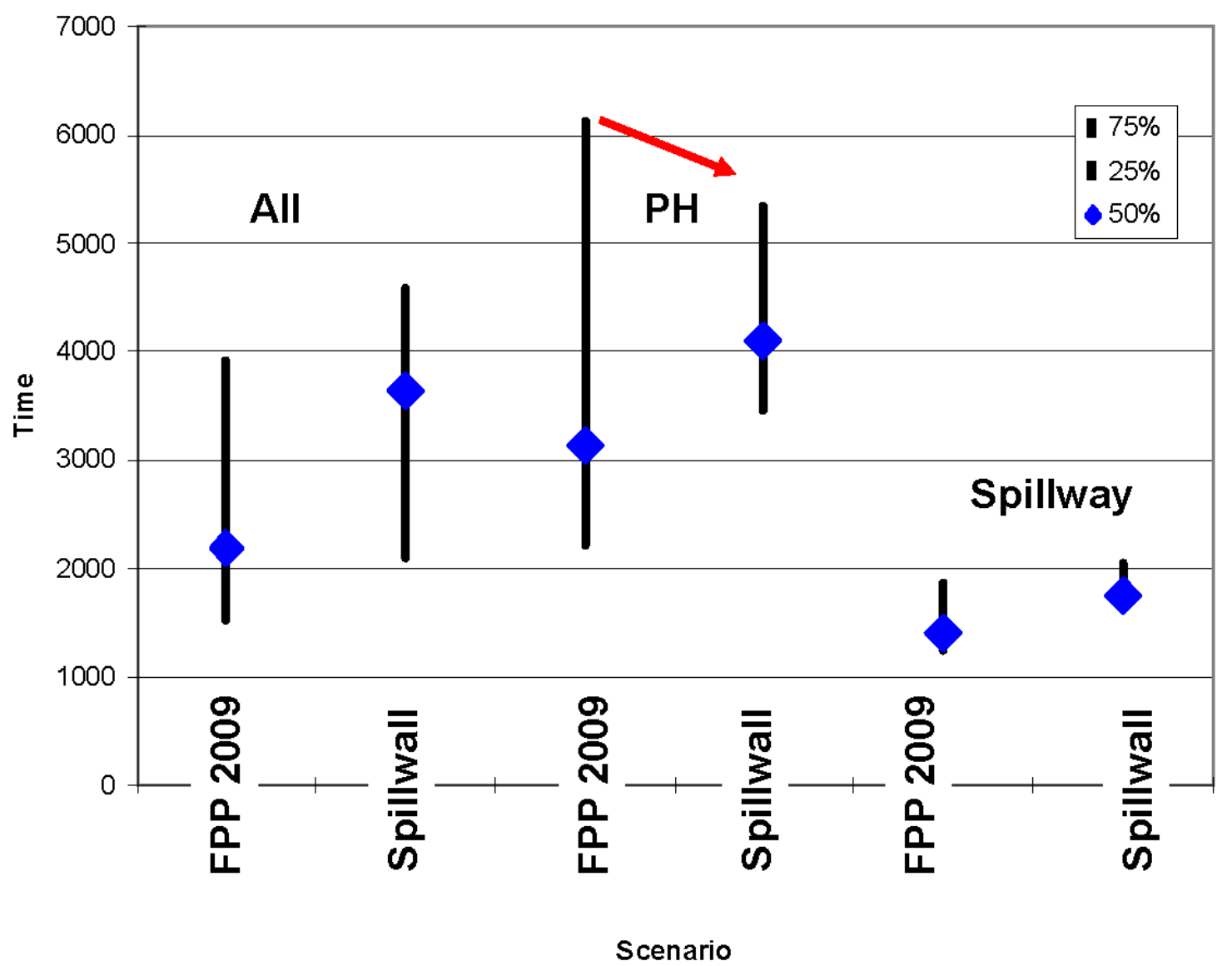

Figure 3.44. Particle Population Gate 2 Passage Times (in seconds) for the Baseline and Spillwall (125 kcfs, $30 \%$ spill) Neutrally Buoyant Particle Tracks. The blue diamond shows the time for $50 \%$ of the particles to pass, the vertical black line the times for $25 \%$ and $75 \%$ of the particle population to pass. The red arrow shows the decrease in time for $75 \%$ of the particle population to pass the Gate 2 location. 


\subsection{Conclusions}

Both 2D and 3D models were created and validated for the John Day tailrace. The 2D MASS2 model was used to assess the impacts of alternatives not near the project, such as island removal and shoreline excavation. The 2D model did not show improvement in egress conditions, characterized by area with velocities greater than $4 \mathrm{ft} / \mathrm{s}$ and depths greater than $30 \mathrm{ft}$, for either case. The 2D model under-represented lateral entrainment into the spillway jets as would be expected from a 2D model representing very 3D flows. The 2D model was deemed to be not an appropriate tool for evaluating hydraulics for alternatives located near the project.

The 3D free-surface CFD model of the John Day tailrace was developed, validated, and then used to model the tailrace hydraulics for two total river flows for multiple operational and/or structural scenarios for each total river.

The CFD results were used as inputs to the PNNL particle tracking software and the particle tracks were analyzed to determine residence times. For all tracks, the changes for spillwayreleased particles changed little with the addition of a spillwall. For TR $250 \mathrm{kcfs}$ running with the Fish Passage Plan spill pattern and a spillwall, the mean residence times for all particles were little changed; however, the tails of the distribution were truncated for both spillway and powerhouse release points, and, for the powerhouse releases, reduced the residence time for $75 \%$ of the particles to pass a downstream cross section from 45.5 minutes to 41.3 minutes. For TR 125 kcfs configured with the operations from the Fish Passage Plan for the TSWs and for a proposed spillwall, the neutrally buoyant particle tracking data showed that the river with a spillwall in place had the overall mean residence time increase; however, the residence time for $75 \%$ of the powerhouse-released particles to pass a downstream cross section was reduced from 102.4 min to 89 minutes. 



\subsection{References}

CD-adapco, Computational Dynamics Limited. 2006. CCM User Guide, STAR-CD Version 4.00. CD-adapco, http://www.cd-adapco.com.

Cook C, B Dibrani, J Serkowski, M Richmond, P Titzler, and G Dennis. 2006. Acoustic Doppler Current Profiler Measurements in the Tailrace at John Day Dam. PNNL-15627, Pacific Northwest National Laboratory, Richland, Washington. Prepared for the U.S. Army Corps of Engineers, Portland District.

ENSR and VA Tech Hydro. 2008. Computational Fluid Dynamics (CFD) Modeling of the John Day Dam Kaplan Turbine. Draft Report Contract Number W9127N-06-D-0004, Task Order No. 013, ENSR International.

Mannheim C and C Sweeney. 2003. Acoustic Doppler Current Profiler and Point Velocity Measurement Field Data Collection Lower Columbia River Projects. ENSR International. Final Report to the U.S. Army Corps of Engineers, Portland District, Oregon under Contract Number DACW57-02-D-0001.

Perkins W and M Richmond. 2004. MASS2, Modular Aquatic Simulation System in Two Dimensions, User Guide and Reference. PNNL-14820-2, Pacific Northwest National Laboratory, Richland, Washington.

Pointwise, Inc.. 2003. Gridgen User Manual, Version 15.

Rakowski C, W Perkins, M Richmond, and J Serkowski. 2008a. Determing John Day Project Tailrace and Forebay Zones Using the MASS2 Model. PNNL-SA-60840, Pacific Northwest National Laboratory, Richland, Washington. Prepared for the U.S. Army Corps of Engineers, Portland District.

Rakowski C, W Perkins, M Richmond, and J Serkowski. 2008b. Simulation of The Dalles Dam Proposed Full Length Spillwall. PNNL-17322, Pacific Northwest National Laboratory. Memorandum for Record to the U.S. Army Corps of Engineers Portland, Oregon.

Richmond M, W Perkins, and Y Chien. 2000. Numerical Model Analysis of System-wide Dissolved Gas Abatement Alternatives. PNWD-3245, Battelle-Pacific Northwest Division, Richland, Washington. Report submitted to U.S. Army Corps of Engineers, Walla Walla District.

Richmond M, C Rakowski, W Perkins, J Serkwoski, L Ebner, and S Schlenker. 2009. "Modeling Juvenile Salmon Egress Conditions in The Dalles Dam Tailrace using Computational Fluid Dynamics." In Waterpower 2009. Spokane, Washington. 



\section{Appendix A}

\section{Statistical Measures of Simulation Error}





\section{Appendix A - Statistical Measures of Simulation Error}

In the process of calibration, simulated values were compared to observed over a relatively long period. For each observed value, $Y_{o b s}$, the corresponding simulated value, $Y$, was used to compute a simulation error: $E=Y-Y_{\text {obs }}$.

Lettenmaier and Wood (1993) present a discussion of simulation error and several statistics by which simulation error can be measured. Several of these statistical measures were chosen and computed on each series of simulation errors to summarize the overall performance of the model. In the calibration/verification results (Section 3.1.1), these statistics are presented for various simulated values. This section describes how those statistics were computed and provides a general description of each. Lettenmaier and Wood (1993) divided simulation errors into systematic error and random error. Systematic error is that portion of the error that can be explained by a consistent over- or underestimation of the observed values. The remainder is random error, the source of which is more complex.

Bias is a measure of the systematic simulation error. It measures the amount the simulated value is consistently above or below the observed over the entire simulation. It is calculated as

$$
\operatorname{Bias}=\bar{Y}-\overline{Y_{o b s}}
$$

Note that this is the same as the arithmetic mean of the error series:

$$
\text { Bias }=\frac{1}{n} \sum_{i=1}^{n}\left(Y_{i}-Y_{o b s}\right)
$$

Mean absolute error (MAE) is a measure of the magnitude of simulation error, including both systematic and random error. It is computed as the mean of the absolute value of the simulation error:

$$
\mathrm{MAE}=\frac{1}{n} \sum_{i=1}^{n}\left|Y_{i}-Y_{o b s}\right|
$$

Root-mean-square error (RMS) is also a measure of the magnitude of simulation error, including both systematic and random error. The RMS error is more sensitive to large outlier errors than MAE, however. The RMS error is calculated as

$$
\mathrm{RMS}=\sqrt{\frac{1}{n}\left[\sum_{i=1}^{n}\left(Y_{i}-Y_{o b s}\right)^{2}\right]}
$$

A commonly used measure of simulation error is the linear Correlation Coefficient $\left(R^{2}\right)$. It is 
calculated as

$$
R^{2}=\left[\frac{\frac{1}{n} \sum_{i=1}^{n} Y_{i} Y_{o b s_{i}}-\overline{Y Y_{o b s}}}{\sqrt{\left(\frac{1}{n} \sum_{i=1}^{n} Y_{o b s_{i}}^{2}-\bar{Y}_{o b s}^{2}\right)\left(\frac{1}{n} \sum_{i=1}^{n} Y_{i}^{2}-\bar{Y}^{2}\right)}}\right]^{2}
$$

The $R^{2}$ value measures the relationship between the variation in simulated and observed data; it does not quantify the error. This should be used with caution, because $R^{2}$ values approach 1.0 when the simulated and observed show any strong linear relationship.

If one of the above statistics is chosen to represent the simulation error of the model, it should represent both the systematic and random error. It is important to note that these statistics do not represent, or consider, any error in the observed data. 


\section{A.1 References}

Lettenmaier DP and EF Wood. 1993. "Hydrologic Forecasting." Handbook of Hydrology, Maidment DR, ed., Ch. 26. McGraw Hill, New York. 



\section{Appendix B}

\section{Additional Validation Graphics}





\section{Appendix B - Additional Validation Graphics}

Additional validation graphics are shown in this appendix. The PNNL Day 1 is shown in the main report to show overall results; the higher flow (TR $210.1 \mathrm{kcfs}, 30 \%$ Spill) and lower flow (TR $122.7 \mathrm{kcfs}, 21 \%$ Spill) are shown in this appendix for completeness.

The TR $210.1 \mathrm{kcfs}, 30 \%$ Spill case had the higher total river flow, higher spill percentage measurement (Figure B.1). The TR $122.7 \mathrm{kcfs}, 21 \%$ Spill had the lowest total river flow and middle spill percentage (Figure B.2). These graphics have vectors from the transecting measurements and a depth-averaged velocity vector from the CFD model at the same locations and the onstation points. Although the field data are much noisier than the CFD data (especially for the transecting data), the CFD data show the same patterns of flow and velocity magnitude. The general pattern of lateral entrainment of the powerhouse flow into the stilling basin is reproduced, and the streamlines seeded above the draft tube outlets show a very 3D behavior with the near-surface water moving across the face of the powerhouse and skeleton bays and then being entrained into the spillway flows.

The goodness of the simulation results were quantified in 1 to 1 plots for transecting and onstation measurements. The 1 to 1 plots for the transecting ADCP data for both the long and short model domain are shown in Figures B.4 and B.3. These figures show a lower $\mathrm{R}^{2}$ than the TR $151.7 \mathrm{kcfs}, 10 \%$ Spill; however, they show that truncating the extent of the model made no difference. The lower $\mathrm{R}^{2}$ was expected as the depth-averaged vectors from the ADCP transecting data (Figures B.1) were 1) depth averaged and 2) very noisy. 


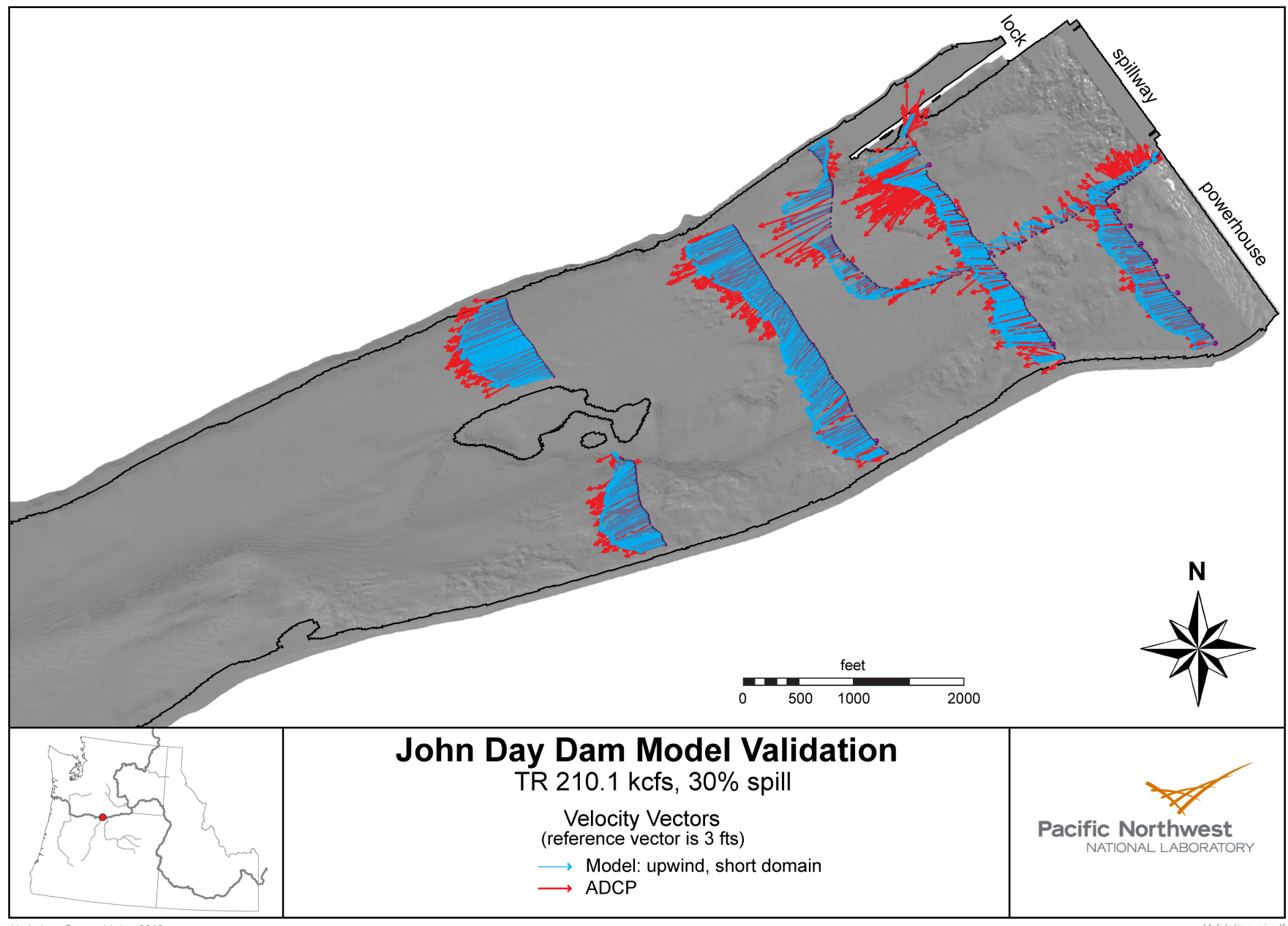

Figure B.1. Comparison of UD Simulation and ENSR Field Measurements of Velocity. Field conditions were very difficult on the day these measurements were made. 


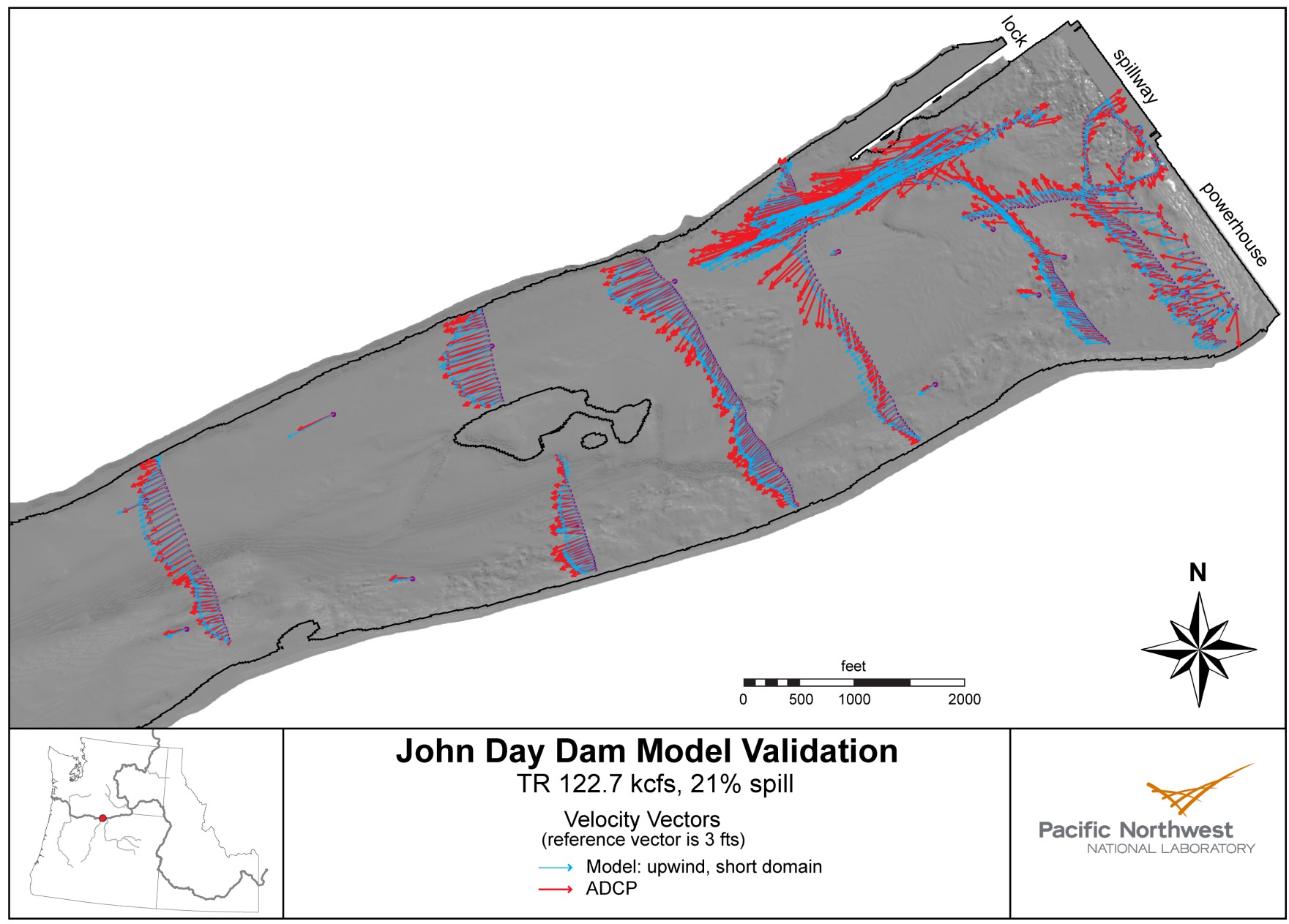

Figure B.2. Comparison of UD Simulation and TR $122.7 \mathrm{kcfs}, 21 \%$ Spill Field Measurements of Velocity 


\section{Short Model}
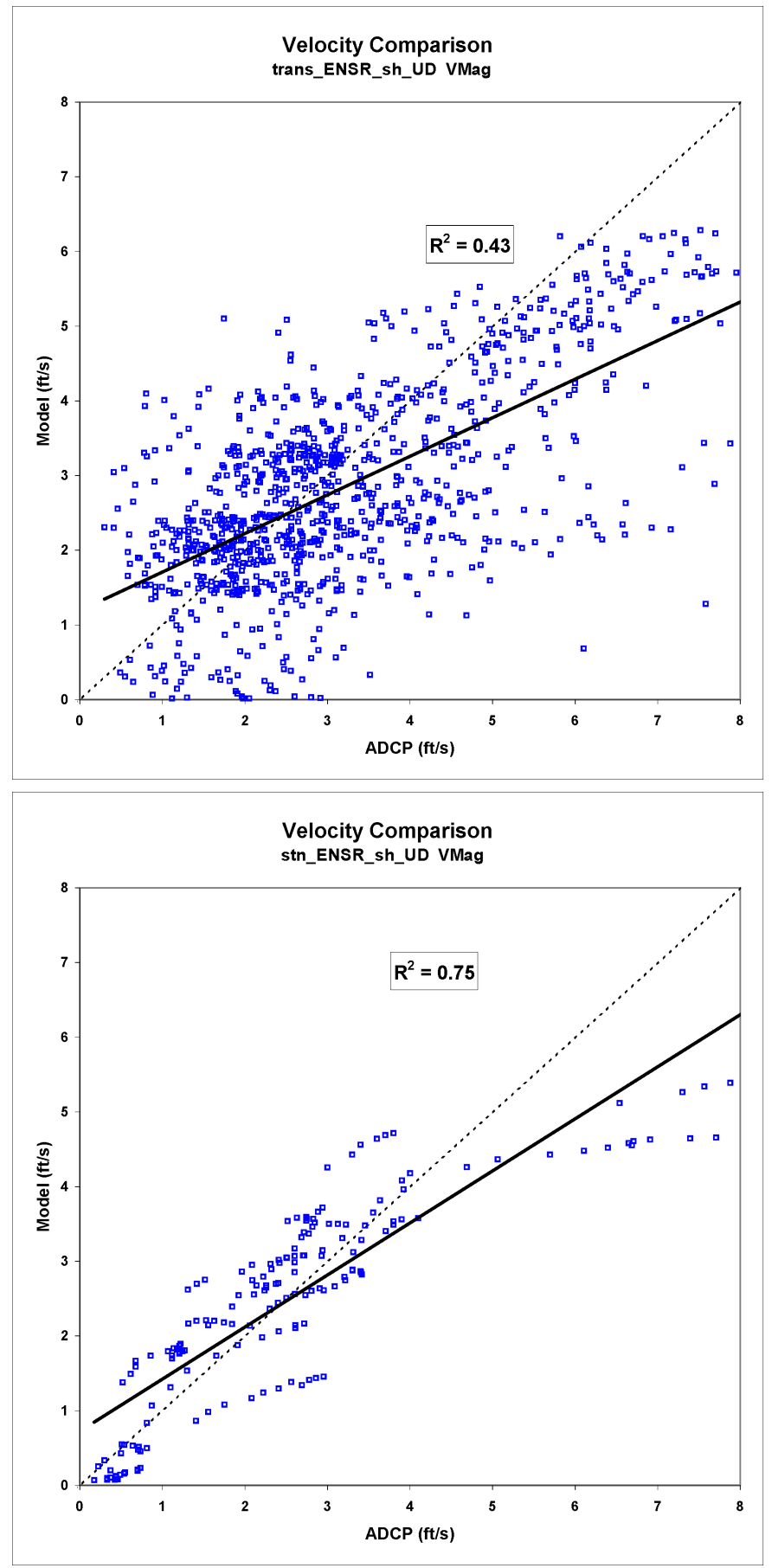

\section{Long Model}
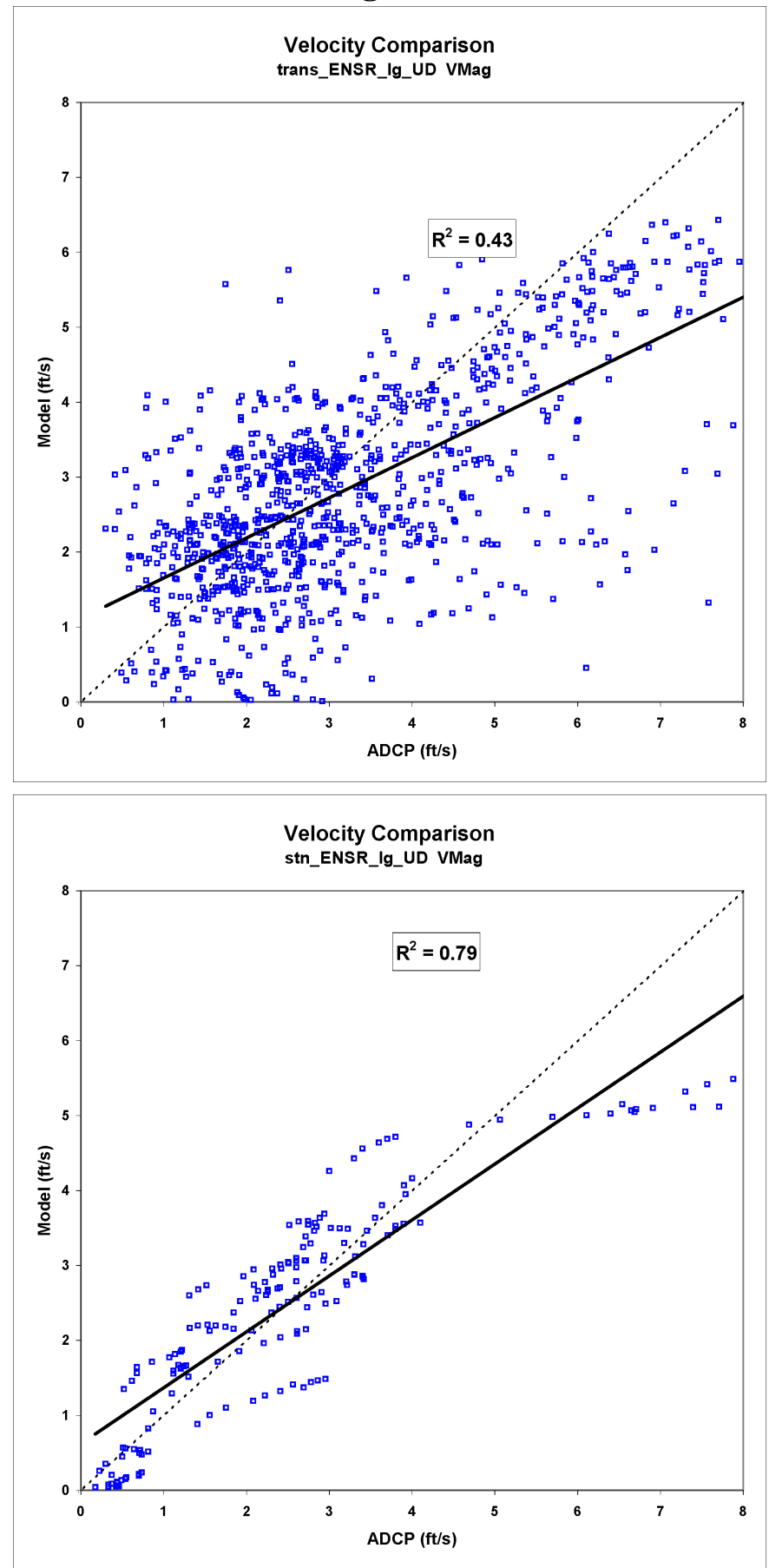

Figure B.3. Validation 1 to 1 Plots for the TR $210.1 \mathrm{kcfs}, 30 \%$ Spill Transecting (top) and OnStation Measurements (bottom). Field conditions were very difficult on the day these measurements were made. 


\section{Short Model}
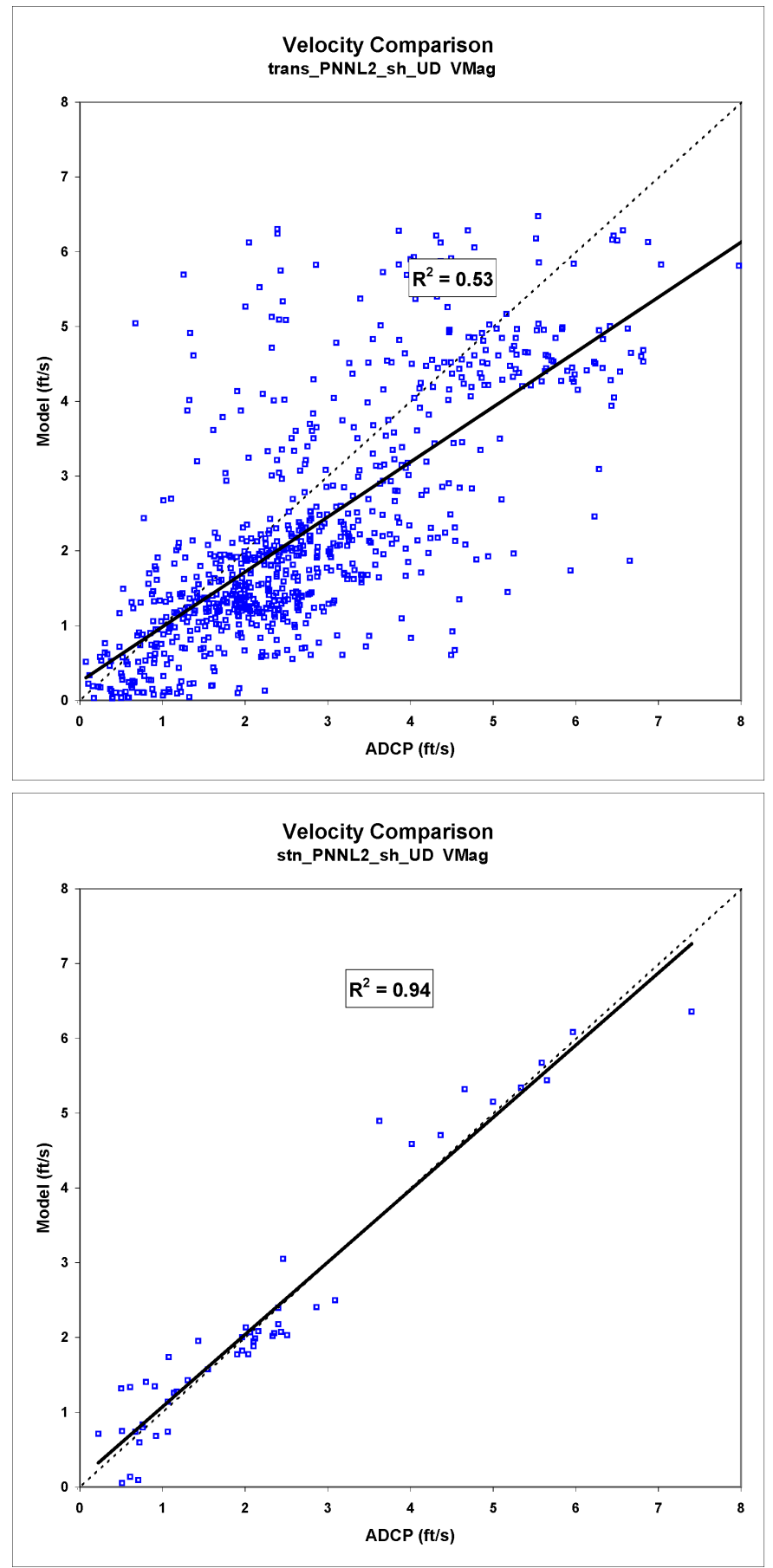

\section{Long Model}
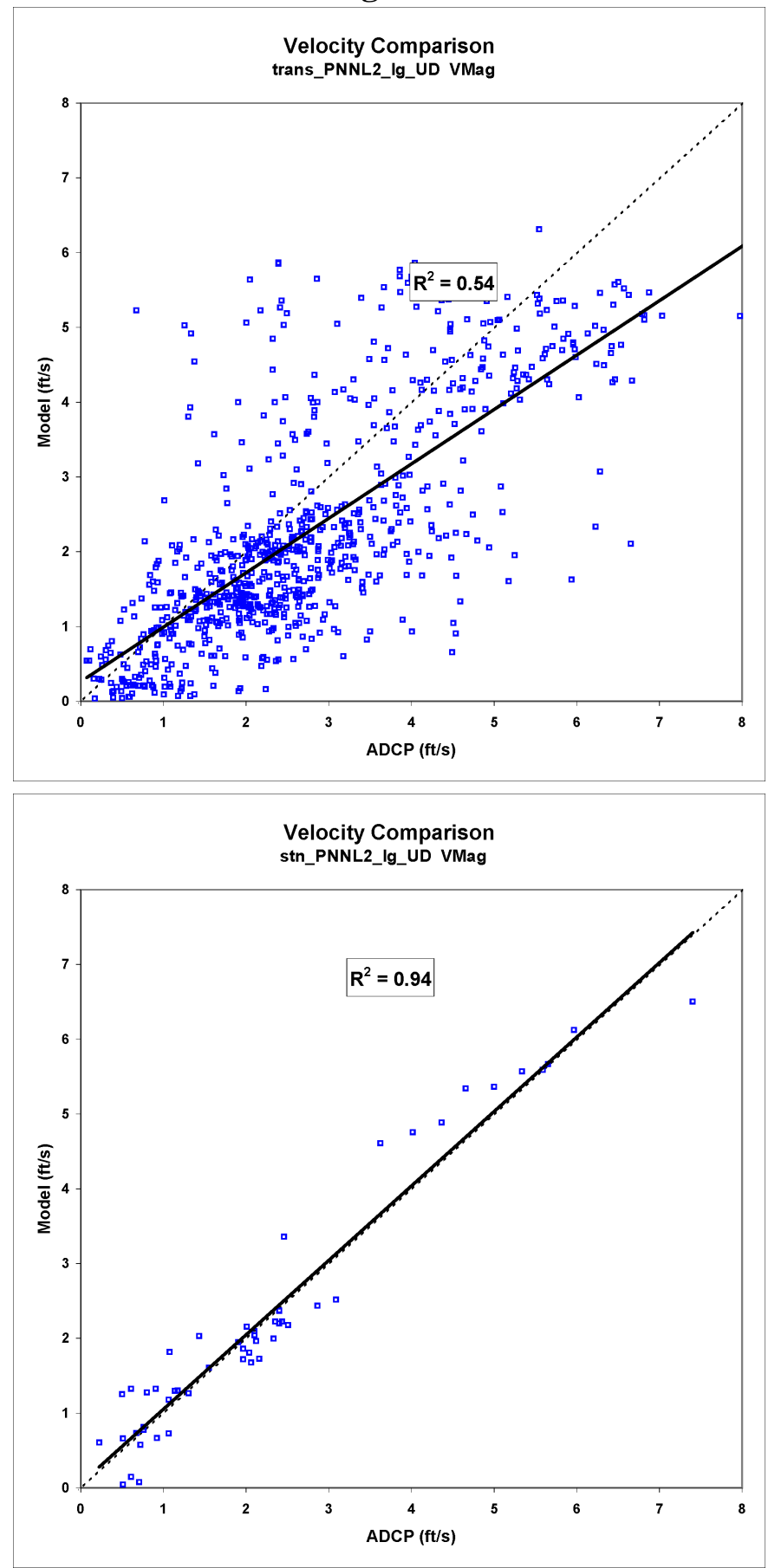

Figure B.4. Validation 1 to 1 Plots for the TR $122.7 \mathrm{kcfs}$, 21\% Spill Transecting (top) and On-Station Measurements (bottom) 



\section{Appendix C}

\section{Additional Results Graphics}





\section{Appendix C - Additional Results Graphics}

\section{C.1 Tracking Results: 125 kcfs Total River, 25\% Spill}

Although 25\% spill is not considered a viable option by fisheries biologists for reasons of forebay attraction concerns, the scenario was run for the spillwall case for comparison to general patterns seen in the physical model and for comparison to the $30 \%$ spill case.

The additional flow through the powerhouse reduces the areas of stagnant and recirculating flow downstream of the powerhouse and consequently reduces egress times for powerhousereleased neutrally buoyant particles (Figures C.1 to C.4). The $25 \%$ spill case is an incremental improvement of the $30 \%$ spill. 


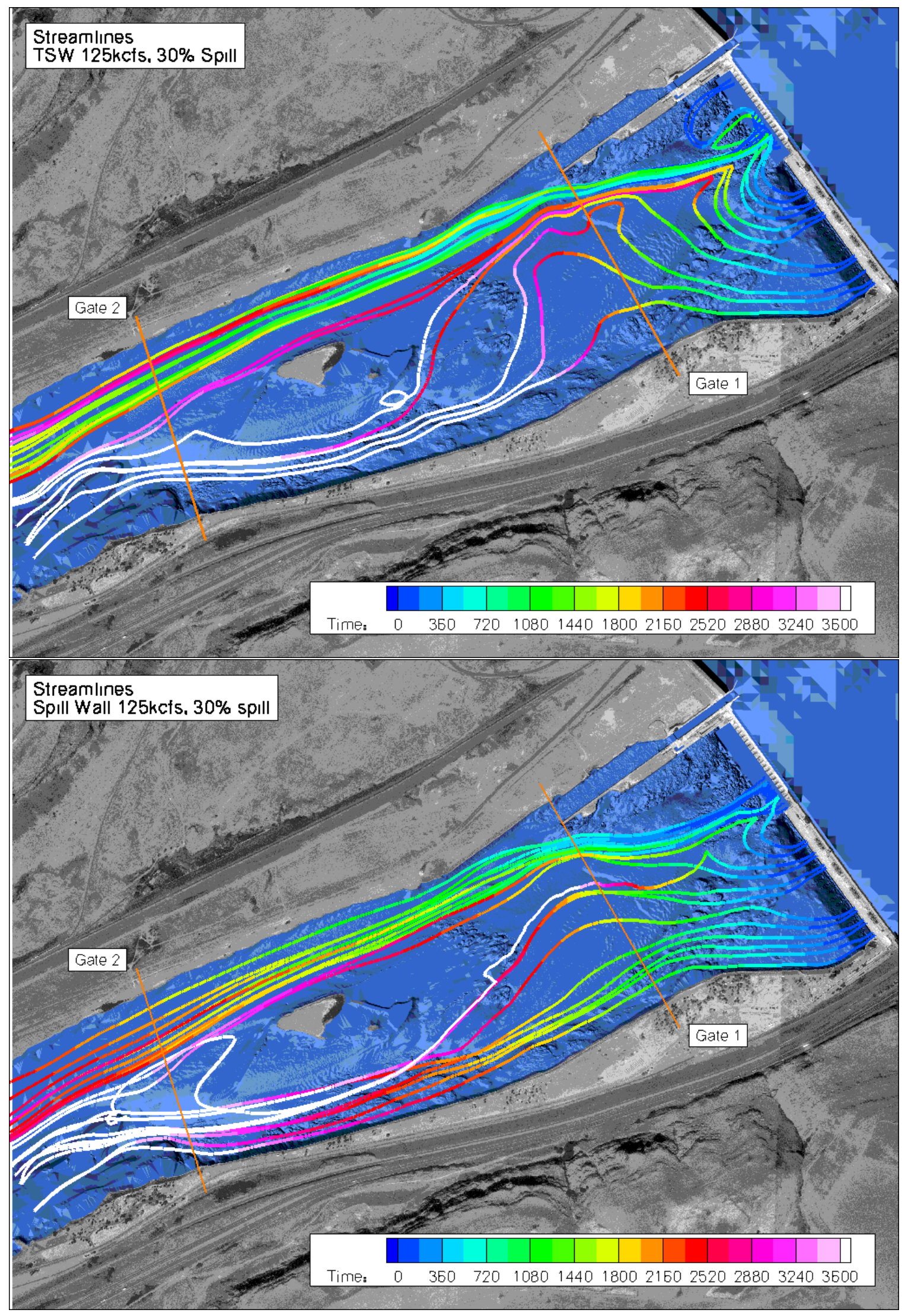

Figure C.1. The Baseline (30\% spill) and Spillwall (25\% spill) TR $125 \mathrm{kcfs}$ Streamline Particle Tracks 


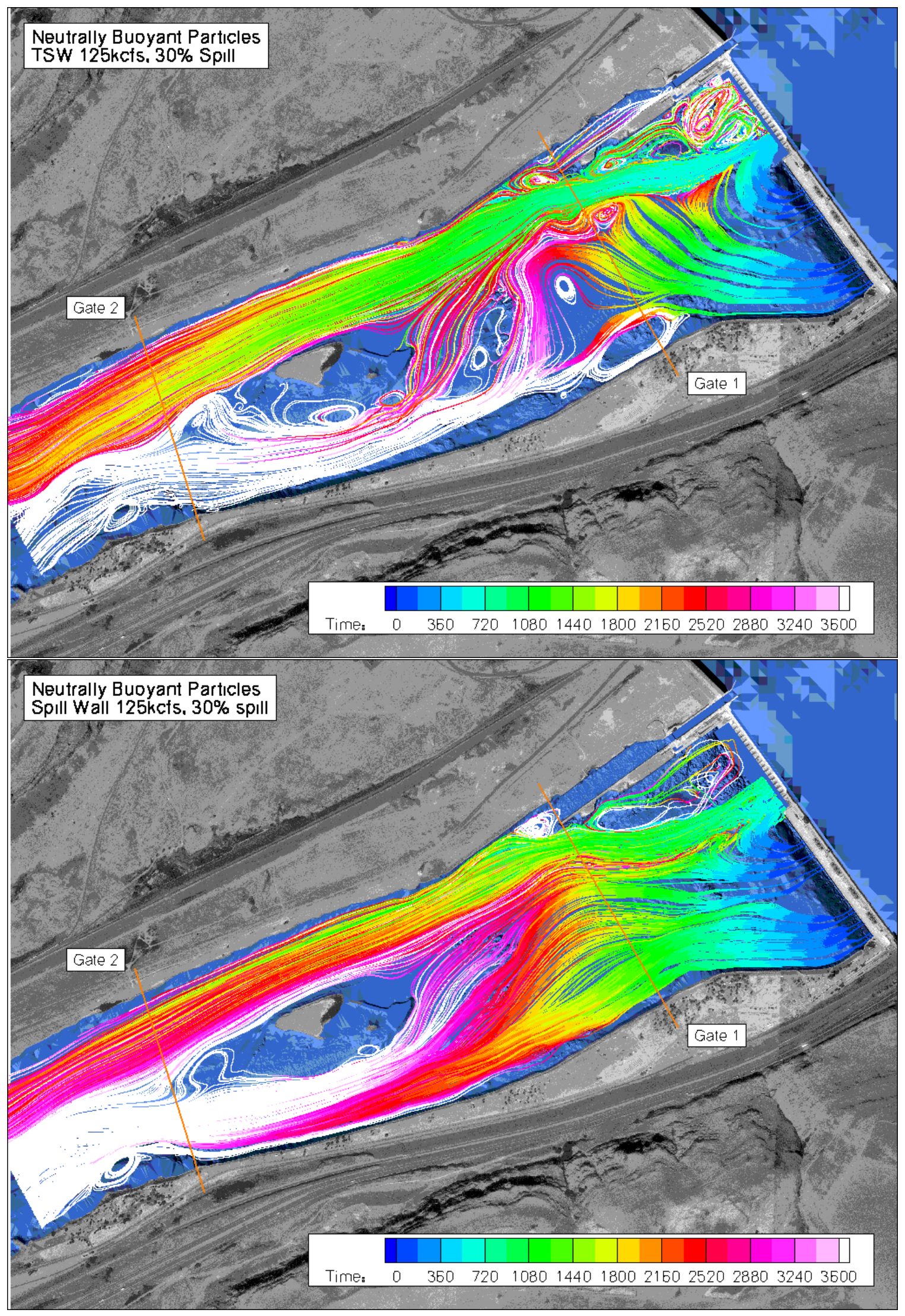

Figure C.2. The Baseline (30\% spill) and Spillwall (25\% spill) TR 125 kcf Neutrally Buoyant Particle Tracks 


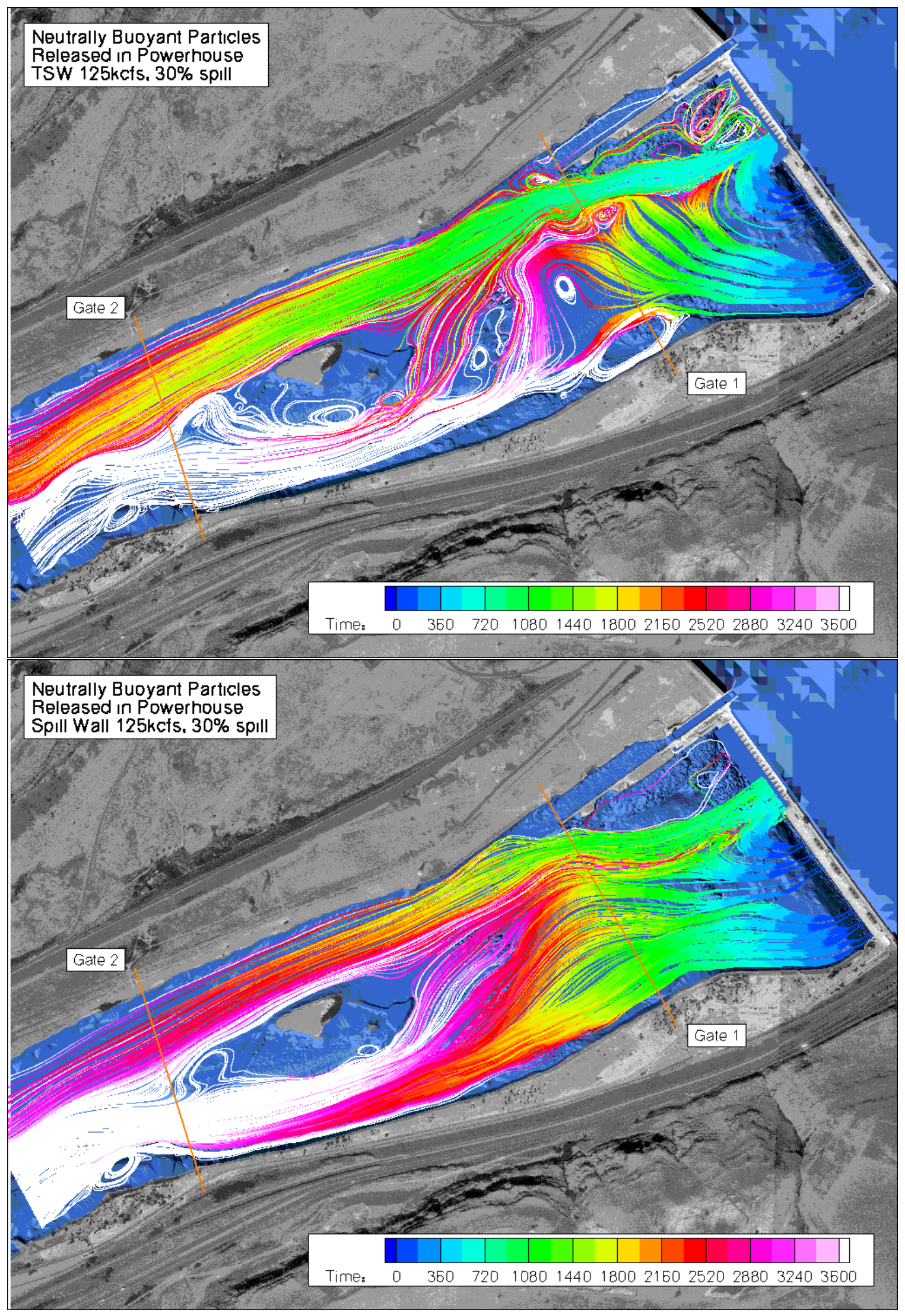

Figure C.3. The Baseline (30\% spill) and Spillwall (25\% spill) TR 125 kcfs Neutrally Buoyant Powerhouse-Seeded Particle Tracks 


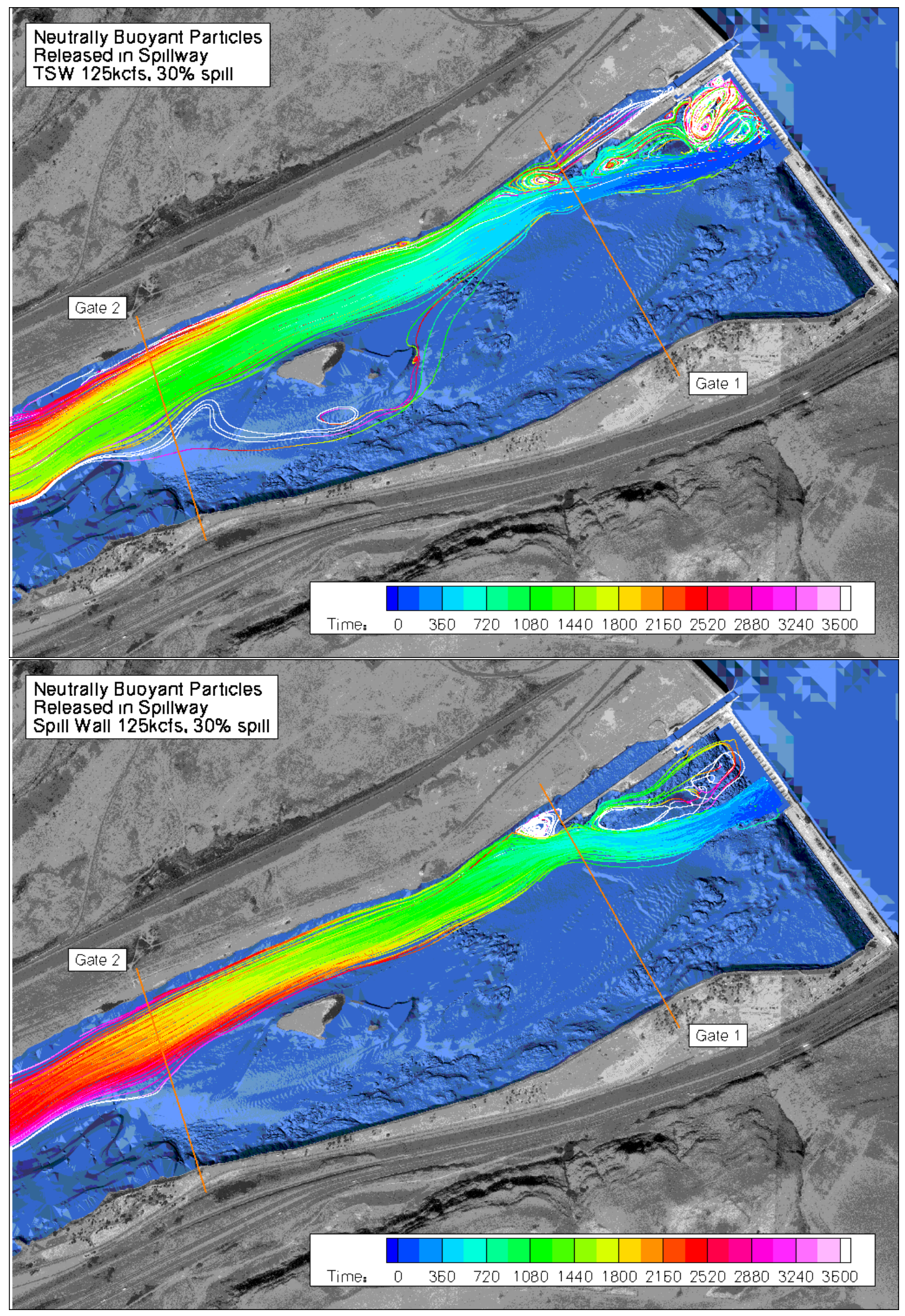

Figure C.4. The Baseline (30\% spill) and spillwall (25\% spill) TR 125 kcfs Neutrally Buoyant Spillway-Seeded Particle Tracks 


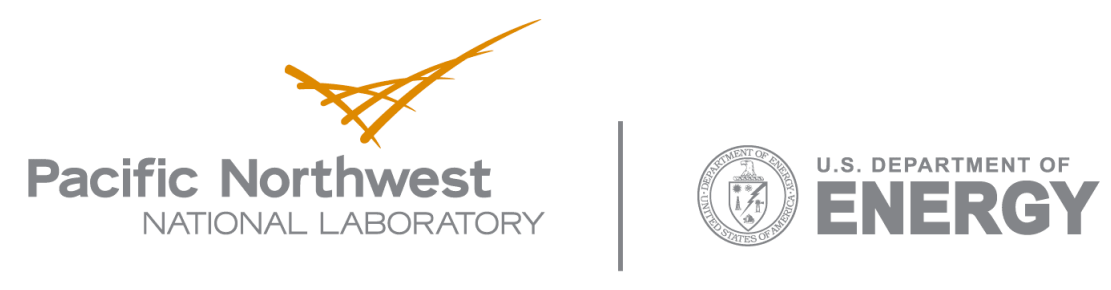

902 Battelle Boulevard

P.O. Box 999

Richland, WA 99352

1-888-375-PNNL (7665)

www.pnl.gov 